\title{
Georgia Tech Final Report Demonstration In Situ Plasma Vitrification Technology for Savannah River Site Contaminated Soils (U)
}

by

R. F. Schumacher

Westinghouse Savannah River Company

Savannah River Site

Aiken, South Carolina 29808

\section{RESEIVED \\ JUL 071998 \\ OSTI}

DOE Contract No. DE-AC09-96SR18500

This paper was prepared in connection with work done under the above contract number with the U.S.

Department of Energy. By acceptance of this paper, the publisher and/or recipient acknowledges the U. S.

Government's right to retain a nonexclusive, royalty-free license in and to any copyright covering this paper, along with the right to reproduce and to authorize others to reproduce all or part of the copyrighted paper.
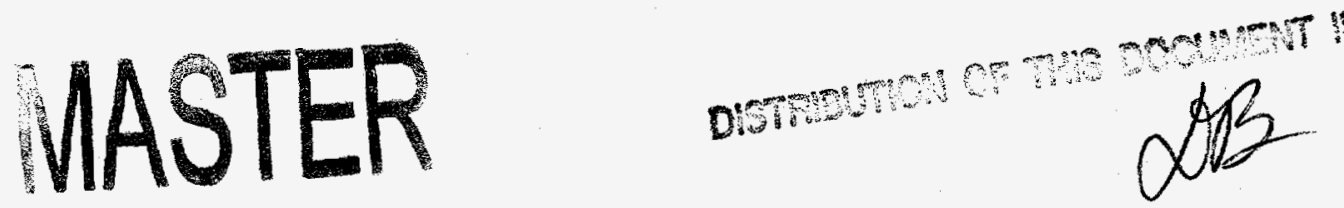


\section{DISCLAIMER}

This report was prepared as an account of work sponsored by an agency of the United States Government. Neither the United States Government nor any agency thereof, nor any of their employees, makes any warranty, express or implied, or assumes any legal liability or responsibility for the accuracy, completeness, or usefulness of any information, apparatus, product, or process disclosed, or represents that its use would not infringe privately owned rights. Reference herein to any specific commercial product, process, or service by trade name, trademark, manufacturer, or otherwise does not necessarily constitute or imply its endorsement, recommendation, or favoring by the United States Government or any agency thereof. The views and opinions of authors expressed herein do not necessarily state or reflect those of the United States Government or any agency thereof.

This report has been reproduced directly from the best available copy.

Available to DOE and DOE contractors from the Office of Scientific and Technical Information, P. O. Box 62, Oak Ridge, TN 37831; prices available from (423) 576-8401.

Available to the public from the National Technical Information Service, U. S. Department of Commerce, 5285 Port Royal Road, Springfield, VA 22161. 


\section{DISCLAIMER}

Portions of this document may be illegible electronic image products. Images are produced from the best available original document. 
Westinghouse Savannah River Company Page 1 of 3
WSRC-TR-97-0182

Revision 0

Keywords: plasma, in-situ, vitrification, soil, glass waste form, plasma torch.

Retention Time: Permanent

February 4, 1998

To: D.A. Crowley, 773-43A

From: R.F. Schumacher, SRTC 773-43A (725-5991)

D.T. Herman, SRTC 773-41A (725-5898)

A.L. Sadler, (WSRC-Retired)

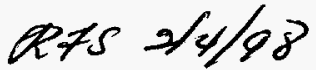

Georgia Tech Final Report - Demonstration of In Situ Plasma Vitrification Technology for Savannah River Site Contaminated Soils - (U)

\section{SUMMARY}

Previous experience with in-situ (Joule-heated) vitrification (ISV) of Savannah River Site (SRS) highly weathered soil, has shown that the SRS soil is very refractory and a poor electrical conductor. These findings bring into question the likelihood of utilizing the Joule-heat type of vitrification treatment for waste sites and basins at SRS. An alternative approach may be in-situ plasma vitrification (ISPV). The ISPV approach provides a similar vitrified product and also has a safety advantage in that the melting is initiated at the bottom of a borehole compared to top-down melting for Joule heated-ISV-

Vitrification research utilizing DOE Landfill Focus Area funds was completed at Georgia Institute of Technology (GIT). Six laboratory bottom to top ISPV experiments were conducted with 100 and $200 \mathrm{~kW}$ plasma torches. These tests were conducted in large steel containers with actual SRS soils. In spite of the difficult soil conditions the results demonstrated the positive potential of this technique for vitrifying the SRS soils.

\section{INTRODUCTION}

In-situ vitrification of radioactive and hazardous waste sites by Joule heating is a commercially developed technology (Geosafe Corporation) with hundreds of tests and fairly extensive commercial demonstrations. It should be noted that during the testing there have been a small number of glass or hot gas expulsions from the melt which increases the concerns about safe operation of the process. The ISV process utilizes the passage of large electrical currents through the soil between graphite electrodes to provide the thermal energy required to melt the soil. The melt is initiated on the surface and as the melt progresses deeper into the earth the electrodes are gradually lowered. Eventually a large melt is created with depths up to ten or fifteen feet. 
Initial attempts to use this technology for the Savannah River Site (SRS) were not successful due to the high electrical resistivity and refractory nature of the SRS soils. In order to achieve vitrification of the SRS soils it would be necessary to mix or saturate the SRS soils with a suitable flux or generate extremely high temperatures in the vitrification regions. The SRS soils would be representative of other highly weathered sedimentary coastal regions of the United States. A novel and patented method for treating waste sites has been proposed by GIT(1). This process utilizes a non-transferred plasma arc torch with temperature capability between 4,000 to $7,000^{\circ} \mathrm{C}$, to vitrify in situ refractory soil and toxic or radioactive waste. Utilizing funding from DOE's Office of Science and Technology (OST), investigations were undertaken at two regional Universities to study both soil additives and in-situ plasma arc vitrification of SRS soils. The soil additive effort was conducted at Clemson University and has been reported previously (2). The report included as Appendix A will describe the effort completed at GIT.

\section{BACKGROUND}

Based on previous high-temperature vitrification studies with SRS soils(3-4), the LandFill Stabilization and Containment Focus Area (SR-16LF-52), under the DOE Office of Science and Technology, funded this study of ISPV. The work was initiated early in FY 96 and will be completed with the release of the GIT report included as Appendix A. An ERDA (Education Research \& Development Association of Georgia Universities) contract, No. 95069, was prepared and approved to start in January of 1996. This task was to be completed within nine months at a total cost of $\$ 63,984$. The goal of this effort was to evaluate the feasibility of in-situ plasma vitrification of SRS soil.

\section{CONCLUSIONS}

Six laboratory bottom-to-top in situ vitrification experiments were conducted with the 100 and $200 \mathrm{~kW}$ plasma torches. The plasma torch depths under the surface of the soil varied between two to five feet. Actual SRS soils with and without contaminants, additives, and water were evaluated. The principal conclusions drawn from these studies were as follows:

- SRS soil was readily vitrified to a rock-like, homogeneous vitrified material,

- $\quad$ A fluxing agent was not required to fully vitrify SRS soil,

- Vitrification of a water saturated soil was accomplished, however, the power level of the torch must be such as to evaporate the water around the borehole more rapidly than the soil permeability permits the water to be replaced,

- $\quad$ Seeded contaminants e.g. metals, briquettes, glass, concrete, etc. were fused into the glass matrix and immobilized within the vitrified column,

- Adjacent vitrified columns will coalesce together into a highly contiguous melt if the proper borehole spacing is applied,

- A method of modeling should be developed which would predict the size and possibly shape of the melt from the soil characterization and operating parameters.

Glass and soil analyses for samples obtained from these studies will be presented in a later report. The detailed experimental procedures and additional conclusions are presented in the attached final report - See Appendix A. 


\section{REFERENCES}

1. L.J. Circeo \& S.L. Camacho, "In situ Remediation and Vitrification of -= Contaminated Soils, Deposits, and Buried Materials," U.S. Patent No. 5,276,253.

2. R.F. Schumacher, "Clemson Final Report - High Temperature Formulations for SRS Soils - (U), WSRC-TR-97-0042, February, 14, 1997.

3. C.A. Cicero, D.F. Bickford, W.O. Crews, A.L. Kielpinski, J.C. Marra, A.A. Ramsey, R.F. Schumacher, and T.L. Spatz, "Vitrification of Savannah River Site Contaminated Soils," Emerging Technologies in Hazardous Waste Management VII., D.W. Tedder (Ed.), Washington, DC, American Chemical Society, pg. 616$618,1995$.

4. A.L. Kielpinski, J.C. Marra, J. Etheridge, R.Kirkland, R.F. Schumacher, and V. Rogers, "Development of Plasma Vitrification Technology for Contaminated Soil at the Savannah River Site," Tucson Waste Management 95, OSTI-asDE05060091, WSRC-MS-95-0056.

\section{APPENDIX A}

Final Report Demonstration of In Situ Plasma Vitrification Technology for Savannah River Site Contaminated Soils, L.J. Circeo, P.W. Mayne, R.A. Newsom, \& K.A. Mayer, ERDA Contract No. 95069, December 1996. 


\title{
FINAL REPORT
}

\section{DEMONSTRATION OF IN SITU PLASMA \\ VITRIFICATION TECHNOLOGY FOR SAVANNAH \\ RIVER SITE CONTAMINATED SOILS}

\author{
by \\ Dr. Louis J. Circeo \\ Dr. Paul W. Mayne \\ Mr. Robert A. Newson \\ Ms. Kate A. Mayer
}

The Construction Research Center

College Of Architecture

Georgia Institute Of Technology

Atlanta, Georgia 30332-0159

performed under:

ERDA Contract Number: 95069

Georgia Tech Contract Number: D48-X30

Sponsor: Education Research and Development

Association of Georgia Universities

900 Atlantic Drive

Atlanta, Georgia 30332-0425

DECEMBER 1996 


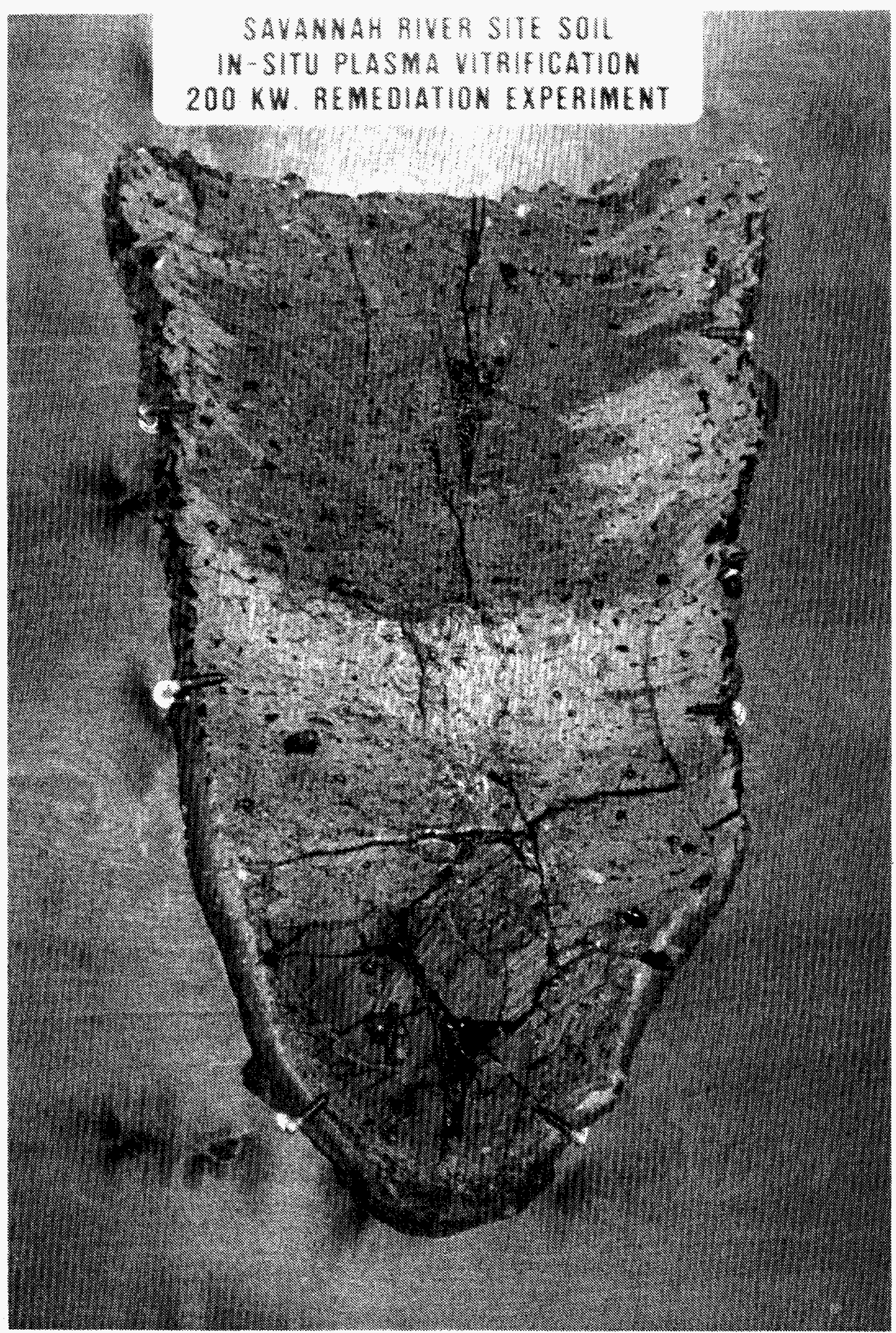

FRONTISPIECE 


\section{ACKNOWLEDGMENTS}

This research was performed for the Westinghouse Savannah River Company (WSRC) under the

Education Research and Development Association of Georgia Universities (ERDA) Program, sponsored by the U.S. Department of Energy. The work was conducted by the Construction Research Center (CRC), Georgia Institute of Technology; Electro-Optics, Environment and Materials Laboratory (EOEML), Georgia Tech Research Institute (GTRI); and the Geosystems Engineering Program, School of Civil and Environmental Engineering, Georgia Institute of Technology.

The WSRC Technical Monitors for this program from the Savannah River Technical Center (SRTC) were Dr. Andrea Kielpinski Sadler; Dr. Raymond F. Schumacher and Mr. David Herman.

The major Georgia Institute of Technology participants in this research program and the principal authors of this report are as follows:

Dr. Louis J. Circeo, Director, CRC was the Program Manager and Principal Investigator for this research program.

Dr. Paul W. Mayne, Assistant Professor, was the Program Director from the Geosystems Engineering Program, School of Civil and Environmental Engineering.

Ms. Kate A. Mayer, Graduate Research Assistant, Geosystems Engineering Program was the principal researcher for the geotechnical studies associated with this research program.

Mr. Robert A. Newson, Research Technologist II, was the GTRI project director and the manager of the Georgia Tech Plasma Applications Research Facility (PARF).

Special Appreciation is given to Mr. C. Lamar Carney, Mechanical Technician III, GTRI, and Mr. Todd A. Deterding, Research Scientist I, GTRI for the significant roles they played in the operation and maintenance of the PARF, and in their assistance in the preparation and conduct of the experimental program. 


\section{TABLE OF CONTENTS}

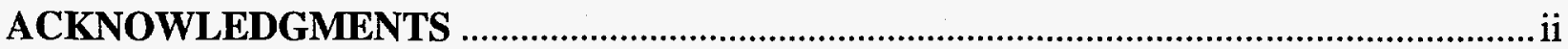

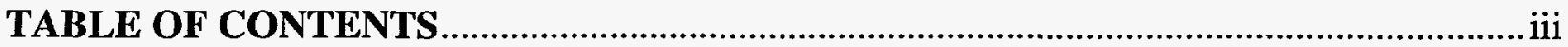

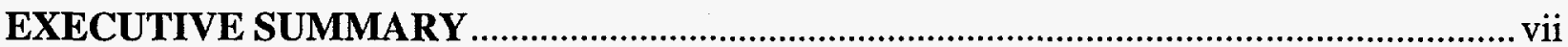

1.0 INTRODUCTION

2.0 BACKGROUND

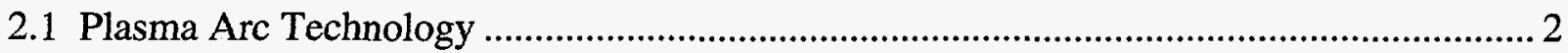

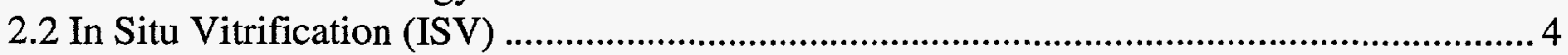

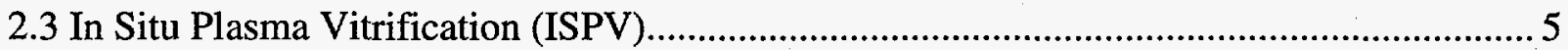

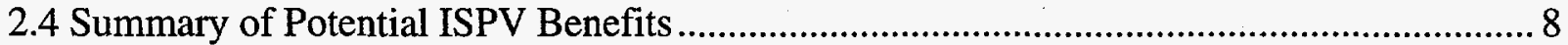

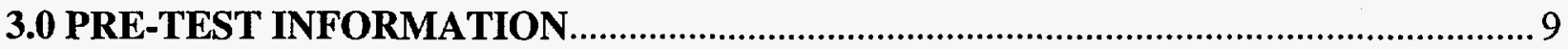

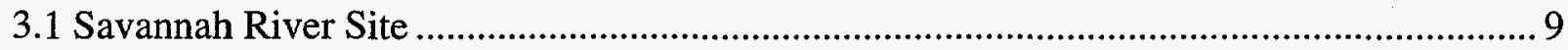

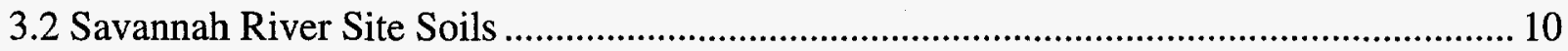

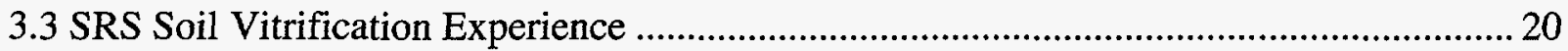

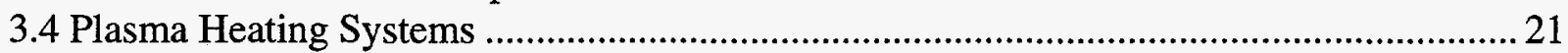

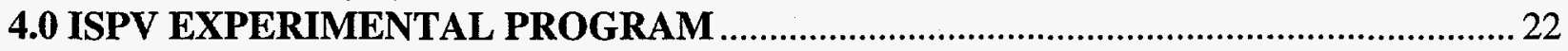

4.1 ISPV Experiment No. 1: $100 \mathrm{~kW}$ in Clean SRS Soil.......................................................2 22

4.2 ISPV Experiment No. 2: $100 \mathrm{~kW}$ in Clean SRS Soil and Fluxant.................................... 28

4.3 ISPV Experiment No. 3: $100 \mathrm{~kW}$ in Clean SRS Soil and High Moisture Content............. 34

4.4 Experiments No. 4 and 5: $100 \mathrm{~kW}$ and $200 \mathrm{~kW}$ in Contaminated SRS Soil. .................... 35

4.5 Experiment No. 6: $200 \mathrm{~kW}$ Dual Contiguous Melts in Clean SRS Soil...........................47

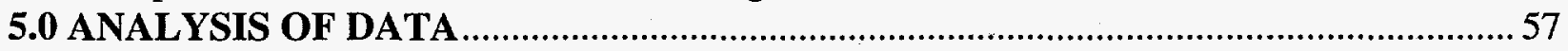

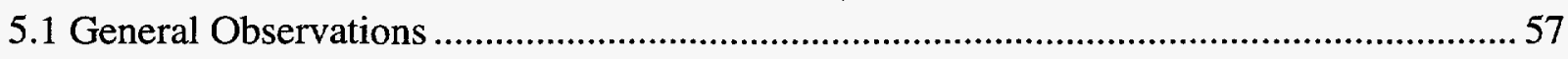

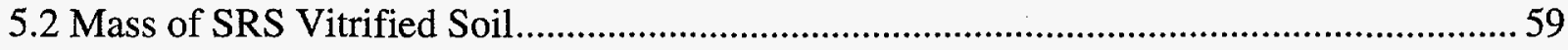

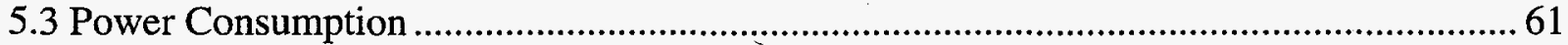

5.4 Low Strain Stiffness and Compressive Strength of Vitrified Soils........................................6 62

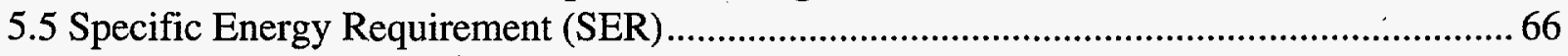

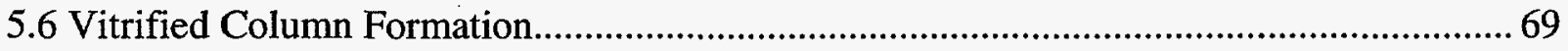

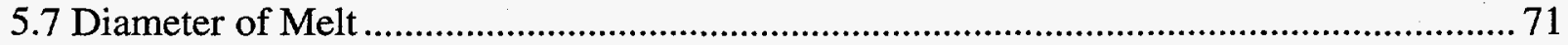

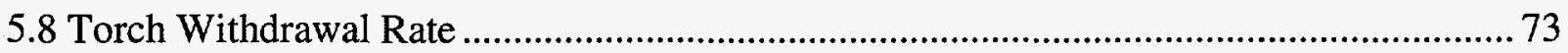

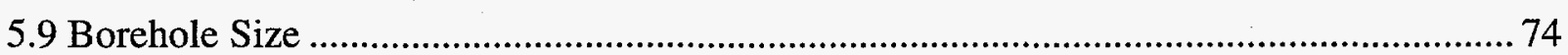

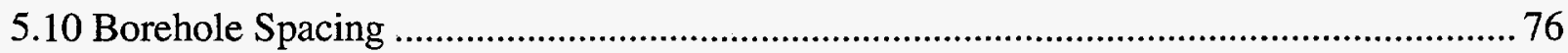

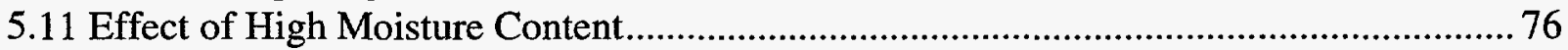

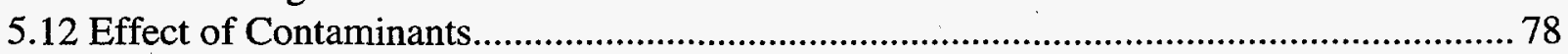

5.13 Toxicity Characteristics Leaching Procedure (TCLP) Tests ...........................................79

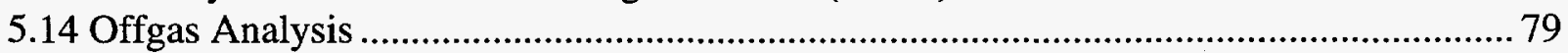

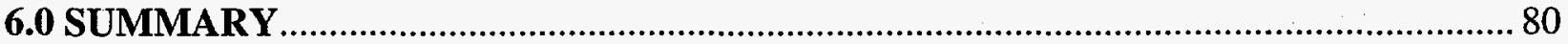

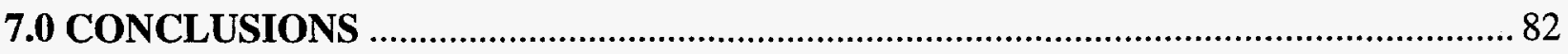

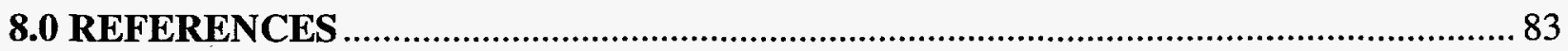

APPENDICES (see next page) 


\section{APPENDICES}

Appendix A. Supplemental Test Data: ISPV Experiment No. 1 …………………………... A-1

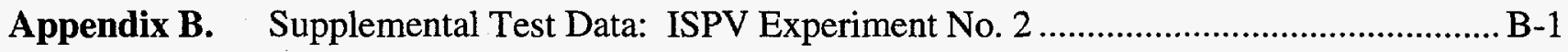

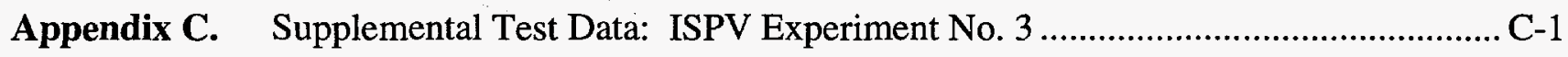

Appendix D. Contaminant Layout Plan for Experiments No. 4 and No. 5 .................................. D-1

Appendix E. Supplemental Test Data: Experiment No. 4 …………………………................ E-1

Appendix F. Supplemental Test Data: Experiment No. 5 ......................................................... F-1

Appendix G. X-Ray Diffraction Tests and SEM Micrographs, Experiment No. 5 ..................... G-1

Appendix H. Supplemental Test Data: Experiment No. 6 ….................................................. H-1 


\section{TABLE OF FIGURES}

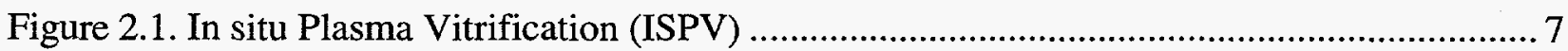

Figure 3.1. Grain Size Distribution for Savannah River Soil................................................... 12

Figure 3.2. Moisture-Density Curve for Savannah River Site Soil............................................ 14

Figure 3.3. Direct Shear Test Results for Savannah River Site Soil........................................ 16

Figure 3.4. Modified Mohr-Coulomb Diagram for Direct Shear Tests on Savannah River Site

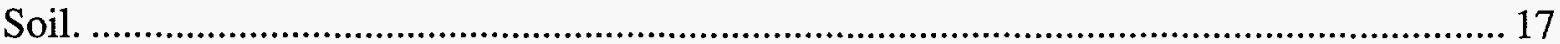

Figure 3.5. Results of Resonant Column Tests on SRS Soil .................................................. 19

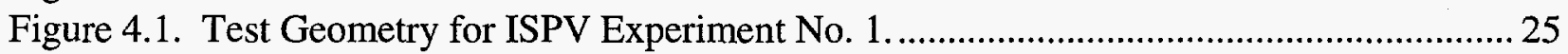

Figure 4.2. Diagram of the Vitrified Column from Experiment No. 1......................................2 26

Figure 4.3. Photograph of a Cross Section of the Vitrified Column from Experiment No. 1.....27

Figure 4.4. Test Geometry for ISPV Experiment No. 2............................................................. 29

Figure 4.5. Photograph of Experiment No. 2 Test Chamber.................................................... 30

Figure 4.6. Diagram of Vitrified Column from Experiment No. 2 ......................................... 32

Figure 4.7. Photograph of Vitrified Product from Experiment No. 2 ……................................... 33

Figure 4.8. Test Geometry for ISPV Experiment No. 3 ........................................................... 36

Figure 4.9. Photograph of Test Chamber Used in Experiment No. 3.......................................... 37

Figure 4.10. Diagram of Vitrified Mass from Experiment No. 3.............................................. 38

Figure 4.11. Test Geometry for ISPV Experiments No. 4 and No. 5......................................... 42

Figure 4.12. Photograph of Container Used in Experiments No. 4 and No. 5............................ 43

Figure 4.13. Photograph of the Melt Columns from Experiments No. 4 and No. 5 in the Steel

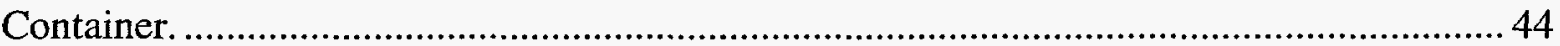

Figure 4.14. Diagram of the Vitrified Columns from Experiments No. 4 and No. 5.................. 45

Figure 4.15. Photograph of the Vitrified Cross Sections of the Experiments No. 4 and No. 5 Melt

Columns.

Figure 4.16. Close-Up Photograph of the Vitrified Cross Section of the Experiment No. 5 Melt

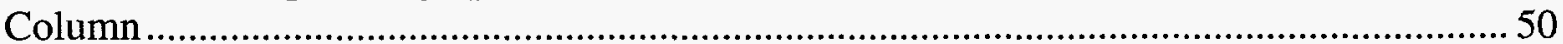

Figure 4.17. Test Geometry for ISPV Experiment No. 6........................................................... 51

Figure 4.18. Photograph of Dual Borehole Geometry during Experiment No. 6........................... 53

Figure 4.19. Photograph of the Contiguous Melt Columns, Experiment No. 6........................... 54

Figure 4.20. Diagram of the Vitrified Columns from Experiment No. 6....................................55

Figure 4.21. Photograph of Vitrified Cross Section from Experiment No. 6.................................56

Figure 5:1. Mass of Vitrified Product vs. Power Consumption. .................................................. 63

Figure 5.2. Change in Shear Modulus and Dry Unit Weight Between the Original SRS Soils and

the Vitrified Products. ......................................................................................................... 67

Figure 5.3. Relationship Between Elastic Modulus and the Ultimate Compressive Strength of the

Original SRS Soils and the Vitrified Products....................................................................6 68

Figure 5.4. Sequence of Vitrified Column Formation (Experiment No. 5 Example)................... 72 


\section{LIST OF TABLES}

Table 3.1. Equivalent Compressive Strengths Obtained from Direct Shear Tests on Savannah

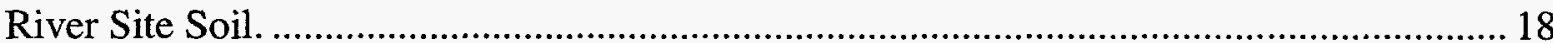

Table 3.2. Results of Resonant Column Tests on Savannah River Site Soil (Boudreau, 1994). . 18

Table 3.3. Strength and Stiffness Data for the Pre-Test SRS Soils.............................................20

Table 4.1. List of In situ Plasma Vitrification Demonstration Experiments ................................2 23

Table 4.2. Summary of Results: Experiment No. 1 1............................................................... 24

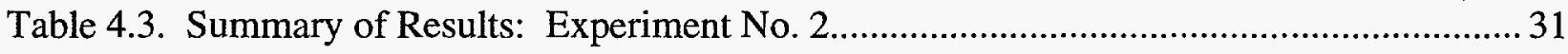

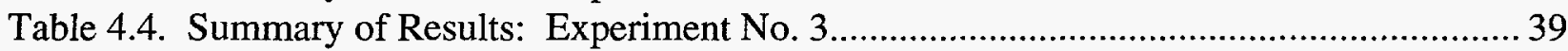

Table 4.5. Summary of Results. Experiment No. 4................................................................. 48

Table 4.6. Summary of Results. Experiment No. 5 ................................................................ 49

Table 4.7. Summary of Results. Experiment No. 6....................................................................5 52

Table 5.1. Compilation of Selected ISPV Experimental Data .....................................................59

Table 5.2. Comparison of Pre-Test and Post Test Strength and Stiffness Data for SRS Soil....... 65

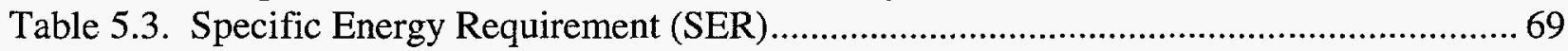

Table 5.4 Diameter of Melt of SRS Soil as a Function of Torch Power Level and Torch

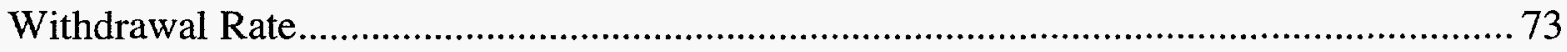




\section{EXECUTIVE SUMMARY}

New environmental technologies are needed to remediate the wide variety of sites which have become contaminated with various radionuclides, heavy metals, toxic materials and organics. A novel method for treating waste sites now under development at the Georgia Institute of Technology is in situ remediation and vitrification by means of a non-transferred plasma arc torch. This process is called "In situ Plasma Vitrification (ISPV)." Contaminated soil (which may include buried wastes) is permanently stabilized by using the intense temperatures created by a plasma $\left(4,000^{\circ}-7,000^{\circ} \mathrm{C}\right)$ to destroy hazardous compounds and to vitrify the soil and its contaminants. By producing a wasteform with long-term chemical durability and stability, vitrification has been deemed the best demonstrated available technology (BDAT) for hazardous and radioactive wastes by the Environmental Protection Agency. It is a permanent treatment technology, as opposed to interim technologies which may require application at intervals.

A buried waste deposit requiring treatment by plasma remediation would be treated by inserting the plasma torch in a borehole and vitrifying the material around the torch, producing a column of vitrified material as the torch is slowly withdrawn. Plasma arc torches operated at power levels exceeding 5MW would be expected to produce vitrified columns greater than 10 feet in diameter. A matrix of overlapping treatment columns would thus form a contiguous vitrified mass of remediated soil. Similarly, plasma vitrification can be used for selective underground treatment; e.g., to create underground horizontal or vertical barriers to prevent migration of contaminants in groundwater, or to selectively vitrify subterranean contaminated zones and to treat "hot spots" in aquifers which feed groundwater contamination plumes.

In September, 1995 the Savannah River Technology Center (SRTC) sponsored a project at the Georgia Institute of Technology to demonstrate the capability of the ISPV process to vitrify typical Savannah River Site (SRS) contaminated soils. Six laboratory bottom-to-top in situ vitrification experiments were conducted at the $100 \mathrm{~kW}$ and $200 \mathrm{~kW}$ plasma torch power levels. The plasma torch depths under the surface of the soil varied between two to five feet. Highly-weathered, highly-refractory, humid soils such as those found at SRS constitute the greatest challenge for in situ remediation and vitrification. Since, chemically, these soils are up to $95 \% \mathrm{SiO}_{2}$, they demand higher melting temperatures than, for example, Western soils which contain natural fluxing agents (iron, calcium, and alkalis). Moreover, they do not have the natural electrical conductivity of the latter; such conductivity is crucial to using conventional joule-heated in situ vitrification (ISV) technology. The higher moisture content of Southeastern soils as compared to those found in the Western United States also impose a greater challenge on the heating mechanism for vitrifying such soils.

The four $100 \mathrm{~kW}$ ISPV tests consisted of an SRS baseline soil, the addition of a limestone fluxant, vitrification in a highly saturated soil medium, and an SRS baseline soil seeded with contaminants. The two $200 \mathrm{~kW}$ ISPV tests consisted of an SRS baseline soil seeded with contaminants, and dual contiguous melts to coalesce adjacent columns together. In spite of difficult soil conditions, the results of this demonstration project have indicated that the ISPV process was successful in readily vitrifying SRS soils in a bottom-to-top procedure under a variety of geotechnical and environmental conditions. 
The principal conclusions of this study are as follows:

1. SRS soil which was reconstituted in the laboratory to simulate its undisturbed state was readily vitrified to a rock-like, homogeneous cross section.

2. A fluxing agent is not required as an additive to fully vitrify SRS soil.

3. A highly saturated SRS soil was thoroughly vitrified with the plasma torch. In order for vitrification to occur below the ground water level, the plasma torch must be operated at a power level which will evaporate the water around the borehole at a faster rate than the soil permeability permits water to recharge into the region.

4. Seeded contaminants (metals, contaminated briquettes, glass, concrete) were all readily vitrified, stabilized and immobilized within the vitrified soil column.

5. Adjacent vitrified columns will coalesce together in a highly satisfactory contiguous melt if the proper borehole spacing is used.

6. At the laboratory level, ISPV technology has demonstrated the potential to overcome many significant limitations associated with conventional joule-heated in situ vitrification (ISV) technology.

7. ISPV offers the potential to target many buried wastes and soil contaminants that are not safely or economically treatable using currently available or contemplated commercial in situ or ex situ technologies.

8. Fundamental studies are required to understand the interaction of the many variables involved in the ISPV process. In addition, a significant research effort should be initiated to model the ISPV process in order to predict variables such as the mass of vitrified material, melt diameter, torch withdrawal rate, etc. under a variety of geotechnical and environmental conditions.

9. The ISPV concept should be readily adaptable to existing DOE-developed joule-heated in situ vitrification (ISV) technology by replacing the ISV graphite electrodes with one or more plasma torches. The opportunity to use this DOE-developed equipment would take advantage of significant development costs and years of development time that would otherwise be required for implementation and commercialization of ISPV technology. 


\subsection{INTRODUCTION}

Contaminated soils and buried wastes represent one of the most widespread and costly remediation problems in the United States and in other developed countries around the world. The U.S. Department of Energy is currently evaluating treatment methods for remediation and disposal of hazardous, low-level radioactive, and mixed wastes. Among these wastes are soils contaminated with radioactive or hazardous materials, e.g., those which originate near the site of processing facilities, seepage basins, burial grounds, etc. Vitrification, which was selected by the U.S. Environmental Protection Agency as the best demonstrated available technology (BDAT) for treatment of high-level radioactive wastes, is a leading candidate for treating such wastes, in that a highly durable wasteform can be produced.

In situ treatment and vitrification of contaminated soils is an attractive concept for remediation of such soils, since health hazards associated with excavation, transport, and feeding to a treatment unit are avoided. Likewise, transport, emplacement, and storage of the final wasteform is obviated by this method of remediation. Reducing these several process stages to a single step operation presents a unique opportunity for significant savings in both treatment time and remediation costs.

A novel method for treating waste sites now under development at the Georgia Institute of Technology is in situ pyrolysis and vitrification by means of bottom-up melting with a plasma arc torch. Contaminated soil (which may include buried debris and hazardous wastes) is permanently stabilized by using the intense heat created by a plasma $\left(4,000^{\circ}-7,000^{\circ} \mathrm{C}\right)$ to render hazardous compounds harmless and to vitrify the soil and immobilize its residual contaminants. An area requiring vitrification by plasma remediation is treated by inserting a plasma torch at the bottom of a borehole extending to any depth, and melting the material around the torch, so as to produce a column of vitrified material as the torch is slowly raised to the ground surface. Plasma arc torches operated at power levels exceeding $5 \mathrm{MW}$ can be expected to produce vitrified columns greater than 10 feet in diameter. A matrix of contiguous treatment columns would form a large vitrified mass of remediated soil. Similarly, plasma vitrification can be used for selective underground treatment; e.g., to create underground horizontal or vertical barriers to prevent migration of 
contaminants in groundwater, or to selectively target and vitrify subterranean contaminated zones and to treat "hot spots" in aquifers which feed groundwater contamination plumes. Treatment time and costs are expected to be significantly less than any comparable or contemplated ex situ thermal treatment technology.

The purpose of this study effort was to conduct bench-scale demonstrations of in situ plasma vitrification (ISPV) of uncontaminated Savannah River Site soils under a variety of geotechnical and environmental conditions. The demonstrations were performed in a laboratory under simulated conditions of an in situ environment. The principal objectives of this study were to demonstrate and assess the technical and economic feasibility of using plasma arc technology for the in situ plasma vitrification of soils typically found at Savannah River Site (SRS) contaminated sites.

\subsection{BACKGROUND}

\subsection{Plasma Arc Technology}

A plasma torch is a device that converts electrical energy into thermal energy (Camacho, 1988, 1991). A plasma is an ionized gas that is conditioned to respond to electromagnetic forces. The plasma arc is created when a voltage is established between two points. The plasma acts as a resistive heating element and maintains a temperature around $12,000^{\circ} \mathrm{C}$. Plasmas occur naturally in the form of lightning. This resistive heating element presents a distinct advantage over any solid heating element as it is a gas and cannot melt and fail. The plasma arc creates a "flame" that has temperatures ranging from $4,000^{\circ} \mathrm{C}$ to $7,000^{\circ} \mathrm{C}$. Thus, plasma torches operate at much higher temperatures, higher enthalpies, and at efficiencies much greater than those of fossil-fuel burners. In addition, plasma torches require only about $5 \%$ of the gas necessary for fossil fuel burners. Therefore, effluent gases are greatly reduced, and furnace systems can be built that are much more compact than traditional furnaces, at correspondingly reduced capital costs.

On the outside, a plasma torch generally looks like a simple stainless steel cylinder, several inches in diameter and several feet in length; the specific dimensions are related to the torch power levels. This cylinder contains the electrodes, insulators, gas injectors, and water dividers which are integrated into a functional torch. The two electrodes are separated by an 
electrical insulator. Cooling water is circulated within the walls of the tube to prevent the metals (stainless steel and copper) from melting under the high temperatures of the plasma arc. A gas is injected into the tube tangentially to its circumference at the insulator. The gas serves two purposes. First, it replenishes the gas for the plasma (which actually consumes only about $1 \%$ of the total gas flow). Second, the gas stabilizes the plasma arc column and allows the contact location of the arc to be varied by varying the gas flow rate. In this manner, the copper electrode surfaces can be consumed at a uniform rate. The type of gas used has no great effect on the process; air, argon, nitrogen, oxygen, helium, or other gases can be used. Typically, air is the simplest and least expensive gas source.

The only consumables in a plasma torch are the electrodes. The average life of the electrodes in megawatt power level plasma torches is between 200 and 1,000 hours before the surface wears enough to allow the cooling water to leak. A leak does not present an immediate problem to the functioning of the torch; however, the leak indicates extreme wear on the electrode and the need for timely replacement. Changing an electrode takes approximately 30 minutes. The plasma torch is powered by DC voltage, obtained through conversion from a standard $\mathrm{AC}$ power supply. Plasma torches of the reverse-polarity design generally operate in the $100 \mathrm{~kW}$ to $10 \mathrm{MW}$ power level range. The electrical to thermal energy conversion is approximately $90 \%$ efficient (Camacho, 1988).

The plasma torch system consists of the following components: the plasma arc torch assembly, power supply and control panel, closed-loop water-cooling system and heat exchanger, and a gas source. Offgas treatment will also be required during application to contaminated sites. Applications envisioned by the ISPV process are in situ remediation of sites containing radioactive or mixed wastes, including soils, seepage pits, and buried wastes. A plasma torch system can be readily transported. A $1 \mathrm{MW}$, mobile, reverse polarity system (designed for ex situ melting), placed on three trailers, has been in operation for several years in Canada.

Several plasma torch furnace processes for the destruction of hazardous and toxic wastes have been developed and successfully tested. The very high temperatures and energy 
densities, in conjunction with an ionized and reactive medium, have fully demonstrated the potential of plasma technology to remediate many waste and mixed-waste materials in an environmentally safe and cost-effective manner. Thus far, materials vitrified with plasma arc torches have readily passed all standard leaching tests. Among the promising wastedisposal technologies under consideration are processes to remediate asbestos, polychlorobiphenyls (PCB's), hospital medical wastes, municipal solid wastes, hazardous or toxic wastes, and low-level radioactive wastes. Some of these processes have been commercialized, while others are still in the development stage.

\subsection{In Situ Vitrification (ISV)}

The basic concept of in situ vitrification of contaminated soils and buried wastes is not new. The DOE sponsored the development of the original concepts for remediation of contaminated soils by in situ melting beginning in 1980 (Brouns et al., 1983). This included the design, construction, and implementation of field-scale in situ vitrification systems (Buelt et al., 1987). The DOE has also developed innovative offgas processing systems, including hoods for special purposes.

In situ vitrification (ISV) using four graphite electrodes has been demonstrated to be an effective technology for stabilizing some contaminated soils. It is being employed in the private sector for treatment of certain contaminated soil sites. It is still being developed at DOE sites for remediation of radioactively contaminated soils and seepage pits. The conversion of contaminants and geologic materials to a glassy, rock-like material is highly desirable because of its permanency and verifiability (Spalding et al., 1989). However, the standard ISV technology has several severe limitations. For example, it is exclusively a topto-bottom process, directly opposite of what is considered the most effective in situ thermal vitrification technique (Circeo et al., 1994). In addition, it is heavily dependent upon the soil composition and environment for its applicability. There are also limits on depth of processing (currently, 20 feet), and ISV cannot selectively spot melt a buried contaminant or readily treat sites with contained volatiles, large voids, or concentrations of combustible buried wastes (Roberts et al., 1992; Thompson et al., 1992). These limitations prevent ISV 
from general application to many DOE sites containing buried hazardous wastes and mixed radioactive wastes.

\subsection{In Situ Plasma Vitrification (ISPV)}

Several laboratory-scale tests of the ISPV process at the $100 \mathrm{~kW}$ and $200 \mathrm{~kW}$ power levels have taken place in the past four years. The results, thus far, have been very encouraging (Circeo and Mayne, 1993; Circeo and Camacho, 1994). Based on these bench-scale laboratory tests, the ISPV concept promises to eliminate the aforementioned ISV limitations of soil environment, depth and volatiles. Thus, the development of the ISPV technology offers the potential to target many mixed wastes and buried contaminants that are not safely or economically treatable using currently available in situ or ex situ technologies.

The ISPV concept should be directly applicable to the remediation of contaminated sites by operating one or more multi-megawatt power level plasma torches in cased boreholes. The process would start at targeted depths of remediation to produce in situ melting and subsequent solidification (see Figure 2.1). Contaminated sites would include soil and rock materials containing surface and subterranean deposits of contaminants such as hazardous/toxic wastes, heavy metals and organics, buried objects, concentrated waste sediments and sludges, sanitary landfills, radioactive wastes, and underground storage tanks (Circeo and Mayne, 1993; Circeo and Camacho, 1994; Bogatov et al, 1995).

After being lowered to the bottom of the borehole, the torch is activated. The borehole casing adjacent to the plasma flame would be immediately melted, and remediation of the contaminants would begin at that location. Melting would readily occur below the groundwater table, providing that water recharge into the region being melted can be reasonably controlled. As the melt grows, the torch is raised within the borehole to form a cylindrical melt. Large sites may be treated by forming contiguous melts through the use of boreholes placed in a grid configuration. All gases would be drawn out through the top of the boreholes and collected in a hood for treatment as appropriate. This hood would also be required to bridge any subsidence which would likely occur around each borehole, and to provide support and locational control for the torch. 
The ISPV process requires a bottom-to-top in situ vitrification procedure. As has been demonstrated in laboratory-scale studies, this bottom-up melting concept has several advantages over existing technologies (Circeo and Mayne, 1993). In particular, this approach guarantees reaching the target depth, since the process starts there. Also, the borehole itself provides a route for collection and treatment of offgases. The water-cooled torch body would cool the offgases traveling to the surface, thus condensing many metals and other volatiles within the borehole for eventual immobilization in the rock-like vitrified residue. This release path also eliminates the potential for forming subterranean bubbles or elevated pressures within the melt that might cause unanticipated eruptions or explosions of melt at the surface. The gas collection hood and the offgas treatment equipment would be the same or similar to that used with existing ISV or other vitrification methods.

The boreholes can be emplaced by standard drilling techniques or by using pipe pile-driving or vibration methods (Circeo and Mayne, 1993). The latter techniques would avoid bringing any contaminated materials to the surface. Torch diameters are about 12 inches for $10 \mathrm{MW}$ plasma torches. Information obtained from geotechnical firms suggests that pipe piles large enough (18" in diameter) to accommodate torches up to $15 \mathrm{MW}$ can be readily driven to depths of 50 to 75 feet, depending on soil characteristics. Lower-power torches could be used in smaller pipes to reach greater depths and treat large volumes by forming contiguous melts. Of course, plasma torches can operate at any depth, provided that a cased, open borehole is in place. 


\section{IN-SITU PLASMA VITRIFICATION (ISPV)}

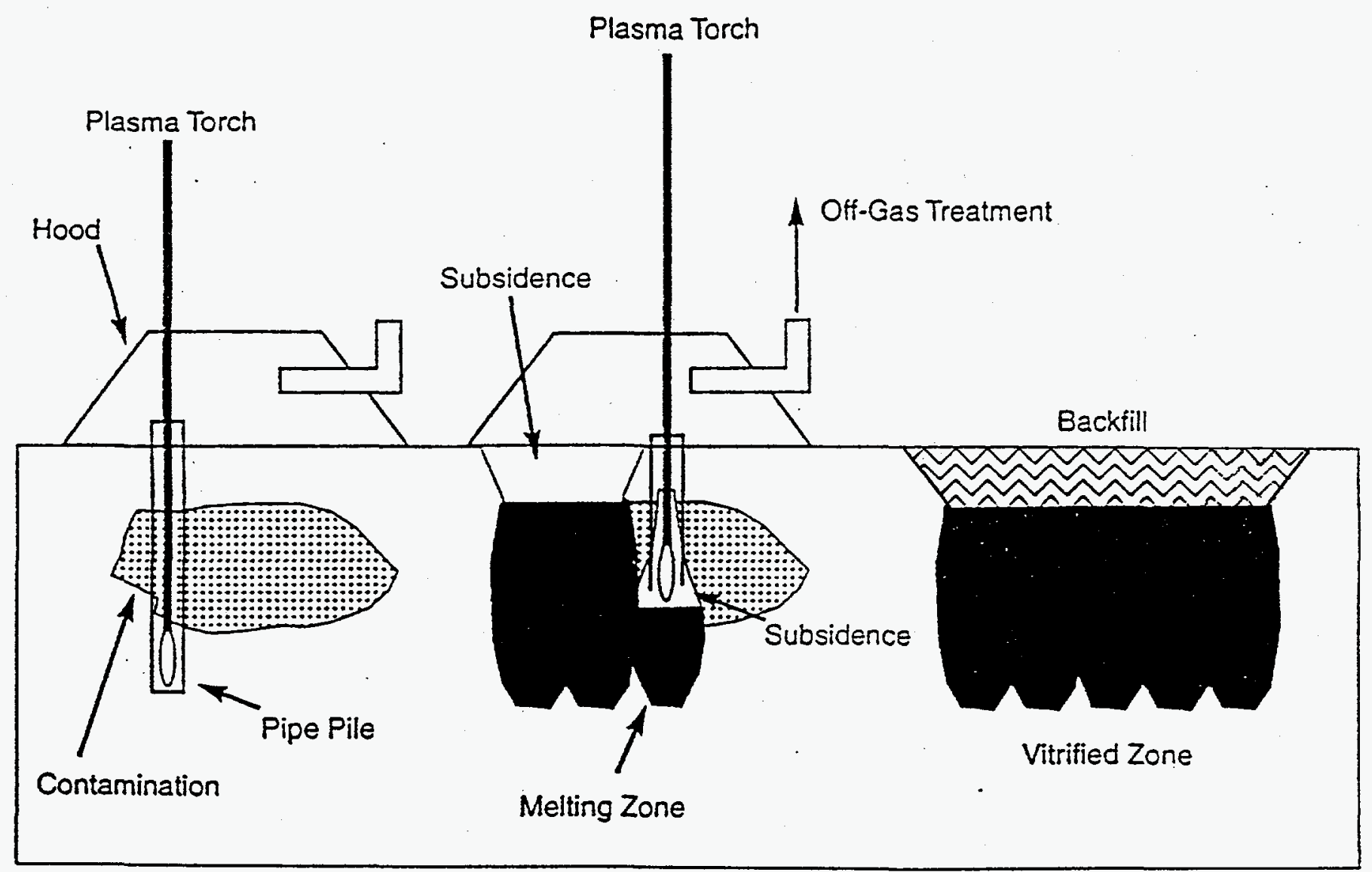

\section{IN-SITU PLASMA VITRIFICATION (ISPV)}

Figure 2.1. Schematic illustration of in-situ plasma vitrification of contaminated materials using a plasma arc torch. The torch is raised during melting to create cylindrical volumes. New material falls into the melt from the upper subsidence zone and is incorporated into the melt. After each melt, the torch is moved to the next pipe pile and melting is repeated. Offgases are processed with standard technology. The final subsidence zone is backfilled. 
In addition to the complete vitrification of an entire contaminated deposit, the ISPV concept could be used to employ alternative remediation techniques. For example, operation of plasma torches at the bottom of each borehole would create a vitrified horizontal layer along the bottom of a contaminated deposit, forming a relatively impermeable sealant to prevent vertical leaching and transport of the contained contaminants. Similarly, vertical barrier walls could be created to restrain horizontal movement of contaminants. In addition, contaminants migrating in ground water could be treated by selectively operating a plasma torch directly in the subterranean contamination plumes to destroy the contaminants or immobilize them in the resulting vitrified soil. Operation of a plasma torch inserted directly into an underground petroleum storage tank would rapidly devolatilize the contained petroleum products, thus remediating the underground storage tank in situ.

The ISPV concept should be readily adaptable to existing DOE-developed joule-heated ISV technology, essentially by replacing the ISV graphite electrodes with one or more plasma torches (Buelt et al., 1987; Circeo et al.; 1994). The ISPV electrical power input system, the offgas hood, and the offgas treatment system should closely parallel the equipment that the DOE has already developed for their full-scale ISV system. The steel jacket for the plasma torch can be made in any length in order to protect the downhole utility lines and to provide cooling along the entire length of the borehole and the offgas hood. Thus, the torch could be mounted vertically near the center of an offgas hood, with all the cooling and gas lines entering the cooling jacket outside the offgas hood. The opportunity to use DOE-developed specialized ISV equipment would take advantage of millions of dollars in development costs and years of development time that would otherwise be required for implementation and commercialization of ISPV technology.

\subsection{Summary of Potential ISPV Benefits}

ISPV is a simple and straightforward bottom-to-top vitrification process which has the potential to rapidly and efficiently remediate virtually any buried waste material at any subterranean depth. Many of the limitations of current or contemplated ISV technologies would be obviated by the ISPV process. The most significant anticipated benefits of ISPV technology are summarized as follows: 
1. It is a simple and straightforward process. The plasma torch destroys hazardous/toxic compounds, gasifies organic materials, heats soils and buried inorganic wastes beyond the melting point, and solidifies the residue into a rock-like solid which is highly resistant to leaching.

2. It uses bottom-up melting as a standard melting procedure.

3. It uses spot melting of contaminated zones at any depth to minimize treatment of large volumes of uncontaminated soil overlying the wastes. A defined contaminated zone, such as a migrating contamination plume, can be selectively vitrified.

4. It is applicable to the remediation of a variety of buried mixed wastes, including hazardous or toxic wastes, heavy metals and organics, buried objects and drums, concentrated waste sediments and sludges, sanitary landfills, radioactive wastes, and underground storage tanks.

5. It involves minimum exposure to buried contaminants by not having to dig up and transport the contaminated materials. Exposure can be further lessened by driving or vibrating pipe piles into the ground to serve as boreholes.

6. The process results in high thermal coupling with the soil, which would make ISPV highly efficient and cost-effective compared to other in situ vitrification technologies.

7. It operates well under virtually all ground conditions, to include highly saturated soils; it is essentially independent of the material composition of the soil.

8. It has a high rate of vitrification and remediation, by using one or more multi-megawatt power level plasma torches.

9. ISPV technology should be able to treat and vitrify buried wastes which cannot otherwise be remediated with other in situ thermal technologies.

\subsection{PRE-TEST INFORMATION}

\subsection{Savannah River Site}

The Savannah River Site (SRS) is one of the principal U.S. Department of Energy (DOE) installations. The SRS is located near Aiken, South Carolina. It covers approximately 310 square miles. This facility was constructed during the early 1950's to create critical nuclear materials, mainly plutonium and tritium, for the production of nuclear weapons. At the present time, one of the principal activities underway at SRS is waste management 
and environmental restoration to clean up the large variety of wastes created during the decades of weapon production. More than 600 facilities on the SRS reservation are being assessed for decontamination and decommissioning. In addition, a large number of sites on the SRS reservation contain soils contaminated with hazardous/toxic wastes, low-level radioactive wastes, and mixed wastes. The demonstration of the potential application of ISPV technology to the treatment of these contaminated soils is the principal objective of this research program.

\subsection{Savannah River Site Soils \\ 3.21 Soil Classification}

Natural sandy soils from the Savannah River Site (SRS) in Aiken, South Carolina, were used in the Georgia Tech laboratory bench scale experiments to simulate and verify the applicability of in situ vitrification by non-transferred plasma arc torches. Clean uncontaminated soil was provided from the SRS. Grain size analyses showed that the soil is gap-graded with $86 \%$ sand particles, $11 \%$ claysize particles, and 3\% silt particles, making the soil a clayey sand. A grain size distribution curve can be seen in Figure 3.1. Previous experiments have shown that the size and type of the final product are influenced by the grain size of the soils. A large percentage of sandy particles tend to increase the final size of the melt and produce a glassy rock similar to obsidian. When the soil is mainly composed of clay-size particles, the final product is a dense partially-crystalline igneous rock that resembles granite (Mayer, 1996).

The mean grain size of the Savannah River Soil is $\mathrm{D}_{50}=0.37 \mathrm{~mm}$. The coefficient of uniformity $\left(\mathrm{C}_{\mathrm{u}}\right)$ was found to be $\mathrm{C}_{\mathrm{u}}=657$, according to:

$$
\mathrm{C}_{\mathrm{u}}=\mathrm{D}_{60} / \mathrm{D}_{10}
$$

where $D_{60}=0.46 \mathrm{~mm}$ and $D_{10}=0.0007 \mathrm{~mm}$. A high coefficient of uniformity is indicative of a soil which contains a wide range of soil particles. The coefficient of curvature, $\left(C_{c}\right)$ was found to be $C_{c}=150$, according to: 


$$
\mathrm{Cc}=\frac{\left(\mathrm{D}_{30}\right)^{2}}{\left(\mathrm{D}_{10}\right)\left(\mathrm{D}_{60}\right)},
$$

where $D_{30}=0.22 \mathrm{~mm}$. This coefficient of curvature shows that the soil is very poorly graded.

Atterberg limit tests were also run on the soil to determine relative plasticity characteristics. A fall cone test was used to determine a liquid limit (LL) of 150 . Plasticity tests on a complete sample of soil showed that the soil is essentially nonplastic. However, plasticity tests which were run on soil that had been sieved through a \#200 sieve gave a plastic limit (PL) of 37 . The plasticity index (PI) was determined to be 113, according to: PI = LL - PL. The plasticity of a soil is related to the amount of clay-sized particles. The original plasticity test found the soil to be non plastic, because the large amount of sand particles were governing the behavior of the soil. Once the larger particles were removed, the large percentage of clay particles in the soil was evident, based on the increased plasticity of the soil. This again highlights the unique gap-graded characteristics of the soil.

Based on the Unified Soil Classification System (USCS), this soil would classify as a silty sand (SM). However, this classification system does not take into account the possibility of a soil being gap-graded with sand and clay-size particles. From the grain size distribution curve and the Atterberg limits of the soil, it can be seen that the Savannah River Soil would be more accurately classified as a poorly graded clayey sand (SC-SP). 


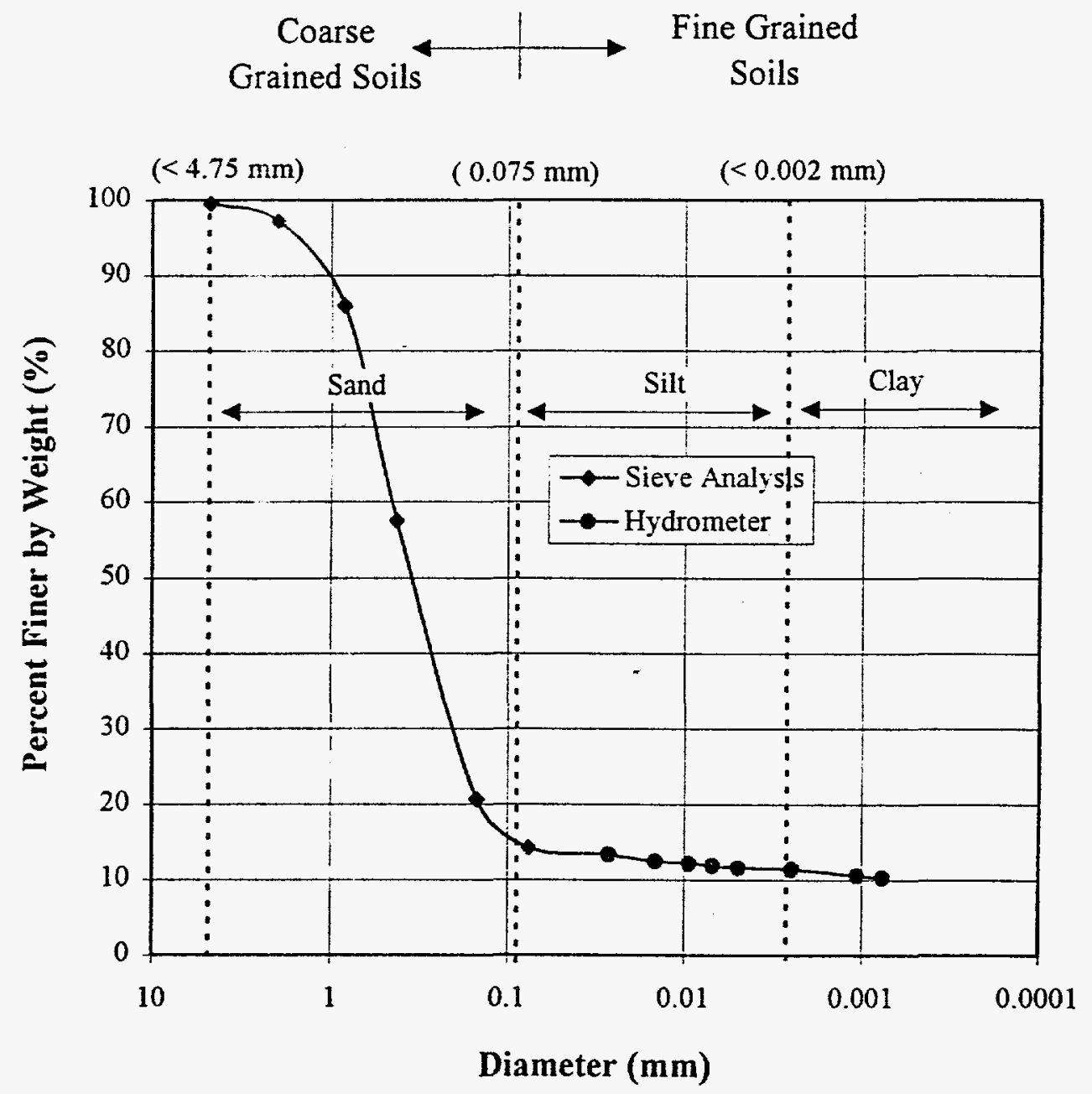

Figure 3.1. Grain Size Distribution for Savannah River Soil. 


\subsection{Compaction and Moisture Density Tests}

Compaction density tests were performed on the Savannah River Soil to determine the optimum water content and maximum dry density of the soil. These tests were run at standard compactive effort according to ASTM D-698-91. Tests were run at six different moisture contents in order to obtain a well-defined curve: $8.0 \%, 9.4 \%, 12.35 \%, 13.36 \%, 13.98 \%$, and $15.62 \%$. A specific gravity of 2.7 was assumed, which is typical for this type of soil. The moisture-density compaction curve for the soil is shown in Figure 3.2. As can be seen from this graph, the optimum moisture content for this soil is around $11 \%$, and higher than the natural water content of the soil, which is around $8.5 \%$. The soil used in the steel containers of the in situ vitrification experiments was dry of optimum, and compacted at a lower unit weight than the maximum unit weight of $1.91 \mathrm{Mg} / \mathrm{m}^{3}$ $\left(119.4 \mathrm{lb} / \mathrm{ft}^{3}\right)$, which would reduce the initial strength of the soil.

\subsection{Shear Strength}

The shear strength of the SRS soil was determined through direct shear tests. The tests were run according to ASTM-D-3080-90, and provide the drained shear strength of the soil at consolidated normal stresses. The soil had a prepared moisture content of $8.45 \%$, which is similar to in situ conditions. The specimens were created with a standard circular cross-sectional area of $31.7 \mathrm{~cm}^{2}\left(4.91 \mathrm{in}^{2}\right)$, and initial heights after consolidation ranging from 0.88 to $1.24 \mathrm{~cm}(0.348$ to 0.487 in).

As shown in Table 3.1 three direct shear tests were run on the soil at different confining pressures: $96 \mathrm{kPa}(13.9 \mathrm{psi}), 182 \mathrm{kPa}(27.8 \mathrm{psi})$, and $287 \mathrm{kPa}(41.6 \mathrm{psi})$. The strength determined from a direct shear test is dependent upon the confining pressure used in the test. Figure 3.3 shows the results of the shear stressdisplacement response for each of the direct shear tests. The peak shear stress defines the shear strength for each of the curves. Figure 3.4 shows the modified Mohr-Coulomb diagram for the tests, and determined the internal friction angle of the soil to be $\phi^{\prime}=35$ degrees at this placement density. 


\section{Compacted Dry Unit Weight}

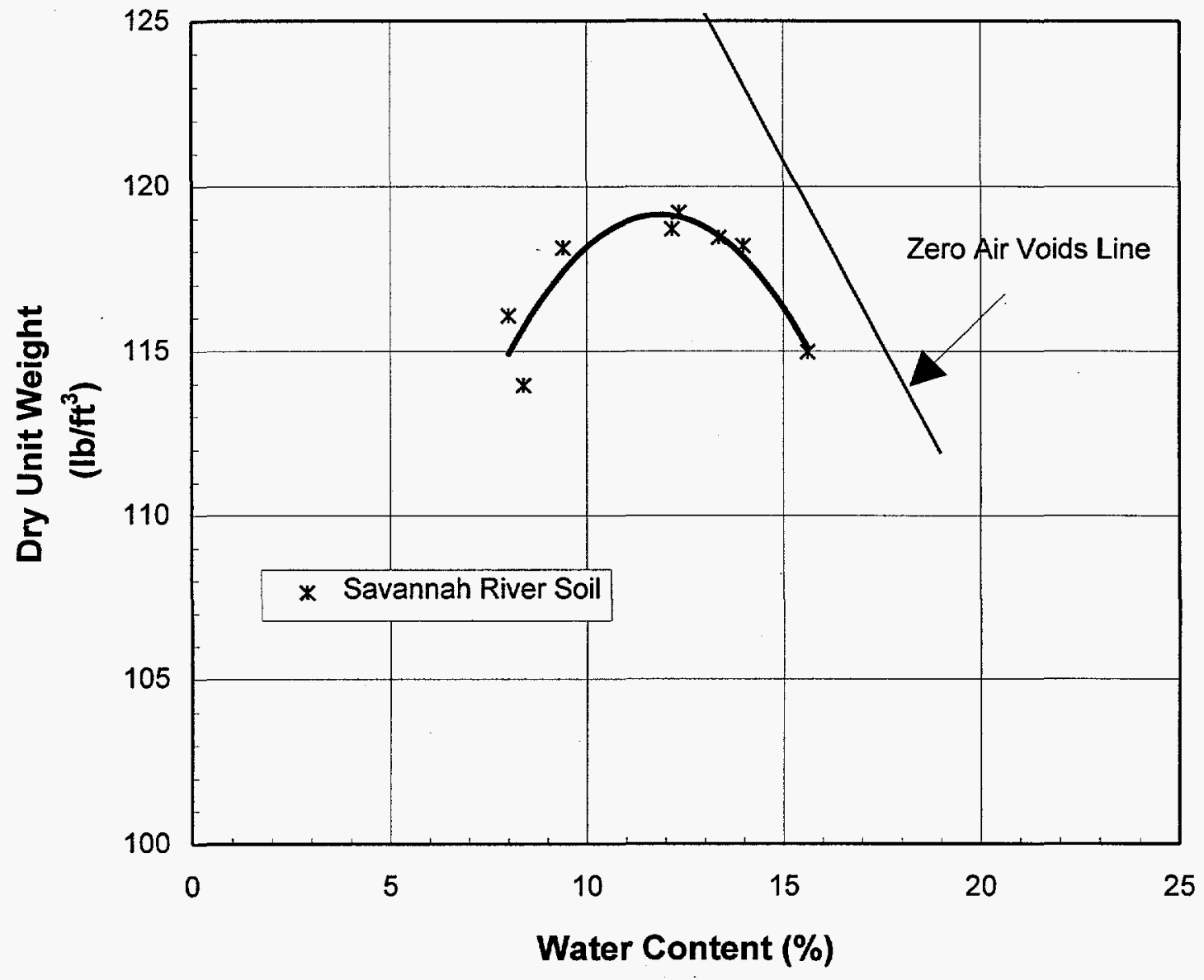

Figure 3.2. Moisture-Density Curve for Savannah River Site Soil. 
It can be seen from this graph that the shear strength of the soil increases linearly with increased confining pressure.

The peak shear stress $\left(\tau_{\max }\right)$ of each test can be seen in Figure 3.4. Based on the definition of shear strength, it can be approximated that:

$$
\left.\tau_{\max }=1 / 2\left(\sigma_{1}-\sigma_{3}\right)_{\max }\right)
$$

The compressive strength for the soil is conventionally defined as $\left.\left(\sigma_{1}-\sigma_{3}\right)_{\max }\right)$. Thus, the compressive strength is approximately taken as $2 \tau_{\max }$.

Table 3.1 shows the equivalent compressive strengths obtained from each test. The vertical confining pressure of the soil in the test chambers varies with depth

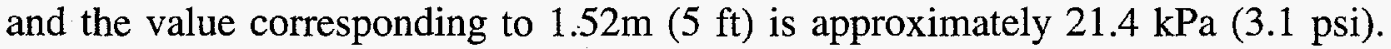
Therefore, the soil used in the tests had an initial equivalent compressive strength of $29.8 \mathrm{kPa}$ ( $4.3 \mathrm{psi}$ ), based on the results of the direct shear tests. However, the compressive strengths of the other soil types were obtained for a confining pressure of $34.5 \mathrm{kPa}$ (5 psi), which would give the Savannah River Soil an equivalent compressive strength of $48.3 \mathrm{kPa}$ ( $7 \mathrm{psi}$ ).

\subsection{Low Strain Soil Stiffness}

The low strain stiffness of the Savannah River Soil was determined through resonant column tests, which were conducted according to ASTM-D-4015-92 by Law Engineering, Atlanta, Georgia (Boudreau, 1994). The resonant column test subjects a soil specimen to small torsional strains $\left(\gamma=10^{-5}\right.$ to $\left.10^{-4}\right)$, while measuring the resonant frequencies in the soil. The soil specimens were $7.3 \mathrm{~cm}$ (2.88 in) in diameter and $14.61 \mathrm{~cm}$ (5.75 in) in height. The resonant frequency of the soil was measured at various confining pressures. The results of the resonant column tests can be seen in Table 3.2 . 


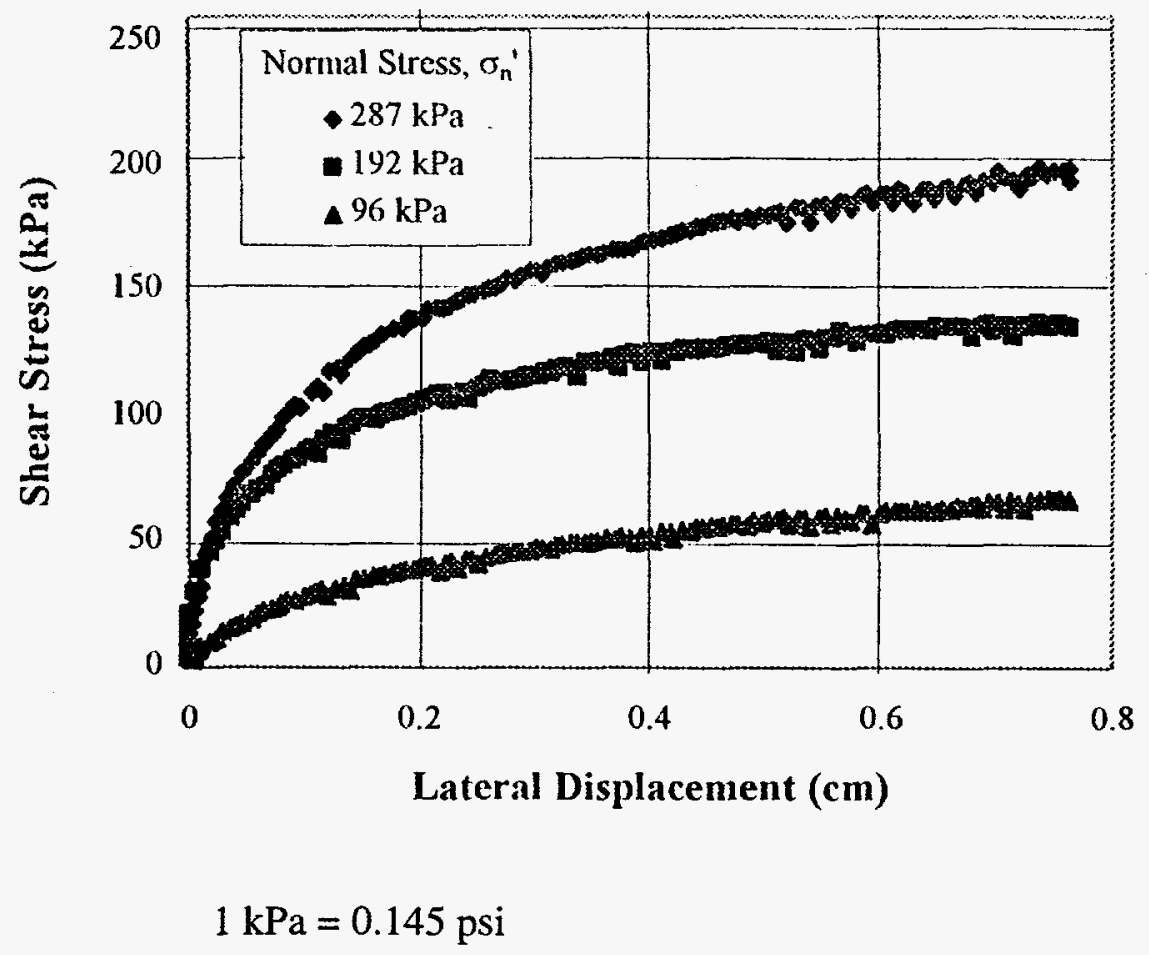

Figure 3.3. Direct Shear Test Results for Savannah River Site Soil. 
Table 3.1. Equivalent Compressive Strengths Obtained from Direct Shear Tests on Savannah River Site Soil.

\begin{tabular}{|c|cc|c|c|}
\hline $\begin{array}{c}\text { Test } \\
\text { Number }\end{array}$ & \multicolumn{2}{|c|}{$\begin{array}{c}\text { Dry Unit Weight } \\
\mathbf{g} / \mathbf{c m}^{\mathbf{3}}(\mathbf{p c f})\end{array}$} & $\begin{array}{c}\text { Confining Pressure } \\
\mathbf{k P a} \text { (psi) }\end{array}$ & $\begin{array}{c}\text { Compressive Strength } \\
\mathbf{k P a} \text { (psi) }\end{array}$ \\
\hline 1 & 1.38 & $(86.2)$ & $96(13.9)$ & $133.9(19.4)$ \\
\hline 2 & $1.78(111.1)$ & $182(27.8)$ & $274.8 \quad(39.8)$ \\
\hline 3 & $1.56(97.4)$ & $287(41.6)$ & $398.7 \quad(57.8)$ \\
\hline
\end{tabular}

Table 3.2. Results of Resonant Column Tests on Savannah River Site Soil (Boudreau, 1994).

\begin{tabular}{|c|c|c|c|c|}
\hline $\begin{array}{c}\text { Depth } \\
(\mathbf{m})\end{array}$ & $\begin{array}{c}\text { Void Ratio, } \\
\mathbf{e}_{\theta}\end{array}$ & $\begin{array}{c}\text { Confining Pressure } \\
\mathbf{( k P a}\end{array}$ & $\begin{array}{c}\text { Shear Modulus } \\
(\mathbf{M P a})\end{array}$ & $\begin{array}{c}\text { Elastic Modulus } \\
(\mathbf{M P a})\end{array}$ \\
\hline 4.6 & 0.650 & 43.2 & 40.5 & 93.2 \\
\hline 8.8 & 0.546 & 155.2 & 116.4 & 267.7 \\
\hline 16.8 & 0.705 & 204.5 & 146.3 & 336.6 \\
\hline 24.4 & 0.600 & 300.1 & 172.3 & 396.4 \\
\hline 43.6 & 0.727 & 473.1 & 191.0 & 439.4 \\
\hline 60.0 & 0.831 & 824.2 & 205.5 & 472.5 \\
\hline
\end{tabular}

\footnotetext{
$* 1 \mathrm{~m}=3.281 \mathrm{ft}$

$1 \mathrm{kPa}=0.145 \mathrm{psi}$

$1 \mathrm{MPa}=145 \mathrm{psi}$
} 
The stiffness of the soil at this small level of strain can be represented by the low strain shear modulus, $G_{\max }=\rho V_{s}^{2}$, where $\rho$ is the mass density of the soil $\left(\gamma_{t} / g\right)$, and $V_{s}$ is the shear wave velocity. The elastic modulus, $E$, can be found from the shear modulus using the equation, $E=2 G(1+v)$, where $v$ is Poisson's ratio. A value of $v=0.15$ has been used for the low strain value of Poisson's ratio (Tatsuoka and Shibuya, 1992). The low strain shear modulus of the Savannah River Site soil corresponding to the chamber tests is $\mathrm{G}=40.5 \mathrm{MPa}$ (5.9 ksi), and the elastic modulus of the soil is $\mathrm{E}=93.2 \mathrm{MPa}(13.5 \mathrm{ksi})$. Figure 3.5 shows the results of resonant column tests for the SRS soil. A summary of the stiffness data for SRS soil can be seen in Table 3.3.

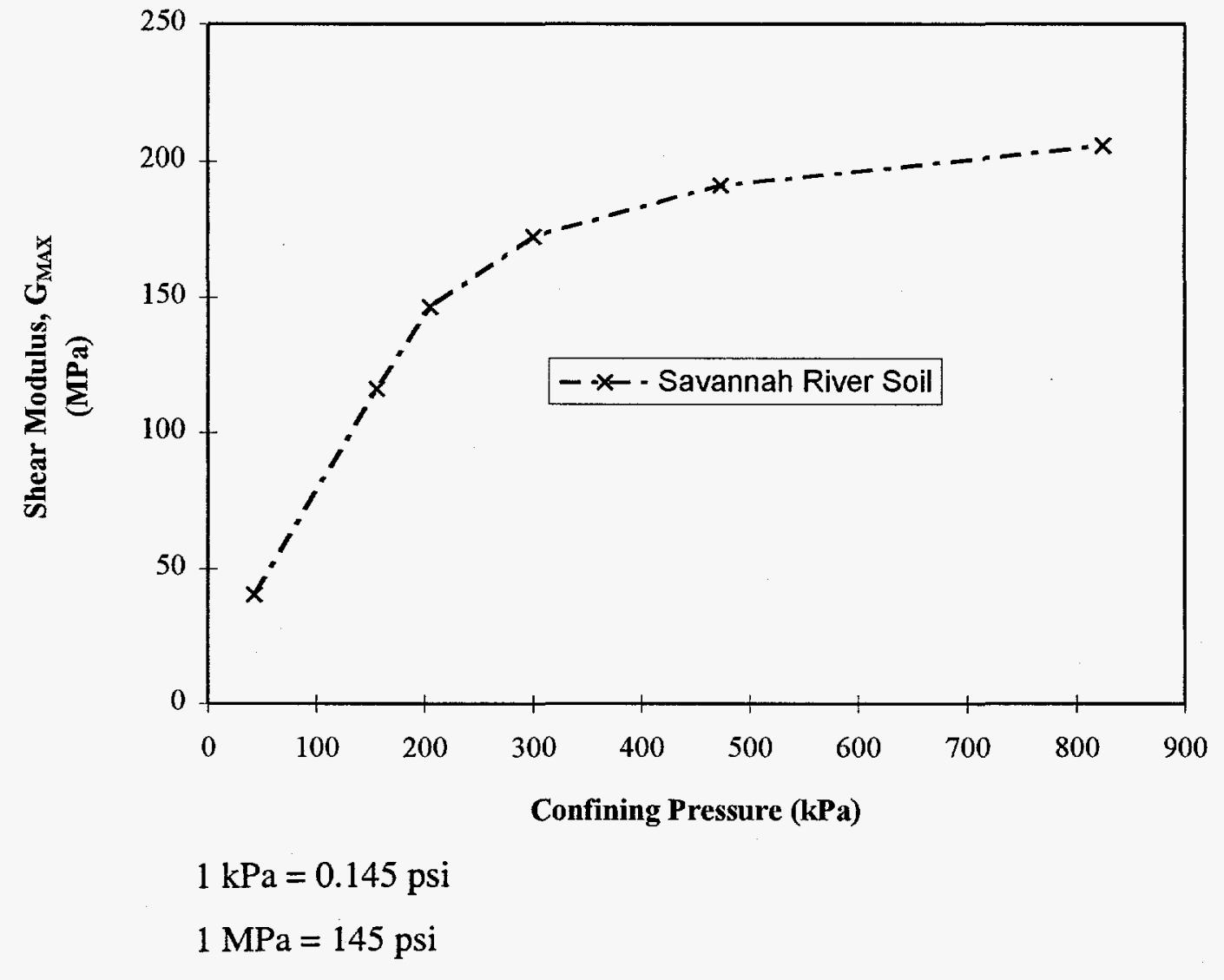

Figure 3.5. Results of Resonant Column Tests on SRS Soil. 
Table 3.3. Strength and Stiffness Data for the Pre-Test SRS Soils.

\begin{tabular}{|l|r|r|}
\hline Mass Density, \#/ft ${ }^{3}\left(\mathrm{Mg} / \mathrm{m}^{3}\right):$ & 89.89 & $(1.44)$ \\
\hline Shear Wave Velocity, ft/sec $(\mathrm{m} / \mathrm{sec}):$ & 413.15 & $(125.93)$ \\
\hline Elastic Modulus, ksi (MPa): & 13.51 & $(93.2)$ \\
\hline Low Strain Shear Modulus, ksi (MPa): & 5.88 & $(40.5)$ \\
\hline Ultimate Compressive Strength, ksi (MPa): & 0.0072 & $(0.05)$ \\
\hline
\end{tabular}

\subsection{Summary}

The Savannah River Site soil used in this series of demonstration tests, is a gapgraded clayey sand with $86 \%$ sand particles, $11 \%$ clay-size particles, and $3 \%$ silt particles. The soil has a liquid limit of 150 and a plastic limit of 37 , giving a plasticity index of 113 . Compaction-density tests conducted at standard effort show that the optimum moisture content for the soil is around $11 \%$, and the maximum unit weight is $1.91 \mathrm{Mg} / \mathrm{m}^{3}\left(119.4 \mathrm{lb} / \mathrm{ft}^{3}\right)$. The soil has a compressive strength of $0.05 \mathrm{MPa}(7.2 \mathrm{psi})$ and a low strain shear modulus of $40.5 \mathrm{MPa}(5.88$ $\mathrm{ksi}$ ), giving an elastic modulus of $93.2 \mathrm{MPa}(13.51 \mathrm{ksi})$. It would classify as a poorly graded clayey sand (SC-SP).

\subsection{SRS Soil Vitrification Experience}

Two series of bench-scale in situ vitrification (ISV) tests on SRS soils were conducted in 1989 and in 1994 (Campbell and Buelt, 1990; Lowery et al., 1994). In the 1989 series of experiments it was determined that the alkali and alkali-earth concentrations in the native SRS soils were not sufficient to vitrify it with the standard graphite electrode ISV process. Historically, soils containing less than $1.4 \%$ by weight of alkali material (e.g., $\mathrm{Na}_{2} \mathrm{O}$ and or $\mathrm{K}_{2} \mathrm{O}$ ) have been very difficult to vitrify using the ISV process. The sodium oxide and potassium oxide compounds in the soil act as primary charge carriers in the molten soil. This permits the molten soil to be sufficiently conductive to pass the necessary current required to sustain and to propagate the melt. SRS soils contain about $0.5 \%$ by weight of alkali material. Consequently, the addition of fluxant material (e.g., 
$\mathrm{Na}_{2} \mathrm{CO}_{3}$ ) up to a total of $5 \%$ by weight permitted the soil to be successfully processed with the bench-scale ISV equipment.

The 1994 series of tests consisted of crucible tests and engineering scale experiments:

1. The crucible tests were performed to evaluate the feasibility of introducing chemical fluxants into the soil in a semi-intrusive manner; i.e., pressing lances containing fluxants into the soil. This technique proved successful in vitrifying the soil. However, in a field-scale experiment the number of lances required to achieve the necessary fluxant concentrations may become excessive.

2. The engineering scale experiments were conducted with increased ISV power levels on unadulterated SRS soils. These experiments successfully vitrified the soil. However, specific energy requirements (the electrical energy requirements to vitrify a unit mass of soil; i.e., $\mathrm{kWh}$ /pound) were 1.5 to 2 times higher than what is normally required to melt alkali-rich soils such as those found at the Hanford Site.

\subsection{Plasma Heating Systems}

There were two Plasma Heating Systems (PHS's) used in this demonstration series. Both systems were manufactured by Plasma Energy Corporation (PEC), Raleigh, North Carolina.

\subsection{The PT50 Plasma Heating System.}

The PEC PT50 plasma heating system is on loan to Georgia Tech from the Technology Applications Division, Georgia Power Company. It operates in the non-transferred mode only. It is rated at $100 \mathrm{~kW}$ and has been operated primarily using air as the plasma gas. Argon and hydrogen have also been used as plasma gases in this system. The plasma torch which was used for these in situ demonstrations is six (6) feet long and 2.5 inches in diameter. At operating conditions the PT50 plasma torch has a water flow of 30 GPM and a plasma gas flow of 5 SCFM. The PT50 plasma heating system is ideal for use in a laboratory 
setting to conduct bench-scale experiments of plasma arc technology applications. These tests can be conducted very rapidly and at low cost.

\subsection{The PT150 Plasma Heating System}

The PEC PT150 plasma heating system is a convertible system; i.e., it can operate either in the transferred arc mode or in the non-transferred arc mode. It is rated at $240 \mathrm{~kW}$ and operates preferably on air or nitrogen. However, the power supply limited the power level of the non-transferred arc plasma to a maximum of 200 $\mathrm{kW}$. The plasma torch is 65 inches (5.42 feet) long and four (4) inches in diameter. At operating conditions the PT150 plasma torch has a water flow of 50 GPM and a plasma gas flow of 50 SCFM. The torch is ruggedly constructed to withstand harsh industrial, conditions. This plasma heating system is at the power level threshold sufficient to evaluate and demonstrate the technical, industrial and economic feasibility of plasma technology applications. In this report the PT150 plasma heating system shall be referred to as the " $200 \mathrm{~kW}$ plasma torch."

\subsection{ISPV EXPERIMENTAL PROGRAM}

The research program for this project consisted of six separate experiments to demonstrate the ISPV concept in SRS soil under a variety of geotechnical and environmental conditions. Table 4.1 presents a compilation of these six experiments.

\subsection{ISPV Experiment No. 1: $100 \mathrm{~kW}$ in Clean SRS Soil.}

The purpose of this experiment was to establish an ISPV baseline for clean SRS soil, approximating its natural undisturbed state. The experiment was conducted with the 100 $\mathrm{kW}$ plasma torch. A steel cylinder two feet in diameter and three feet high was filled with SRS soil, with a 4-inch borehole in the center, extending to a depth of 2.5 feet, 6 inches from the bottom of the cylinder (Figure 4.1). The borehole was lined with a thin metal stovepipe casing. Five thermocouples were installed in the cylinder at the locations indicated in Appendix A. The test procedure for this experiment is also outlined in Appendix A. 
The plasma torch was inserted to a depth of two feet, which was 6 inches above the bottom of the borehole (12 inches from the bottom of the cylinder). The experiment was conducted for a period of 305 minutes (5.08 hours). The torch was raised 14 inches during this test. The experiment was conducted successfully, in accordance with the test plan. The operating conditions of the experiment are described in Appendix A. Table 4.2 contains a summary of pertinent results of this experiment. Figure 4.2 is a diagram of the cross section of the vitrified soil column from this experiment. Figure 4.3 is a photograph of a cross section of the vitrified column.

Table 4.1. List of In situ Plasma Vitrification Demonstration Experiments

\begin{tabular}{|l|l|l|l|l|}
\hline $\begin{array}{c}\text { Experiment } \\
\text { Number }\end{array}$ & Date (1996) & Power Level & \multicolumn{1}{|c|}{$\begin{array}{l}\text { ARS Soil } \\
\text { Additives }\end{array}$} & \multicolumn{1}{c|}{ Remarks } \\
\hline 1 & Feb. 22 & $80 \mathrm{~kW}$ & None & Natural moisture content \\
\hline 2 & Mar. 26 & $68 \mathrm{~kW}$ & Fluxant Added & Marble chips $\left(\mathrm{CaCO}_{3}\right)$ \\
\hline 3 & Mar. 27 & $60 \mathrm{~kW}$ & None goil \\
\hline 4 & Apr. 10 & $96 \mathrm{~kW}$ & $\begin{array}{l}\text { Contaminants } \\
\text { Added concrete, }\end{array}$ & $\begin{array}{l}\text { Metals, glass, concrete, } \\
\text { contaminated briquettes }\end{array}$ \\
\hline 5 & Apr. 11 & $200 \mathrm{~kW}$ & $\begin{array}{l}\text { Contaminants } \\
\text { Added }\end{array}$ & $\begin{array}{l}\text { Metals, gontaminated briquettes } \\
\text { contarated soil }\end{array}$ \\
\hline 6 & Aug. 13 & $200 \mathrm{~kW}$ & None & Dual contiguous melts \\
\hline
\end{tabular}


Table 4.2. Summary of Results: Experiment No. 1 .

\section{Initial Conditions}

a. Soil Type: SRS Soil (SC-SP)

b. Borehole Diameter: 4 inches

c. Additives: None

d. Density: 90 pounds per cubic foot

e. Moisture Content: $8.3 \%$

f. Weight of Soil: 910 pounds

g. Volume of Soil: $9.10 \mathrm{ft}^{3}$

\section{Test Conditions}
a. Average Power Level: $80 \mathrm{~kW}$
b. Total Withdrawal Distance: 24 inches
c. Average Torch Withdrawal Rate: $12.7 \mathrm{~min} / \mathrm{inch}$

\section{Post Test Results}

a. Test Duration: 305 minutes (5.08 hours)

b. Power Consumption: $408 \mathrm{kWh}$

c. Vitrified Mass
(1) Maximum Diameter: 22 inches
(2) Height: 24 inches
(3) Weight: 146.5 pounds
(4) Volume: $1.10 \mathrm{ft}^{3}$

d. Specific Energy Requirement (SER): $2.78 \mathrm{kWh} / \#$ 


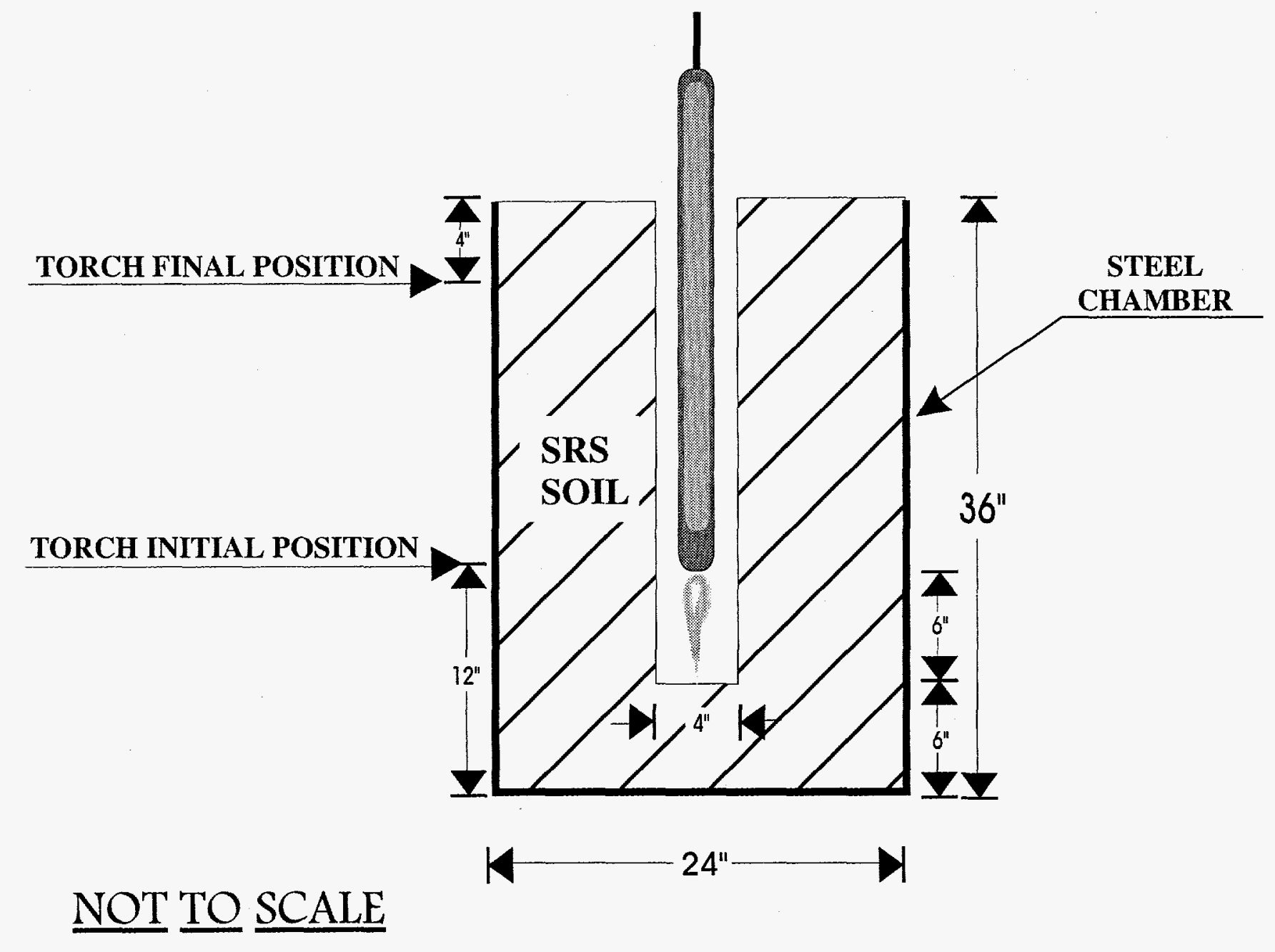

Figure 4.1. Test Geometry for ISPV Experiment No. 1. 


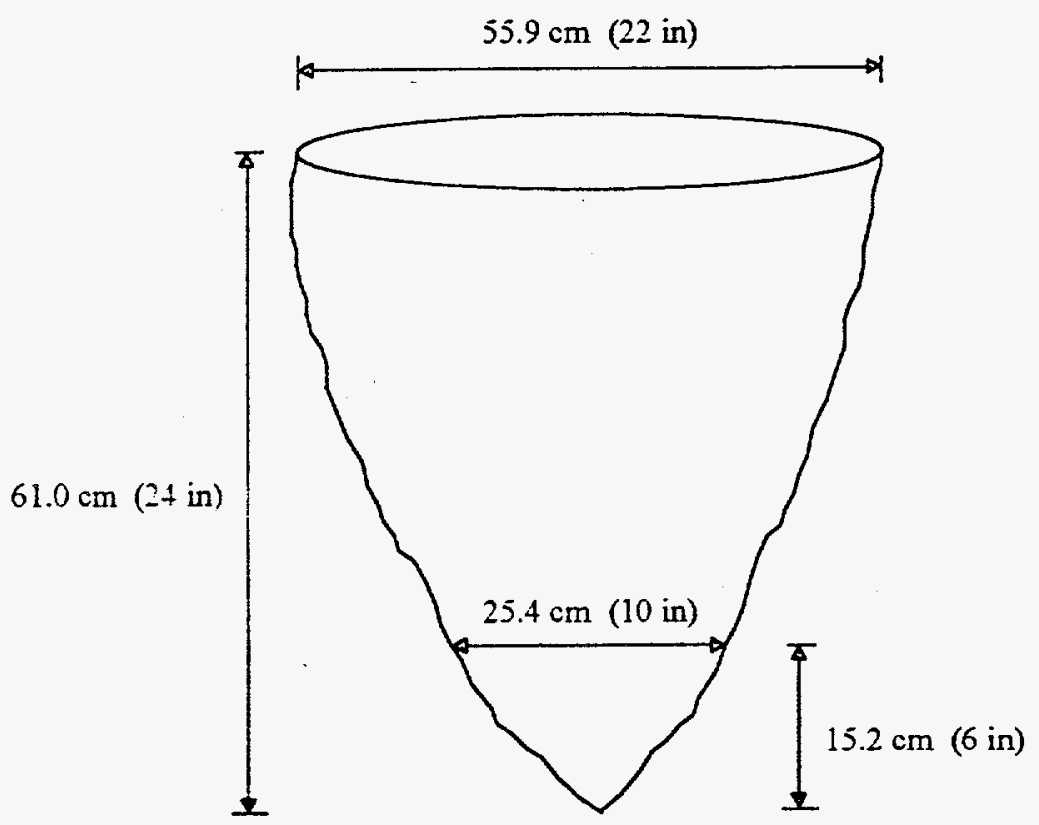

Figure 4.2. Diagram of the Vitrified Column from Experiment No. 1. 


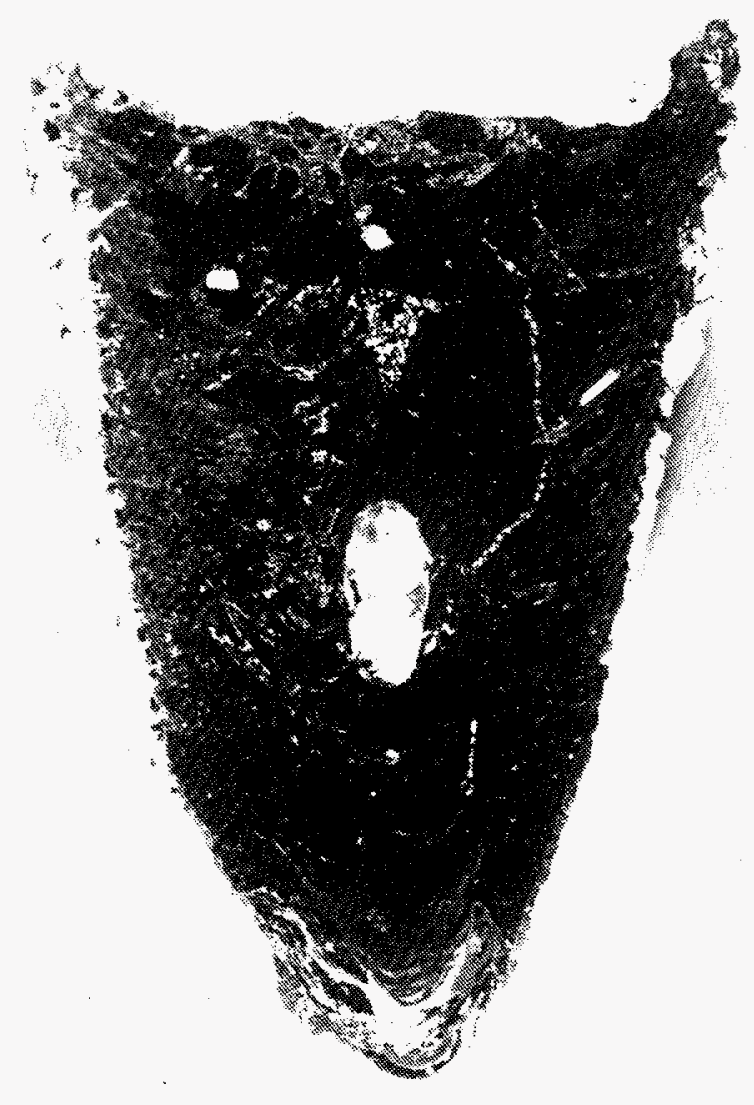

Figure 4.3. Photograph of a Cross Section of the Vitrified Column from Experiment No. 1. 


\subsection{ISPV Experiment No. 2: $100 \mathrm{~kW}$ in Clean SRS Soil and Fluxant.}

The purpose of this experiment was a scoping study to repeat Experiment No. 1 with the addition of a fluxant. Previous studies (Campbell and Buelt, 1990; Lowery et al., 1994) suggested that the melting rate, specific energy requirements, and the size of the vitrified mass may be greatly improved with the addition of a fluxant. The experiment was conducted with the $100 \mathrm{~kW}$ plasma torch. As in Experiment No. 1, a steel container vessel two feet in diameter and three feet high was filled with SRS soil. In addition, a one foot high gas collection cover with an exhaust port was mounted on top of the container. Four-inch and 8-inch concentric stovepipe liners were placed in a borehole in the center of the cylinder. The 2-inch space between the liners was filled with 61 pounds of commercial limestone, $\mathrm{CaCO}_{3}$ (Parker's mini marble chips), to provide the fluxant along the length of the borehole (Figure 4.4). The borehole extended to a depth of 2.5 feet, 6 inches from the bottom of the cylinder. The test procedure for this experiment is outlined in Appendix B.

The plasma torch was inserted to a depth of two feet which was 6 inches above the bottom of the borehole (12 inches from the bottom of the cylinder). The experiment was conducted for a total of 260 minutes ( 4.33 hours). The torch was raised a total of 20 inches during the test. Figure 4.5 is a photograph of the test chamber taken during the experiment.

The geometry developed in the test plan to add the fluxant to the soil was not successful. The fluxant melted rapidly and dropped into the molten pool before it could mix with the soil. Therefore, it would be expected that the fluxant had only a minor effect on the resulting vitrified mass. In addition, the premature melting of the fluxant effectively resulted in an 8-inch borehole for most of the experiment. It is anticipated that this very large borehole permitted a significant amount of the plasma energy to escape to the surface, resulting in a smaller mass of vitrified materials. The test sequence of the experiment is described in Appendix B. Table 4.3 contains a summary of pertinent results of this experiment. Figure 4.6 is a diagram of the vitrified column from Experiment No. 2. Figure 4.7 is a photograph of the vitrified mass. 


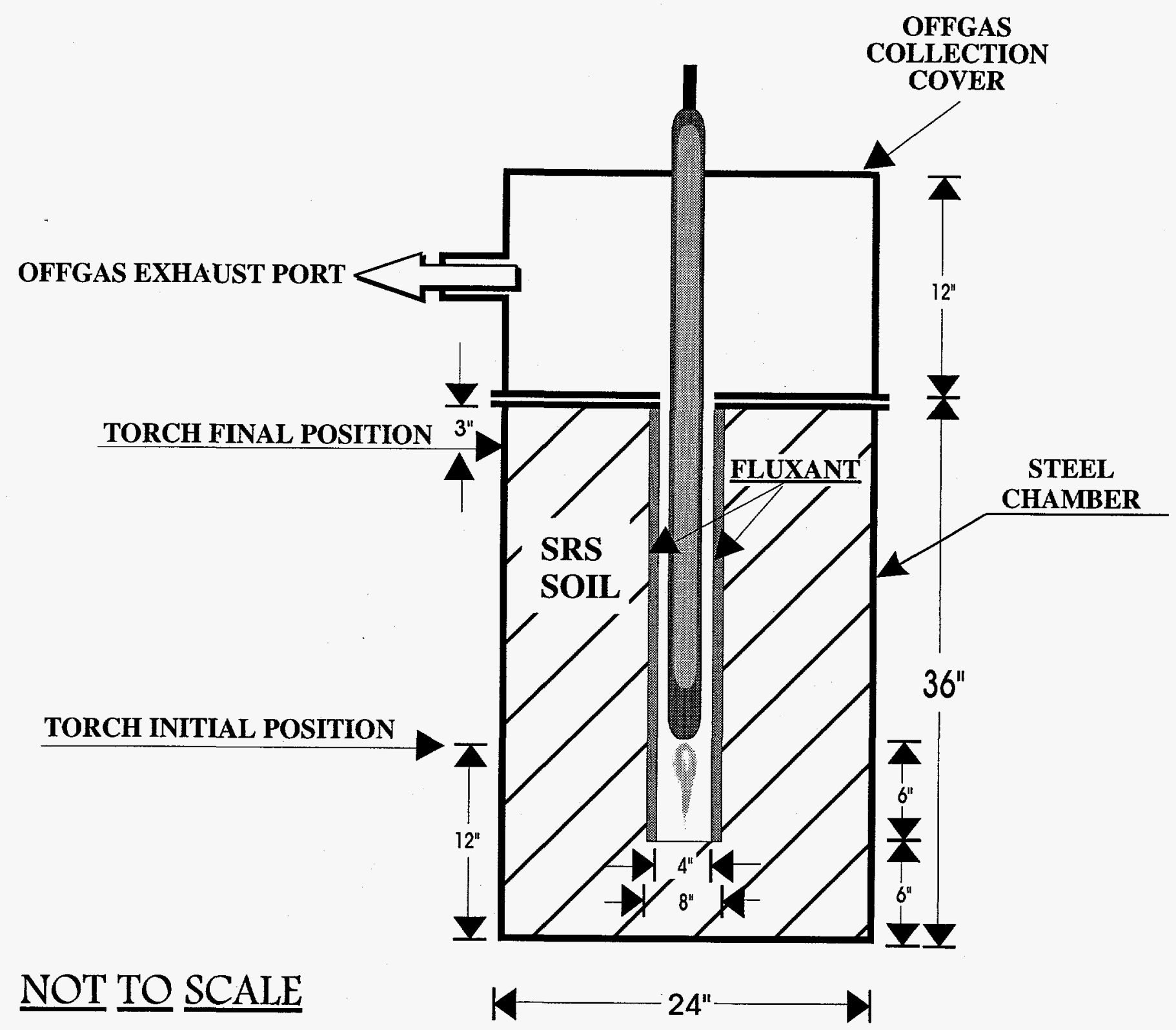

Figure 4.4. Test Geometry for ISPV Experiment No. 2. 


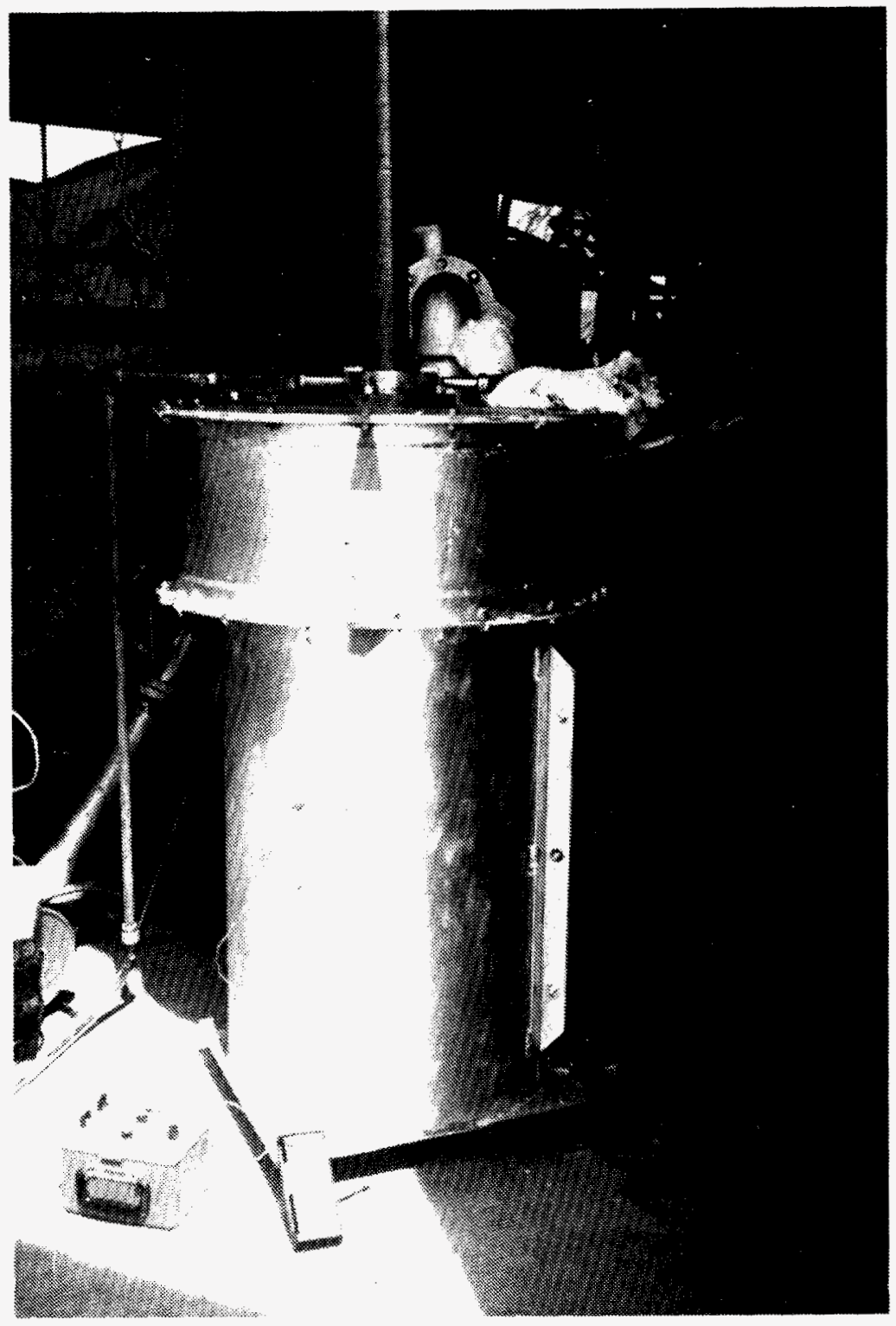

Figure 4.5. Photograph of Experiment No. 2 Test Chamber. 
Table 4.3. Summary of Results: Experiment No. 2.

\section{Initial Conditions}
a. Soil Type: SRS Soil (SC-SP)
b. Borehole Diameter: 4 inches ( 8 inches after fluxant melted prematurely)
c. Additives: Fluxant: 61 pounds of limestone, $\mathrm{Ca} \mathrm{CO}_{3}$ (Parker's mini marble chips)
d. Density: 90.4 pounds per cubic foot
e. Moisture Content: $10 \%$
f. Weight of Soil: 773 pounds
g. Volume of Soil: $8.55 \mathrm{ft}^{3}$

\section{Test Conditions}
a. Average Power Level: $68 \mathrm{~kW}$
b. Total Withdrawal Distance: 24 inches
c. Average Torch Withdrawal Rate: $10.8 \mathrm{~min} / \mathrm{inch}$

\section{Post Test Results}
a. Test Duration: 260 minutes ( 4.33 hours)
b. Power Consumption: $292 \mathrm{kWh}$
c. Vitrified Mass
(1) Maximum Diameter: 12 inches
(2) Height: 16.5 inches
(3) Weight: 88.3 pounds*
(4) Volume: $0.66 \mathrm{ft}^{3}$

d. Specific Energy Requirement (SER): $3.31 \mathrm{kWh} / \#$

\footnotetext{
*The melted fluxant formed into a weak crust around the bottom of the vitrified mass with a weight of 54.7 pounds. Total weight of vitrified mass plus crust was 143 pounds.
} 


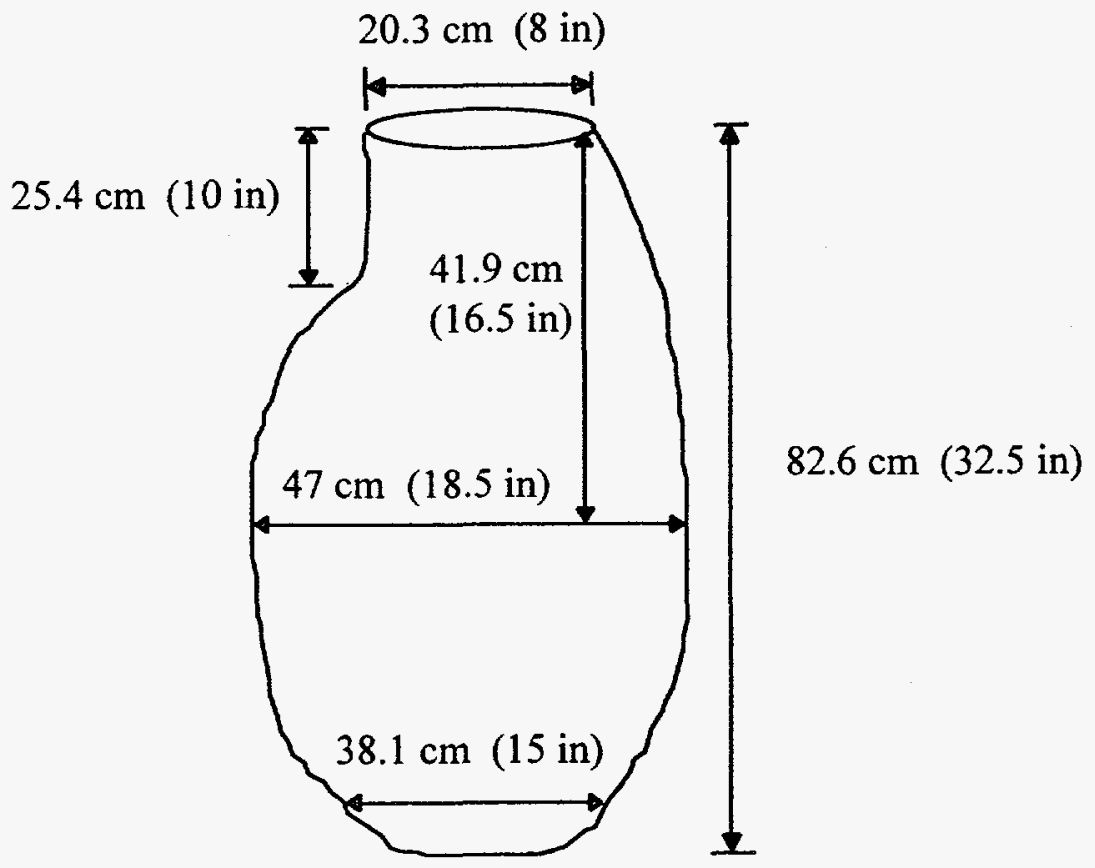

Figure 4.6. Diagram of Vitrified Column from Experiment No. 2. 


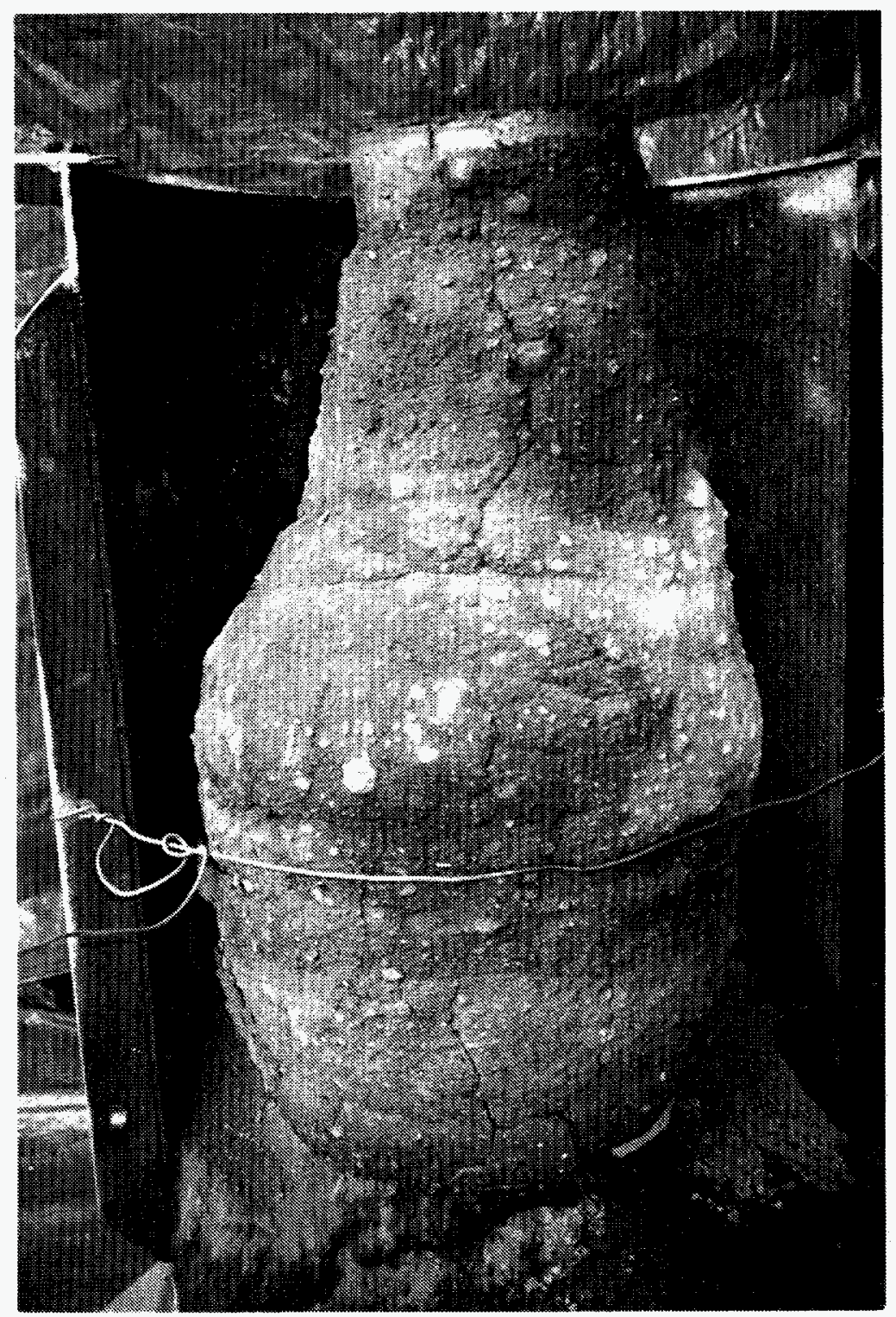

Figure 4.7. Photograph of Vitrified Product from Experiment No. 2. 


\subsection{ISPV Experiment No. 3: $100 \mathrm{~kW}$ in Clean SRS Soil and High Moisture Content.}

The purpose of this experiment was to evaluate the capability of the ISPV process to vitrify fully saturated soil at or near the ground water table. The experiment was conducted with the $100 \mathrm{~kW}$ plasma torch. A steel container vessel two feet in diameter and a three feet high was filled with SRS soil, with a 4-inch stovepipe-lined borehole in the center of the cylinder (Figure 4.8). The borehole extended to a depth of 2.5 feet, 6 inches from the bottom of the container vessel. In order to simulate a fully saturated soil, the bottom 1.5 inches of the cylinder was filled with small pea gravel. In addition, the pea gravel was placed in five vertical 1.25 -inch diameter columns, equally spaced, around the inside wall of the steel cylinder. The purpose of the bottom gravel was to permit water to recharge into the soil around the borehole as it is boiled off by the plasma torch. The five vertical columns of pea gravel were placed to provide steam vents to prevent excessive pressure buildup in the container vessel. Figure 4.9 is a photograph of the top of the test vessel taken during the experiment. A container of water connected to the bottom of the test vessel by a hose fed water to the pea gravel base of the steel container by gravity. This arrangement permitted the water to remain at a constant level throughout the experiment. This level was established at 12 inches above the bottom of the cylinder. It was also at this level that the plasma torch was placed to begin the soil vitrification process. The test procedure for this experiment is outlined in Appendix C.

At the beginning of the experiment the plasma torch was operating almost entirely in water contained in the borehole. After this water was boiled off, the vitrification process began. However, after the thin metal casing below the water level was melted, water began to flow by gravity directly into the lower borehole region. In addition, vitrification of a portion of the 4.5 inches of soil below the bottom of the borehole, combined with the pea gravel layer in the bottom of the container, resulted in excessive soil permeability and subsequent water recharge into the borehole region from the bottom. Because of these high water recharge rates into the borehole region, the plasma heating was, to a large extent, expended in boiling off the water that was continuously filling the borehole. After 121 minutes ( 2.02 hours) of operation with only minor vitrification occurring, it was 
decided to stop the recharging portion of the experiment and to complete the experiment only with the residual water in the container. From this time on, normal vitrification of the soil in the container vessel took place for a period of an additional 229 minutes (3.81 hours). The test sequence of the experiment is described in Appendix C. Figure 4.10 is a diagram of the vitrified mass resulting from this experiment. Table 4.4 contains a summary of pertinent results of this experiment.

\subsection{Experiments No. 4 and 5: $100 \mathrm{~kW}$ and $200 \mathrm{~kW}$ in Contaminated SRS Soil.}

The purpose of these experiments was to evaluate the capability of the SRS soil to fully melt, vitrify, and remediate SRS soil which was seeded with a variety of contaminants at two different power levels. These experiments were conducted with the $100 \mathrm{~kW}$ and 200 $\mathrm{kW}$ plasma torches. Experiments 4 and 5 were conducted adjacent to each other in a large steel rectangular container (69 inches high, 56 inches wide, 44 inches deep), containing 65 inches of soil (Figure 4.11). A photograph of this container is shown in Figure 4.12. Two stovepipe-lined boreholes, 4 inches and 5 inches in diameter, extended down to 6 inches from the bottom of the metal container. The center-to-center spacing between the boreholes was 18 inches ( 1.5 feet). The reason for this dual borehole arrangement was to determine if the two adjacent columns of melt would coalesce into a single contiguous vitrified mass. However, the separation of the boreholes was approximately equal to the combined radii of the two melted columns. Therefore, the columns touched, but did not coalesce, and this part of the experiment was not accomplished. Experiment No. 6 was added to this research program to demonstrate this feature. 


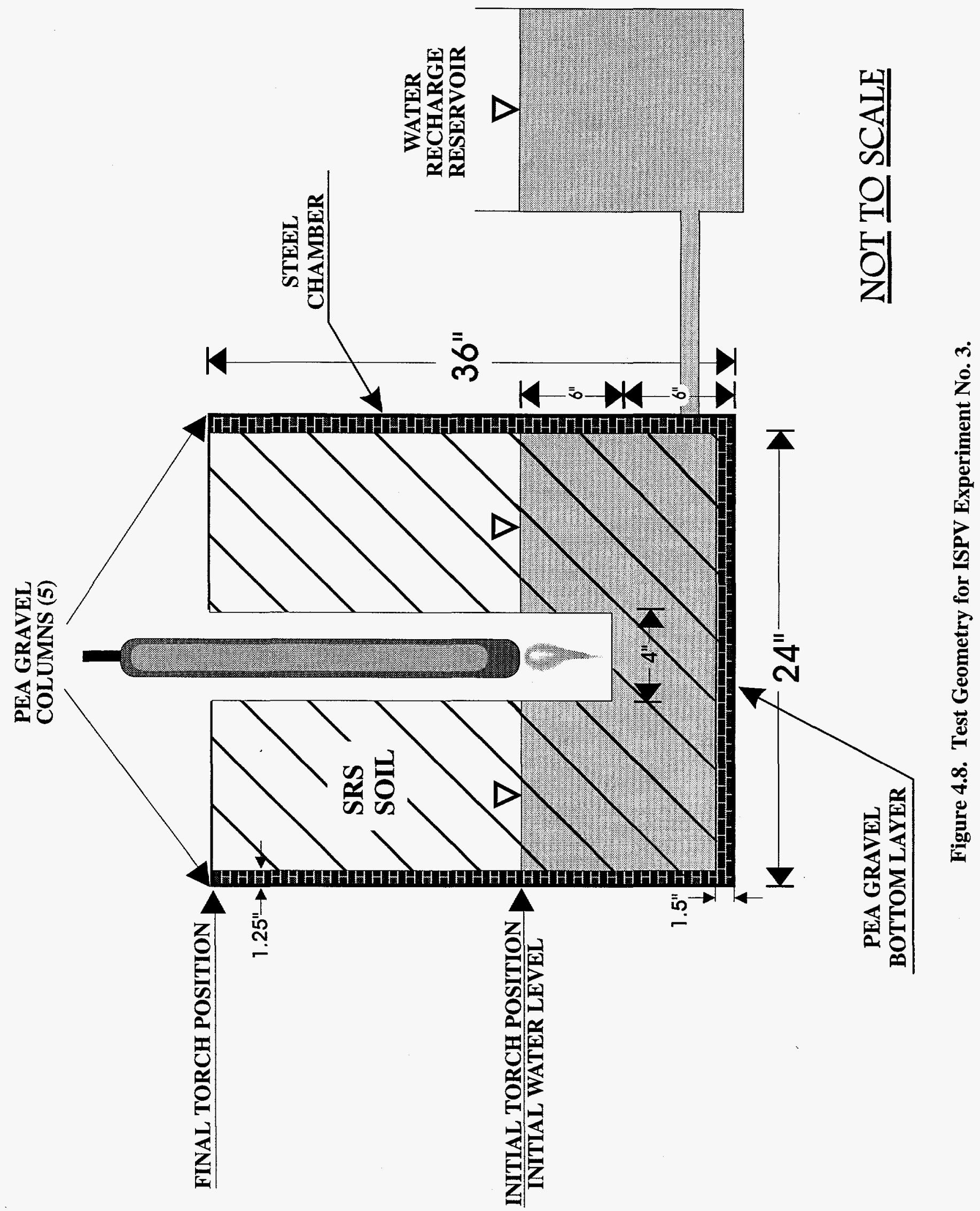




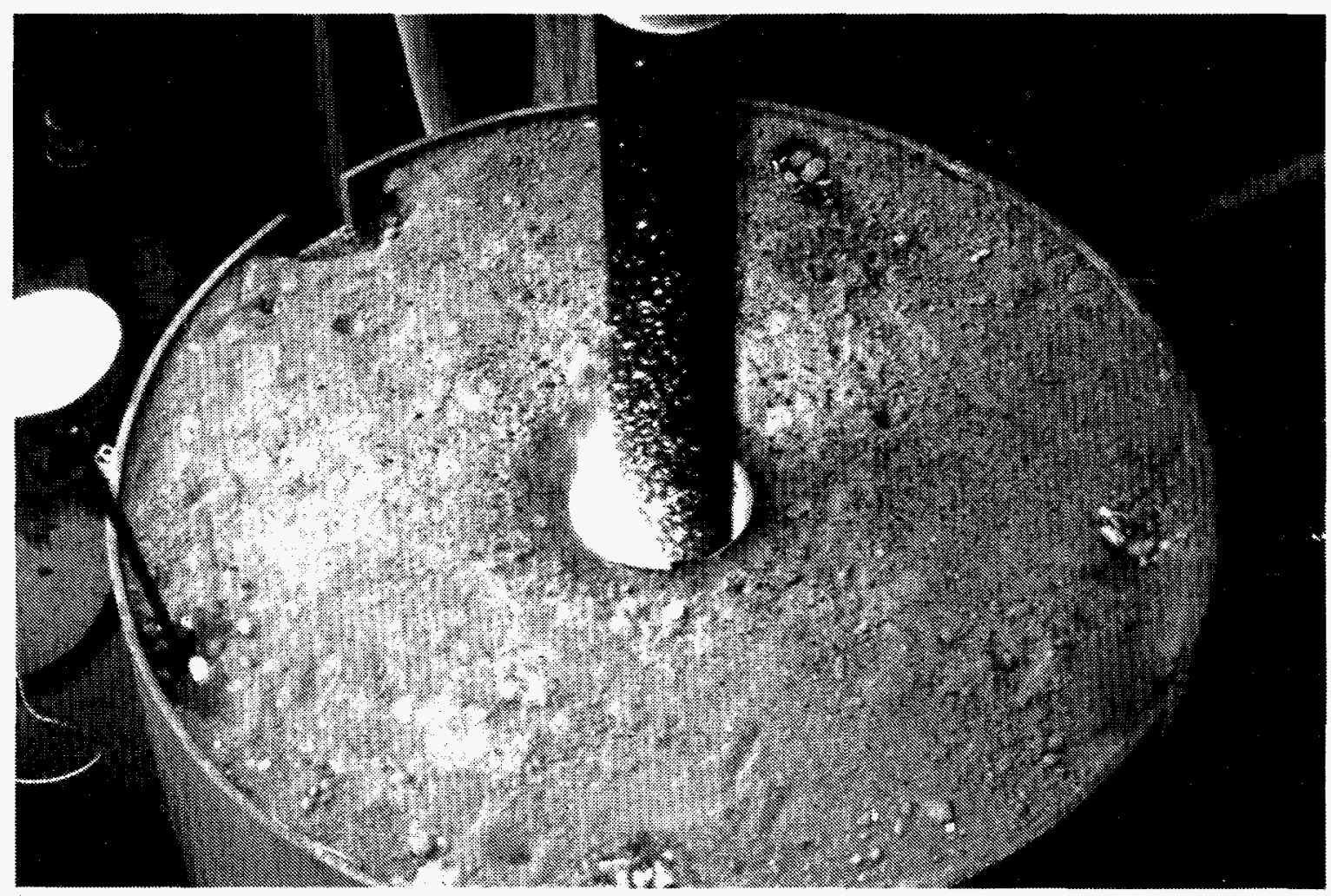

Figure 4.9. Photograph of Test Chamber Used in Experiment No. 3. 


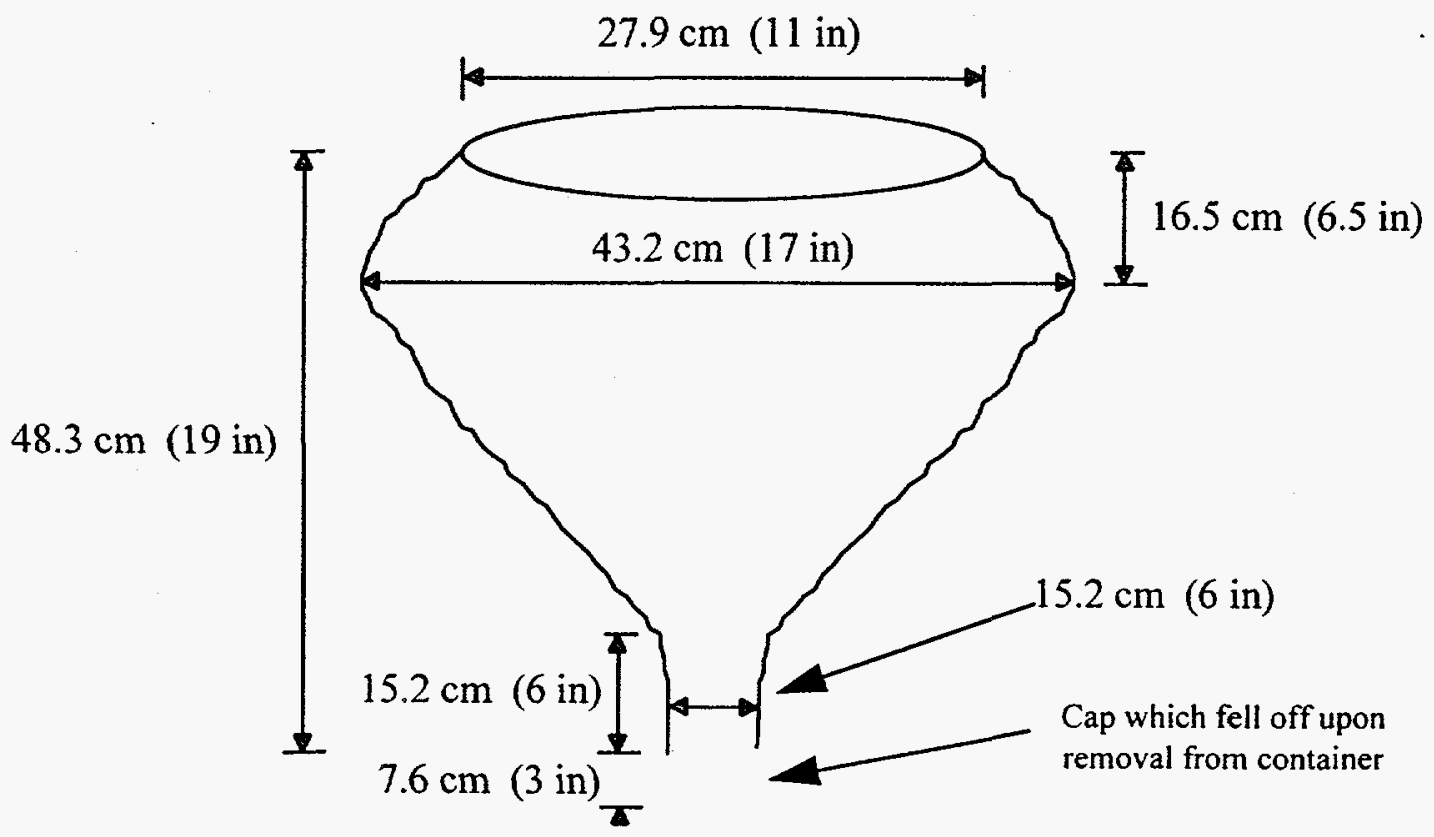

Figure 4.10. Diagram of Vitrified Mass from Experiment No. 3. 


\section{Table 4.4. Summary of Results: Experiment No. 3.}

\section{Initial Conditions}
a. Soil Type: SRS Soil (SC-SP)
b. Borehole Diameter: 4 inches
c. Additives: None
d. Density: 86.4 pounds per cubic foot
e. Moisture Content: $31.4 \%$ (saturated)
f. Weight of Soil: 785 pounds
g. Volume of Soil: $9.08 \mathrm{ft}^{3}$

\section{Test Conditions}

a. Average Power Level: $60 \mathrm{~kW}$

b. Total Withdrawal Distance: 20 inches

(1) 0-121 minutes: 4 inches

(2) 121-350 minutes: 16 inches

c. Average Torch Withdrawal Rate:

(1) 0-121 minutes (no significant melting): $30.25 \mathrm{~min} / \mathrm{inch}$

(2) 121-350 minutes (melting): $14.3 \mathrm{~min} / \mathrm{inch}$

\section{Post Test Results}

a. Test Duration: 350 minutes ( 5.83 hours)

(1) 121 minutes (2.02 hours): no significant melting

(2) 229 minutes ( 3.81 hours): melting

b. Power Consumption: $350 \mathrm{kWh}$ (total)

(1) 2.02 hours (no significant melting): $121 \mathrm{kWh}$

(2) 3.81 hours (melting): $229 \mathrm{kWh}$

c. Vitrified Mass

(1) Maximum Diameter: 17 inches

(2) Height: 25.5 inches

(3) Weight: 143 pounds

(4) Volume: $1.07 \mathrm{ft}^{3}$

d. Specific Energy Requirement (SER): $2.45 \mathrm{kWh} / \#$ (melting period) 
Contaminants were seeded around each borehole in order to ensure they would be encompassed by the melt. The principal contaminants seeded in the soil were small water-filled and empty metal cans, broken glass in plastic containers, small pieces of concrete, and contaminated briquettes containing a variety of wastes and surrogate radioactive materials. The arrangement of the various contaminants for the two experiments is illustrated in Appendix D. The composition of the contaminated briquettes is also described in Appendix D.

Figure 4.13 is a photograph of Experiment No. 4 and No. 5 melt columns after the unvitrified soil was removed from the rectangular container used for the experiment. Figure 4.14 is a diagram indicating the size of each melt column and their relationship to each other in their containment vessel. Figure 4.15 is a cross section of each of these melted columns. Note the homogeneity of the two columns and the absence of any visible contaminants in the vitrified mass.

\subsection{Experiment No. 4: $100 \mathrm{~kW}$ in Contaminated SRS Soil.}

The test procedure for this experiment is described in Appendix E. The $100 \mathrm{~kW}$ plasma torch was used. It was inserted in the smaller 4-inch borehole to a depth 6 inches above the bottom of the borehole ( 12 inches above the bottom of the metal container). The experiment was conducted for a total of 390 minutes (6.5 hours). The torch was raised a total of 52 inches for this experiment. Except for a delay of a few minutes at the beginning of the experiment when the torch melted through the bottom of the metal container, the experiment was conducted successfully, in accordance with the test plan. The test sequence of the experiment and the thermocouple data are shown in Appendix E. Table 4.5 contains a summary of pertinent results of this experiment.

\subsection{Experiment No. 5: $200 \mathrm{~kW}$ in Contaminated SRS Soil}

The test procedure for this experiment is outlined in Appendix F. The $200 \mathrm{~kW}$ plasma torch was used. It was inserted in the larger 5-inch borehole to a depth of 12 inches above the bottom of the borehole (18 inches above the bottom of the 
metal container). This increased height was selected to prevent the plasma flame from melting through the bottom of the metal container, as occurred in Experiment 4. The experiment was conducted for a total of 330 minutes (5.5 hours). The torch was raised a total of 47 inches during the experiment. At 152 minutes into the test, an o-ring in the torch had to be replaced because it was leaking. Following replacement, the rest of the test was uneventful. The test sequence of the experiment and the thermocouple data are given in Appendix F. Table 4.6 contains a summary of pertinent results of this experiment. Figure 4.16 is a close up view of the Experiment No. 5 cross section. 


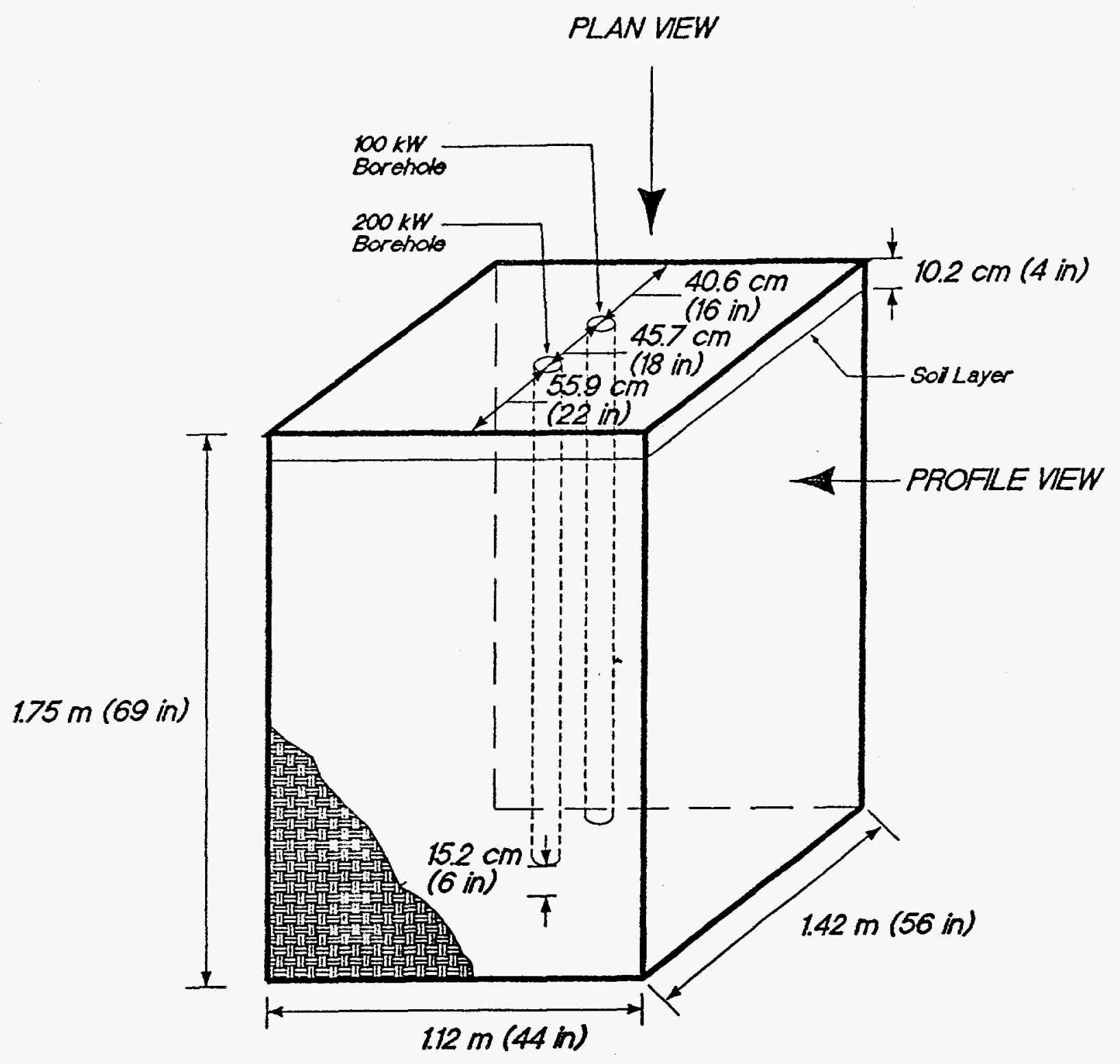

Figure 4.11. Test Geometry for ISPV Experiments No. 4 and No. 5. 


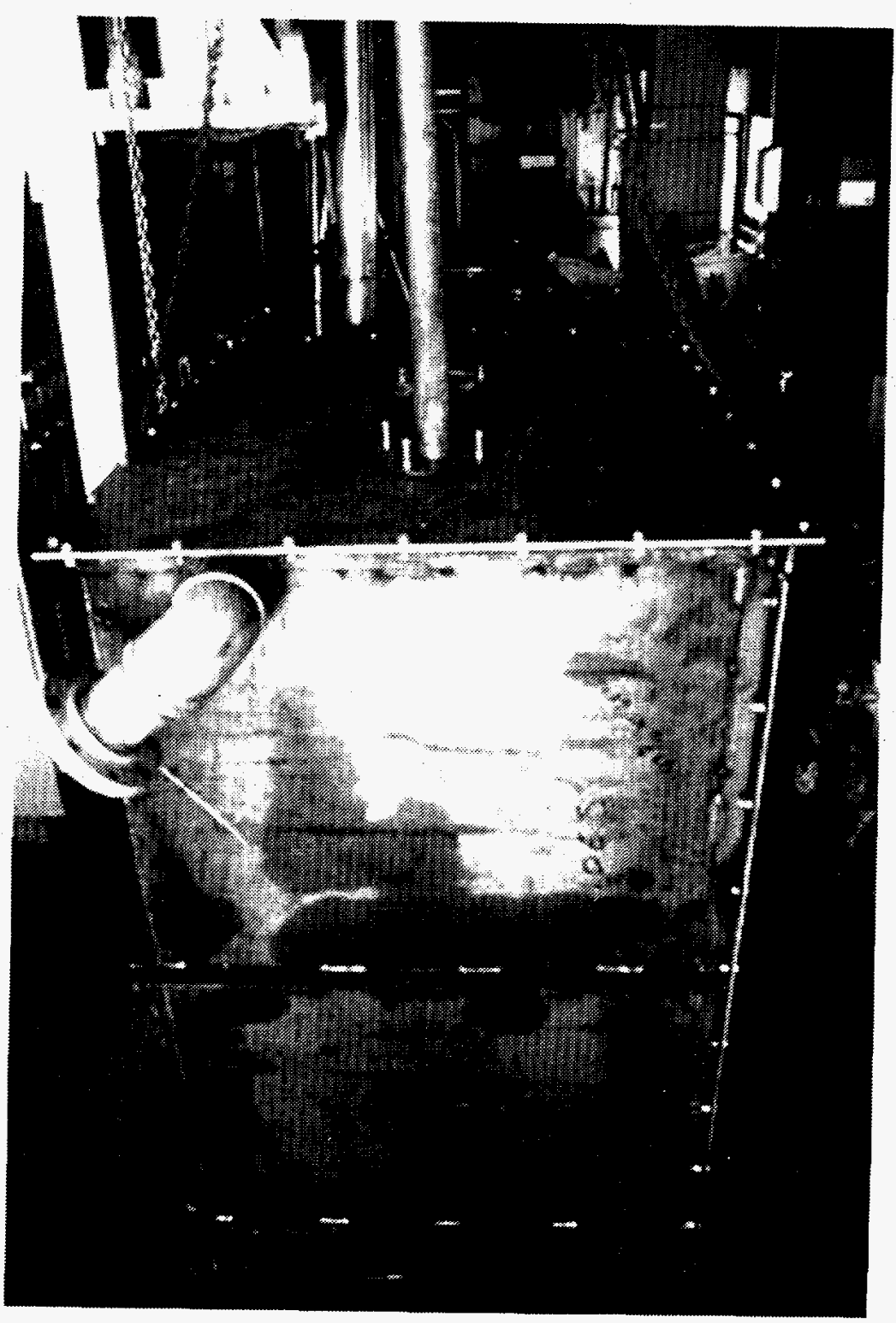

Figure 4.12. Photograph of Container Used in Experiments No. 4 and No. 5. 


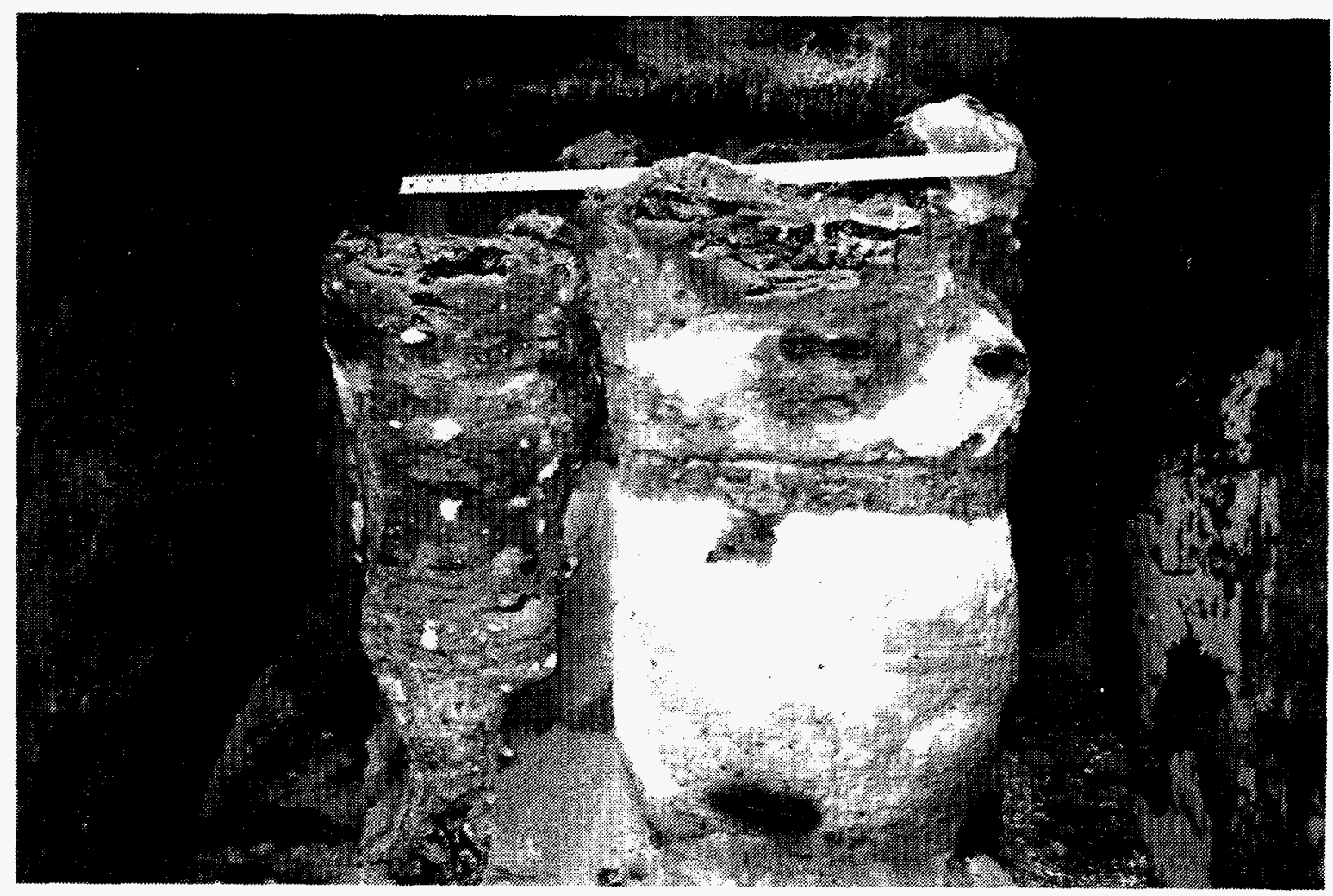

Figure 4.13. Photograph of the Melt Columns from Experiments No. 4 and No. 5 in the Steel Container. 


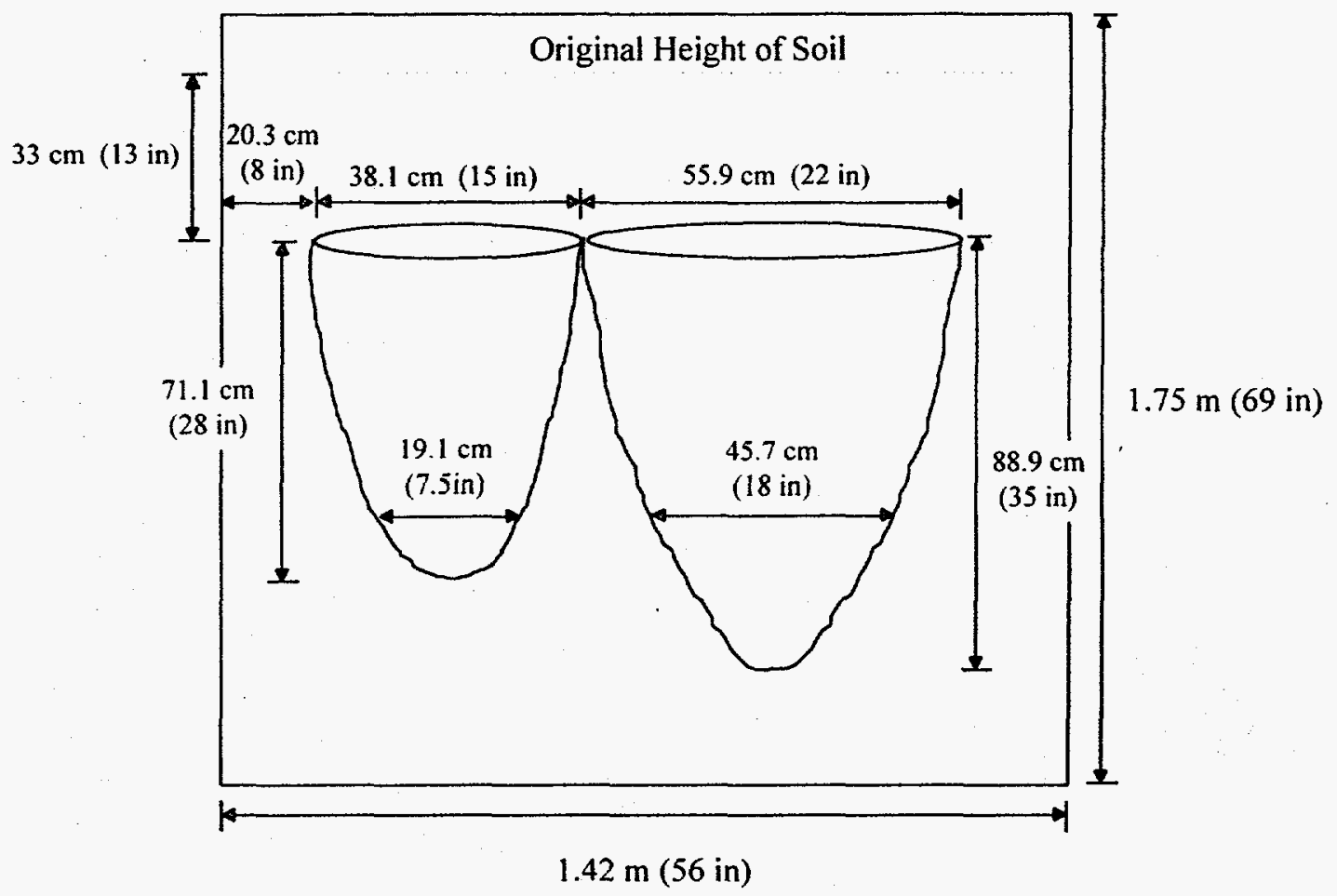

Figure 4.14. Diagram of the Vitrified Columns from Experiments No. 4 and No. 5 . 


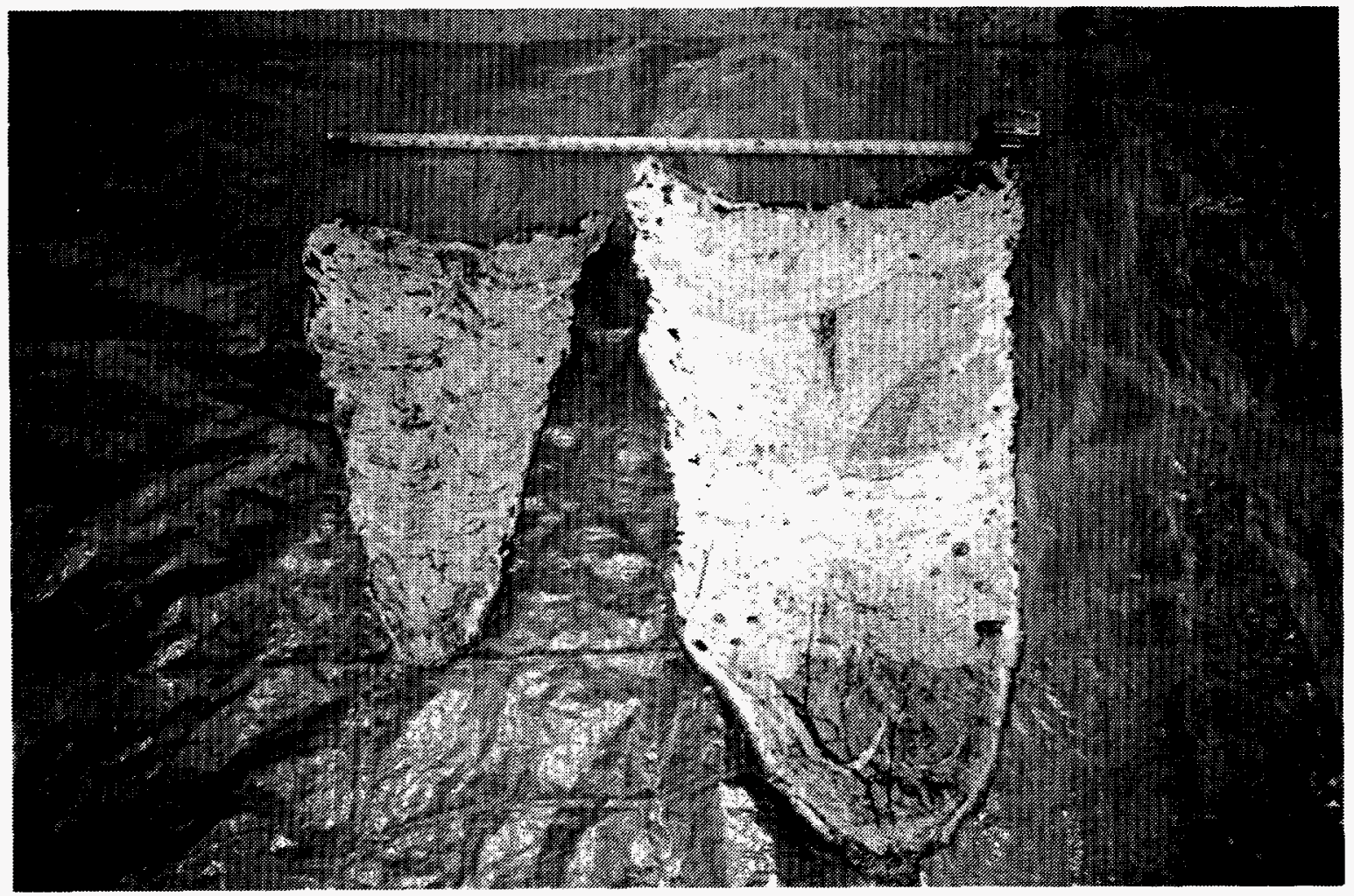

Figure 4.15. Photograph of the Vitrified Cross Sections of the Experiments No. 4 and No. 5 Melt Columns. 
Elemental analysis based on X-Ray Diffraction tests were conducted on several samples taken at several locations in the vitrified column. Scanning Electron Microscope (SEM) photographs of these test samples were also obtained. These data are included in Appendix G.

\subsection{Experiment No. 6: $200 \mathrm{~kW}$ Dual Contiguous Melts in Clean SRS Soil.}

The purpose of this dual melt experiment was to evaluate the ability of adjacent melt columns to coalesce into a single homogeneous vitrified mass. This experiment was added to the original ERDA demonstration program since the vitrified columns in Experiments 4 and 5 did not overlap. The experiment was conducted with the $200 \mathrm{~kW}$ plasma torch. A steel cylindrical container vessel four feet in diameter and four feet high was filled with SRS soil, placed to simulate a natural state. Two 6-inch stovepipe-cased boreholes were placed in the cylinder with a 12-inch distance between their centerlines (Figure 4.17). The test procedure for this experiment is outlined in Appendix $\mathrm{H}$.

The plasma torch was used consecutively in each of the boreholes. The experiments were conducted for 72 minutes (1.20 hours) in borehole number 1 and for 130 minutes ( 2.17 hours) in borehole number 2. The dual borehole geometry during this experiment is shown in Figure 4.18. The torch was raised 24 inches in borehole number 1 , and 24 inches in borehole number 2 . Operations in the first borehole were discontinued after 72 minutes because the molten pool and cavity breached into the second borehole. Continued operation would have resulted in the second borehole filling with molten soil, which would have precluded operating the torch in the second borehole. The test sequence of the experiment are described in Appendix H. Table 4.7 contains pertinent results of this experiment.

Figure 4.19 is a photograph of the contiguous vitrified melt resulting from the dual column melts. Figure 4.20 is a diagram indicating the shape and size of the combined melts. Figure 4.21 is a cross section of the vitrified product cut across the long axis of the contiguous columns. 
Table 4.5. Summary of Results. Experiment No. 4.

\section{Initial Conditions}
a. Soil Type: SRS Soil (SC-SP)
b. Borehole Diameter: 4 inches
c. Additives: Contaminants
d. Density: 90 pounds per cubic foot
e. Moisture Content: $8.3 \%$
f. Weight of Soil: 8,460 pounds (Experiment No. 4. and No. 5. Metal Container)
g. Volume of Soil: $95.23 \mathrm{ft}^{3}$

\section{Test Conditions}
a. Average Power Level: $96 \mathrm{~kW}$
b. Total Withdrawal Distance: 52 inches
c. Average Torch Withdrawal Rate: $7.5 \mathrm{~min} / \mathrm{inch}$

\section{Post Test Results}
a. Test Duration: 390 minutes (6.5 hours)
b. Power Consumption: $624 \mathrm{kWh}$
c. Vitrified Mass

(1) Maximum Diameter: 15 inches

(2) Height: 28 inches

(3) Weight: 195 pounds

(4) Volume: $1.46 \mathrm{ft}^{3}$

d. Specific Energy Requirement (SER): $3.20 \mathrm{kWh} / \#$ 
Table 4.6. Summary of Results. Experiment No. 5 .

\section{Initial Conditions}
a. Soil Type: SRS Soil (SC-SP)
b. Borehole Diameter: 5 inches
c. Additives: Contaminants
d. Density: 90 pounds per cubic foot
e. Moisture Content: $8.3 \%$
f. Weight of Soil: 8,460 pounds (Experiment No. 4. and No. 5. Metal Container)
g. Volume of Soil: $95.23 \mathrm{ft}^{3}$

\section{Test Conditions}
a'. Average Power Level: $200 \mathrm{~kW}$
b. Total Withdrawal Distance: 41 inches
c. Average Torch Withdrawal Rate: $8.05 \mathrm{~min} / \mathrm{inch}$

\section{Post Test Results}
a. Test Duration: 330 minutes ( 5.5 hours)
b. Power Consumption: $1,100 \mathrm{kWh}$
c. Vitrified Mass

(1) Maximum Diameter: 22 inches

(2) Height: 35 inches

(3) Weight: 410 pounds

(4) Volume: $3.07 \mathrm{ft}^{3}$

d. Specific Energy Requirement (SER): $2.68 \mathrm{kWh} / \#$ 


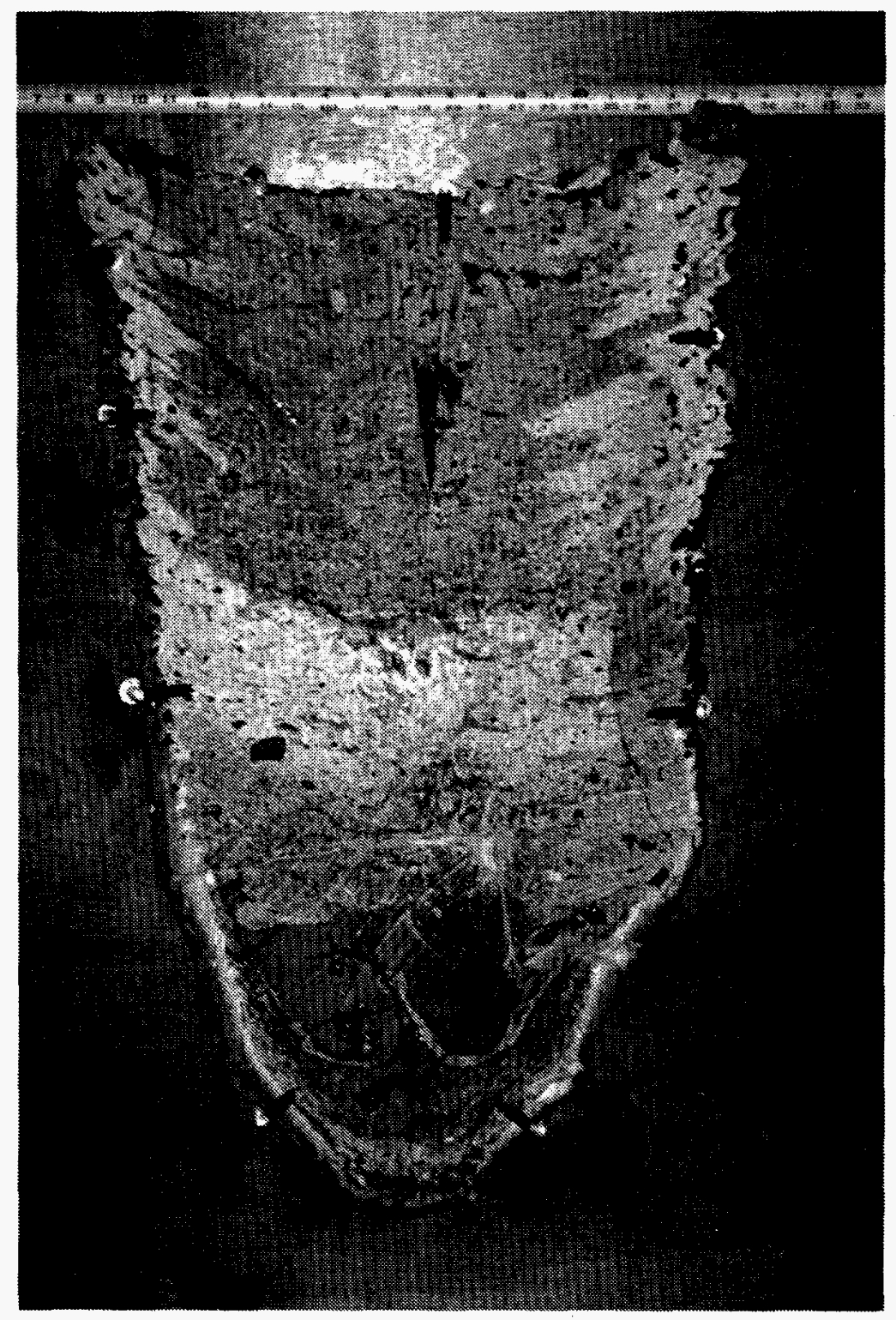

Figure 4.16. Close-Up Photograph of the Vitrified Cross Section of the Experiment No. 5 Melt Column 


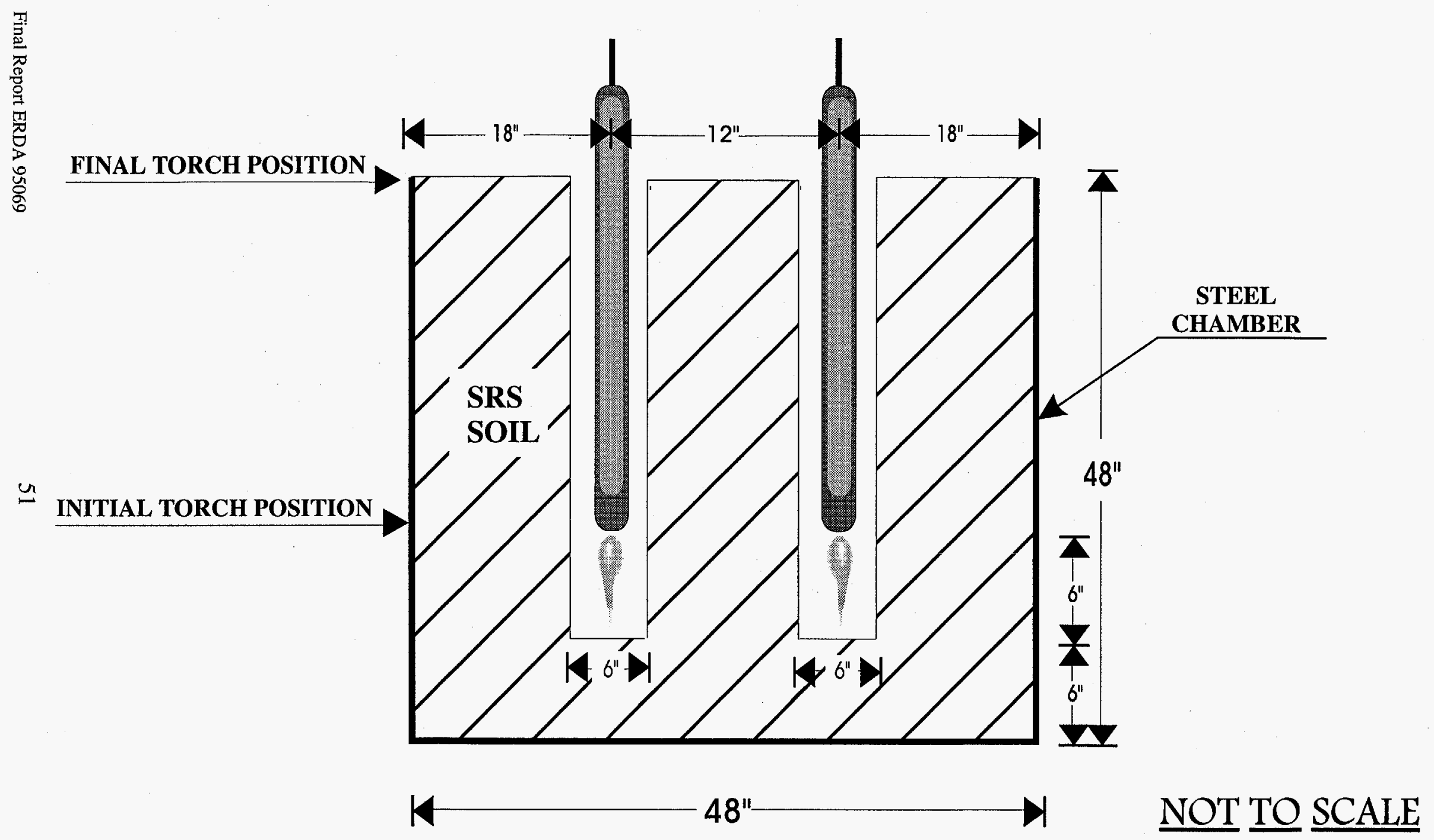

Figure 4.17. Test Geometry for ISPV Experiment No. 6. 
Table 4.7. Summary of Results. Experiment No. 6

\section{Initial Conditions}
a. Soil Type: SRS Soil (SC-SP)
b. Borehole Diameter: 6 inches
c. Additives: None
d. Density: 90 pounds per cubic foot
e. Moisture Content: $8.3 \%$
f. Weight of Soil: 4,379 pounds
g. Volume of Soil: $48.89 \mathrm{ft}^{3}$

\section{Test Conditions}
a. Average Power Level: $200 \mathrm{~kW}$

b. Total Withdrawal Distance

(1) 1 st melt: 24 inches

(2) 2nd melt: 28 inches

c. Average Torch Withdrawal Rate: $3.88 \mathrm{~min} / \mathrm{inch}$ (combined)

(1) 1 st melt: $3.00 \mathrm{~min} / \mathrm{inch}$

(2) 2 nd melt: $4.64 \mathrm{~min} /$ inch

\section{Post Test Results}

a. Test Duration: 202 minutes (3.37 hours)

(1) 1 st melt: 72 minutes ( 1.20 hours)

(2) 2nd melt: 130 minutes (2.17 hours)

b. Power Consumption: $680 \mathrm{kWh}$ (combined)

c. Vitrified Mass

(1) Maximum Diameter: 18 inches on each melt (29 inches combined)

(2) Overlap between Melts: 7 inches

(3) Height:

(a) 1st melt: 15.5 inches

(b) 2nd melt: 16.0 inches

(4) Weight: 306 pounds (combined)

(5) Volume: $2.39 \mathrm{ft}^{3}$

d. Specific Energy Requirement (SER): $2.22 \mathrm{kWh} / \#$ (combined) 


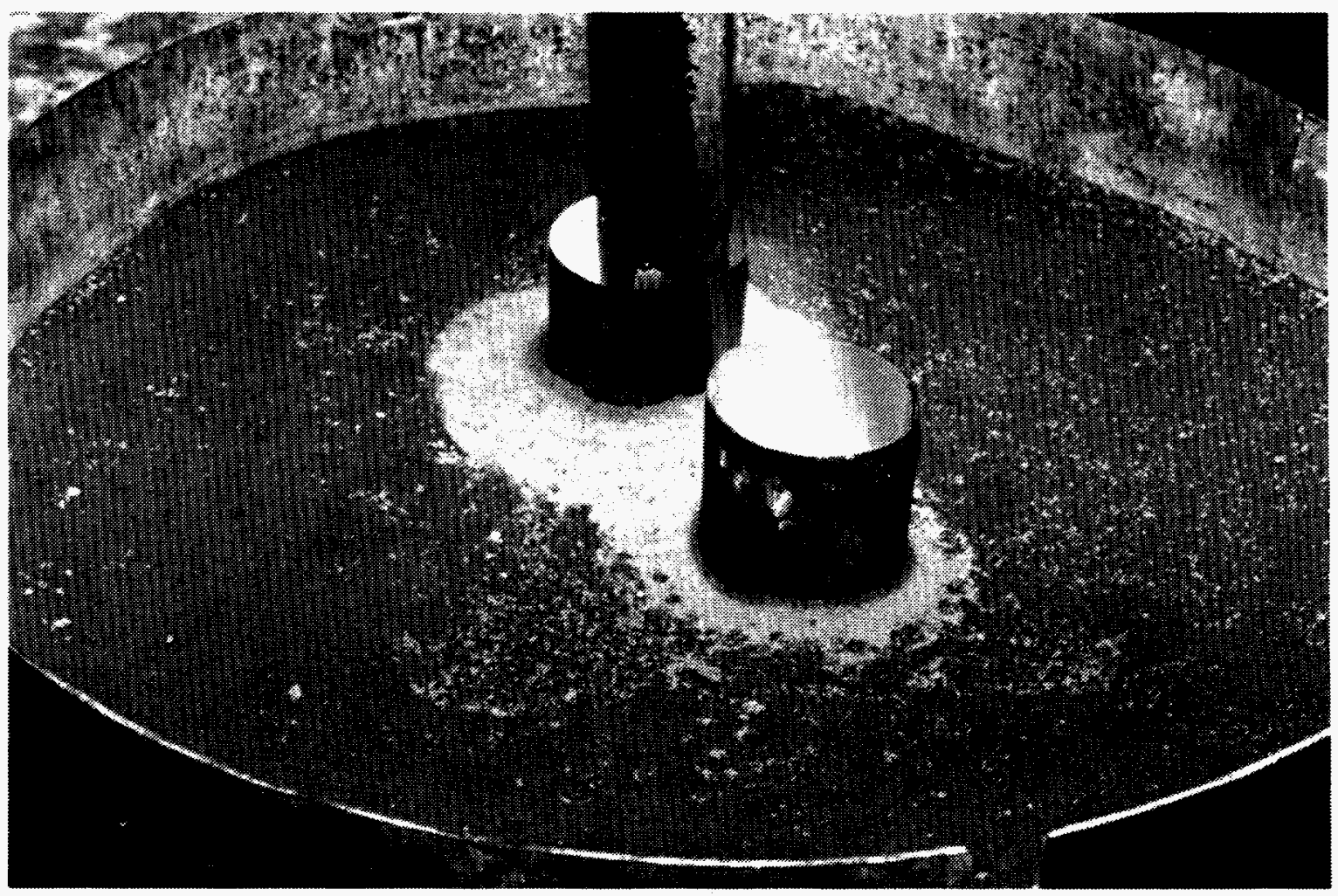

Figure 4.18. Photograph of Dual Borehole Geometry during Experiment No. 6. 


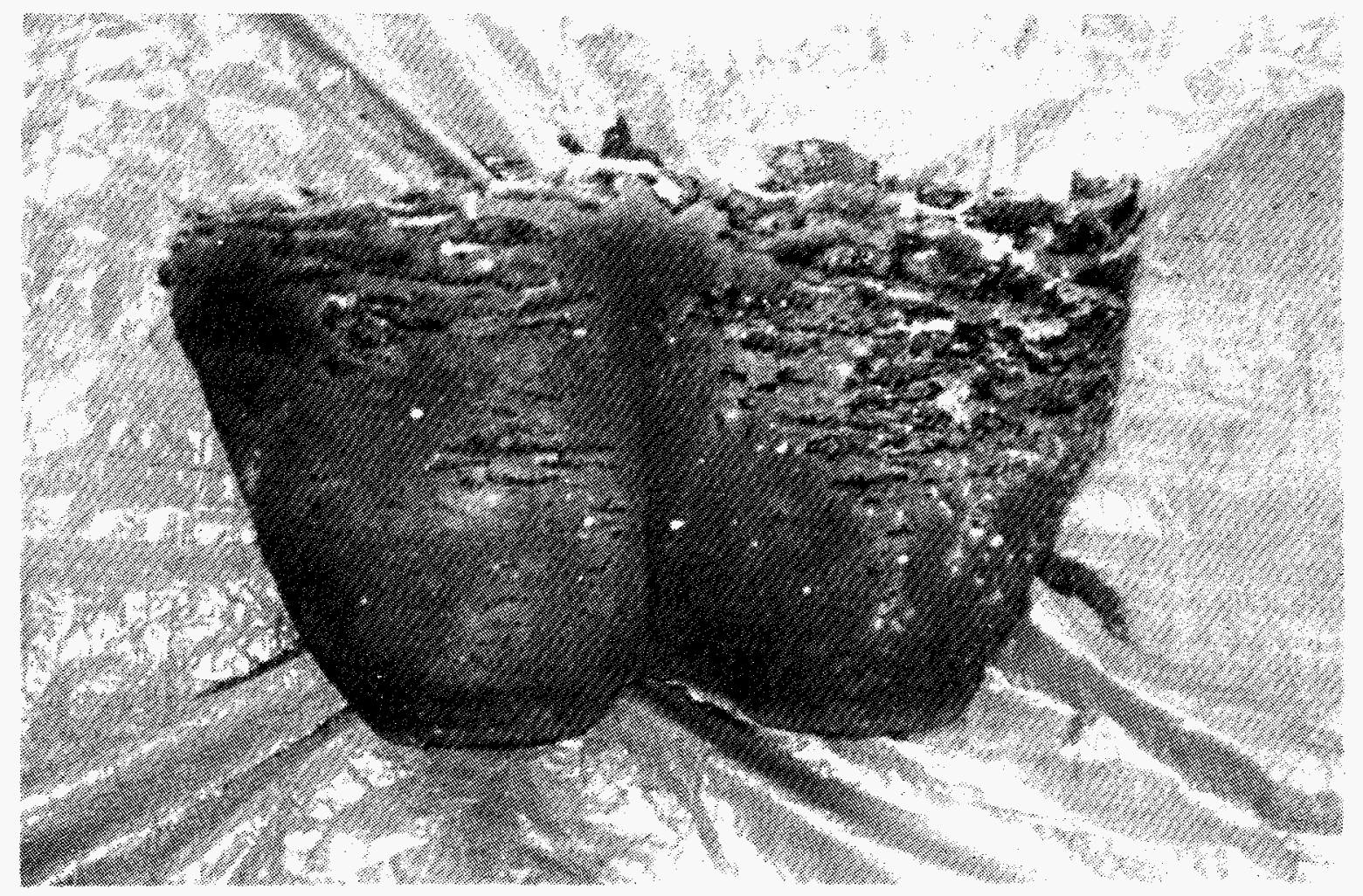

Figure 4.19. Photograph of the Contiguous Melt Columns, Experiment No. 6. 

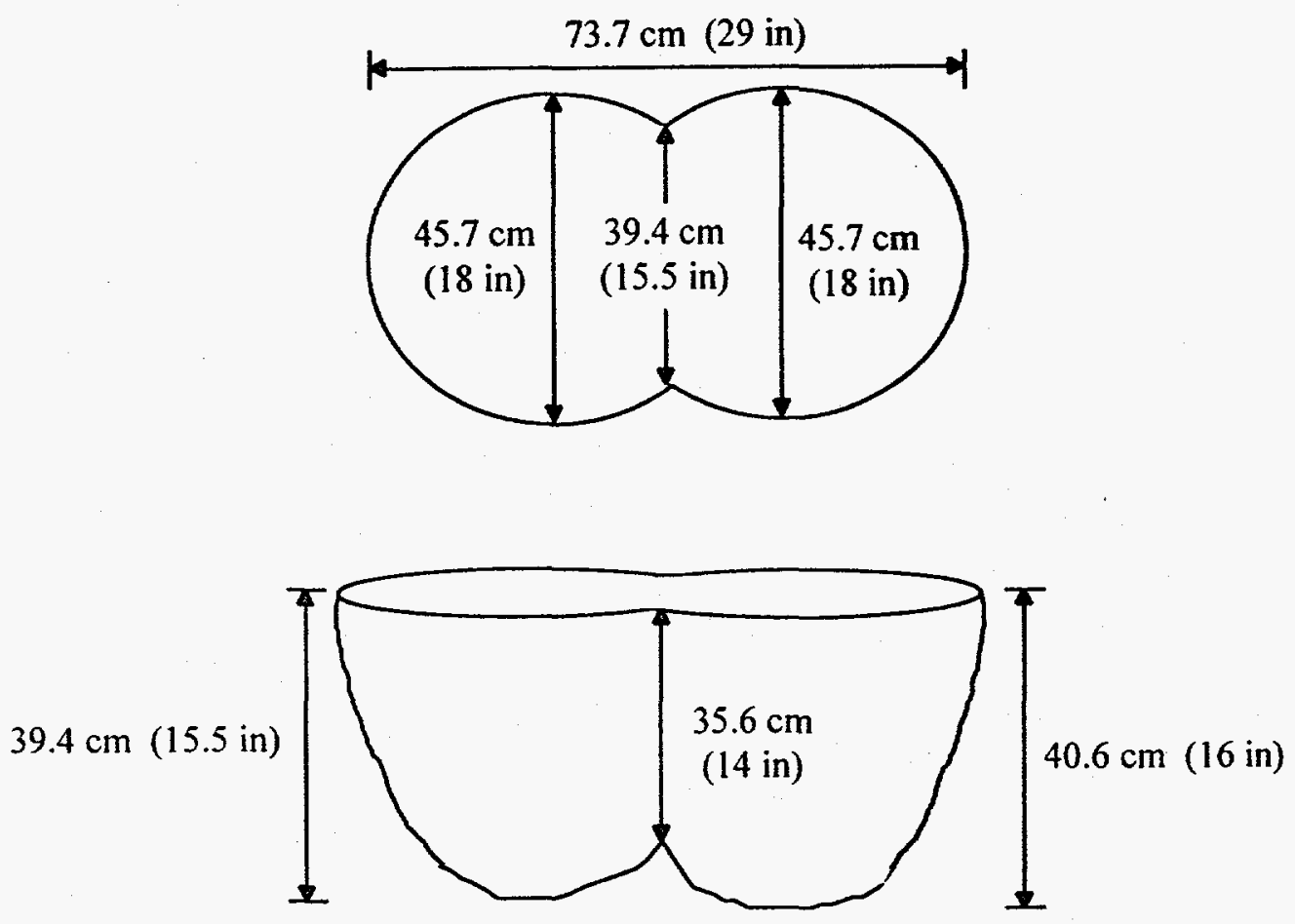

Figure 4.20. Diagram of the Vitrified Columns from Experiment No. 6. 


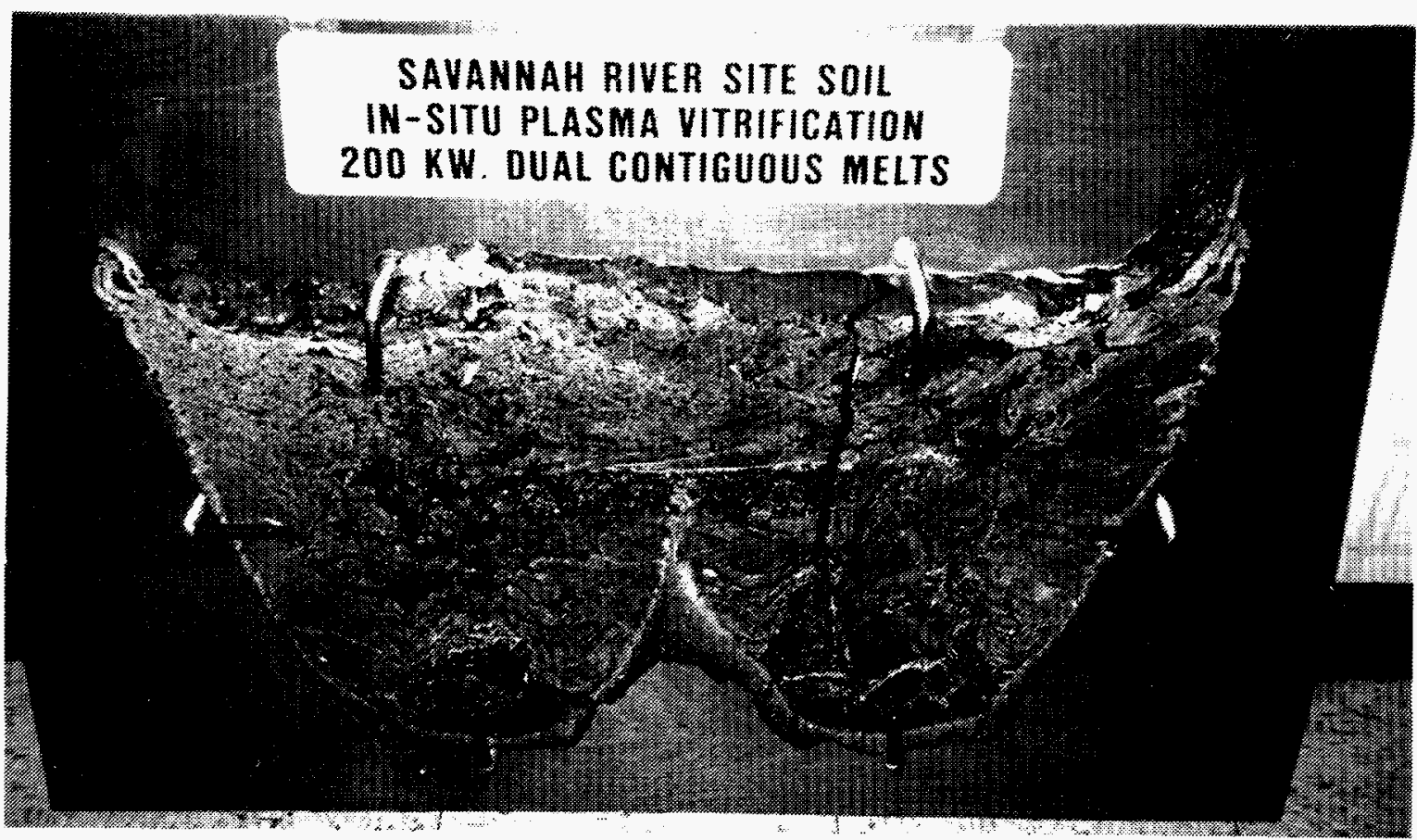

Figure 4.21. Photograph of Vitrified Cross Section from Experiment No. 6. 


\subsection{ANALYSIS OF DATA}

\subsection{General Observations}

The six laboratory vitrification experiments were successful in demonstrating the viability of melting Savannah River Site soil with a non-transferred arc plasma torch. This is a significant observation since previous experiments had indicated that conventional jouleheated in situ vitrification (ISV) with graphite electrodes was not very effective in vitrifying the Savannah River Site soil without the use of fluxing agents (Campbell and Buelt, 1990; Lowery, et al., 1994). A compilation of selected data from the six experiments is given in Table 5.1.

Experiment No. 1 was initially performed to verify that a fluxing agent was not required to melt Savannah River Site soil with a plasma torch. The $100 \mathrm{~kW}$ torch was used in the experiment, and a vitrified product was readily produced. Experiment No. 2 was conducted to investigate the effect of the fluxing agent on the resulting size of the vitrified product. It was assumed that the fluxing agent would facilitate melting of the soil, resulting in a larger melt for a given time duration. When the chamber was opened, a large portion of the solidified melt was a weak "crust," which readily separated from the dense, rock-like vitrified mass. This condition was attributed to the fluxant being melted before it could mix well with the soil. Unless a fluxing agent is mixed with SRS soil prior to vitrification, it was concluded that the use of a fluxing agent would not significantly improve performance of the plasma vitrification process. This is significant since a fluxing agent is normally required in furnace systems and melters for SRS soils, thereby increasing the time and cost of processing the soil.

Experiment No. 3 was conducted to evaluate whether a plasma torch can be used to vitrify soil at or below the ground water table. This demonstration was not fully tested since 1) water quickly recharged into the borehole region below the water level by gravity, and 2) a gravel layer placed in the bottom of the container, beneath the soil, also resulted in a high water recharge rate. During the early part of the test, the water was replenished at such a high rate that almost all of the plasma energy was used to evaporate 
the water, resulting in very little melting of the soil. Once the drainage valve for the incoming water was closed, the plasma torch was able to melt the highly saturated soil, at a rate consistent with the other experiments.

Experiments No. 4 and No. 5 involved the $100 \mathrm{~kW}$ and $200 \mathrm{~kW}$ torches in a large rectangular steel container of SRS soil that was seeded with buried contaminants. The beginning of Experiment No. 4 was disrupted when the $100 \mathrm{~kW}$ torch melted through the bottom of the metal container. After the hole was sealed the torch was raised an additional six inches and was restarted. Subsequently, a vitrified soil column consistent with the other experiments in this series was created. Experiment No. 5 utilized the 200 $\mathrm{kW}$ torch in the same container as Experiment No. 4. This test also experienced a delay midway through the test due to a leaking o-ring in the front electrode portion of the plasma torch. The malfunctioning part was replaced and the test proceeded as planned. The melts created by these two experiments were originally intended to coalesce (i.e., overlap); however, when the tests were performed, the boreholes, with a center-to-center separation of 18 inches, were too far apart for this to occur. Experiment No. 5 produced the largest vitrified soil column of this series of demonstrations ( 22 inches in diameter and 35 inches high, as shown in Figure 4.16).

For Experiment No. 6, the spacing between the two adjacent boreholes was set sufficiently close together for the melts to coalesce (center-to-center spacing of 12 inches). The diameters of the two vitrified soil columns overlapped approximately seven inches. The test was successful in that a contiguous, homogeneous melt of the two columns was achieved. 
Table 5.1. Compilation of Selected ISPV Experimental Data

\begin{tabular}{|c|c|r|r|r|r|r|r|r|}
\hline $\begin{array}{c}\text { Experiment } \\
\text { No. 1 }\end{array}$ & $\begin{array}{c}\text { Borehole } \\
\text { Size } \\
(\text { inches })\end{array}$ & $\begin{array}{c}\text { Power } \\
\text { Level } \\
(\mathbf{k W})\end{array}$ & $\begin{array}{c}\text { Power } \\
\text { Consumption } \\
(\mathbf{k W h})\end{array}$ & $\begin{array}{c}\text { Moisture } \\
\text { Contest } \\
(\boldsymbol{\%})\end{array}$ & $\begin{array}{c}\text { Max. Melt } \\
\text { Diameter } \\
(\text { inches })\end{array}$ & $\begin{array}{c}\text { Weight } \\
\text { Vitrified } \\
\text { Mass (\#) }\end{array}$ & $\begin{array}{c}\text { Withdrawal } \\
\text { Rate } \\
(\mathbf{m i n} / \mathbf{i n})\end{array}$ & $\begin{array}{c}\text { SER } \\
(\mathbf{k W h} / \#)\end{array}$ \\
\hline 1 & 4 & 80 & 408 & 8.3 & 22 & 146.5 & 12.7 & 2.78 \\
\hline 2 & $4 / 8^{*}$ & 68 & 292 & 10 & 12 & 88.3 & 10.8 & 3.31 \\
\hline $3^{* *}$ & 4 & 60 & 229 & 31.4 & 17 & 143 & 14.3 & 2.45 \\
\hline 4 & 4 & 96 & 624 & 8.3 & 15 & 195 & 7.5 & 3.20 \\
\hline 5 & 5 & 200 & 1,100 & 8.3 & 22 & 410 & 8.05 & 2.68 \\
\hline $6 * * *$ & 6 & 200 & 680 & 8.3 & 18 & 306 & 3.9 & 2.22 \\
\hline
\end{tabular}

*Fluxant melted prematurely, resulting in an 8-inch borehole for most of the experiment. **Data listed for melting portion of the experiment only. ****Combined data from dual contiguous melts.

\subsection{Mass of SRS Vitrified Soil}

After an appropriate cooling time of at least one day, each of the ISPV demonstration chambers was opened. The size, shape and mass of the vitrified products were measured so that the influence of the different variables could be noted. Each vitrified mass was surrounded by a thin shell-like crust of soil which was altered by the heat, but not fully vitrified. This material could be easily removed from the vitrified mass, and was not included in the determination of the mass of each vitrified product. The data indicate that an increased power consumption resulted in a larger final mass of the vitrified product. These tests allowed the data collected from previous studies at lower power consumption levels to be extended to include much larger power consumption levels, while still demonstrating the same relationship between power consumption and the resulting mass of the final product. (Beaver and Mayne, 1995; Mayer, 1996). 
Further analysis of the data indicates that the vitrified soil product with the largest mass was obtained in Experiment No. 5. This would be expected because this experiment was conducted for the longest period of time, and was the only test with a single borehole which used the $200 \mathrm{~kW}$ torch. It should be noted that Experiment No. 6 also used the larger torch, but the data shown are actually for two adjacent vitrified columns which coalesced together. By comparing the melting efficiency of the tests, Experiment No. 6 appeared to be more efficient in terms of the size of the vitrified product than the other experiments. Because of the much longer melting time, all of the final vitrified columns obtained from tests on the Savannah River Site soil resulted in a much larger vitrified mass than those in previous experiments, regardless of the soil type or the environmental conditions (Mayer, 1996).

The vitrified product obtained from Experiment No. 2 has a much smaller mass than any of the other experiments. This test used a fluxing agent, which melted almost immediately without mixing with the soil. This created a thick, weak crust at the bottom of the vitrified mass. This crust material, weighing 54.7 pounds, constituted a high percentage of the total weight of the melt (143 pounds). However, it was not included in the weight of the vitrified mass because of its anomalous composition and characteristics. The very large borehole size, which resulted when the fluxant melted prematurely, may also have contibuted significantly to the reduced mass of vitrified material (see paragraph 5.9).

The vitrified product of Experiment No. 3 had a smaller mass than that of Experiment No. 1, even though Experiment No. 3 was run for a longer duration (5.83 hours versus 5.08 hours). Experiment No. 3 was the saturated soil test, which, because of the initial excessive water recharge rate, did not allow the plasma torch to melt the soil. Once the open flow of water was stopped, the residual moisture in the soil was rapidly dissipated, and the vitrification process continued as expected. 


\subsection{Power Consumption}

Previous plasma vitrification experiments conducted at the Georgia Institute of Technology were run with a planned duration of 60 minutes, resulting in a maximum power consumption of about 180 kilowatt-hours. The experiments in this demonstration series conducted on Savannah River Site soil applied significantly longer melting times, with one test (Experiment No. 5) consuming over 1 megawatt-hour of power. Routinely, the torch was operated at a specific soil depth in the container until it was necessary to raise the torch to avoid having the torch come in contact with the pool of molten soil material. These experiments of longer duration allowed the effects of power level and test duration to be better quantified. Thus, improved scaling relationships for the plasma vitrification of soils was achieved.

Power measurements were taken manually at various intervals throughout each experiment. Readings were taken approximately every five minutes at the beginning of the experiments, when the power level was slowly increased, and then every 15-30 minutes for the remainder of the experiment, to ensure that the power level remained relatively constant. The console for the $200 \mathrm{~kW}$ plasma torch had instrumentation indicating the current, voltage, and power readings, allowing the power level to be read directly. Values for the voltage (V) (in volts) and current (I) (in amperes) were obtained from the power supply of the $100 \mathrm{~kW}$ torch, which were then converted into power (P) (in watts), according to the equation:

$$
\mathrm{P}=\mathrm{VI} \text {. }
$$

Increasing the power level of the torch and the test duration resulted in an increased amount of the vitrified product. The experimental trend can be seen in Figure 5.1, which shows a comparison of the final vitrified mass and the power consumption for each of the six experiments. Based on the limited data available from the six experiments it was observed that a relatively good correlation exists between the mass of vitrified soil and the power consumption of the plasma torch. According to Figure 5.1, the mass of vitrified material $M_{v}$ is directly proportional to the power usage $P_{p}$ through the formula:

$$
\mathrm{M}_{\mathrm{v}}=0.4 \mathrm{P}_{\mathrm{p}}
$$


where: $\quad M_{v}=$ Mass of vitrified material created, in pounds

$\mathrm{P}_{\mathrm{p}}=$ Power usage by the plasma torch in kilowatt-hours $(\mathrm{kWh})$

It should be noted that this is the best correlation observed with the mass of vitrified soil. Although this type of a relationship should be expected, it is interesting to note that the several other variables used in the experiments (fluxant, moisture content, contaminants, torch withdrawal rate, etc.) had much less impact on the total mass of the vitrified material than the electrical power consumption used in each experiment.

\subsection{Low Strain Stiffness and Compressive Strength of Vitrified Soils}

The vitrified soil masses from each of the experiments were removed from their steel containers and cut into sections using a portable diamond tipped circular saw. Representative cores were taken from the samples using a 2-inch diamond bit core, according to ASTM D-2113. Tests were performed on the cores to determine the compressive strength and stiffness of the transformed vitrified material. It should be noted that it was somewhat difficult to obtain an acceptable core of the vitrified Savannah River Site soil material. Often, the cores did not achieve an acceptable length for testing because of fractures and discontinuities in the material. However, sufficient cores were obtained to conduct the planned strength and stiffness tests of the vitrified soils. A comparison of the pre-test and post-test strength and stiffness data is shown in Table 5.2.

\subsection{Low Strain Stiffness}

Ultrasonic wave propagation methods were used to determine the compression wave (P-wave) velocities $\left(\mathrm{V}_{\mathrm{p}}\right)$ of the material. The low strain shear modulus $\left(\mathrm{G}_{\max }\right)$ can be determined from the compression wave velocities according to the equation:

$$
\mathrm{G}_{\max }^{2}=1 / 2 \rho \mathrm{V}_{\mathrm{p}}(1 / 2 v) /(1 / v) .
$$

The elastic modulus, $\mathrm{E}$, can be found from the shear modulus using the equation, $E=2 G(1+v)$, where $v$ is Poisson's ratio. The Poisson's ratio is the ratio of the horizontal strain to the vertical strain. The Poisson's ratio of the specimens was assumed to be 0.15 . 


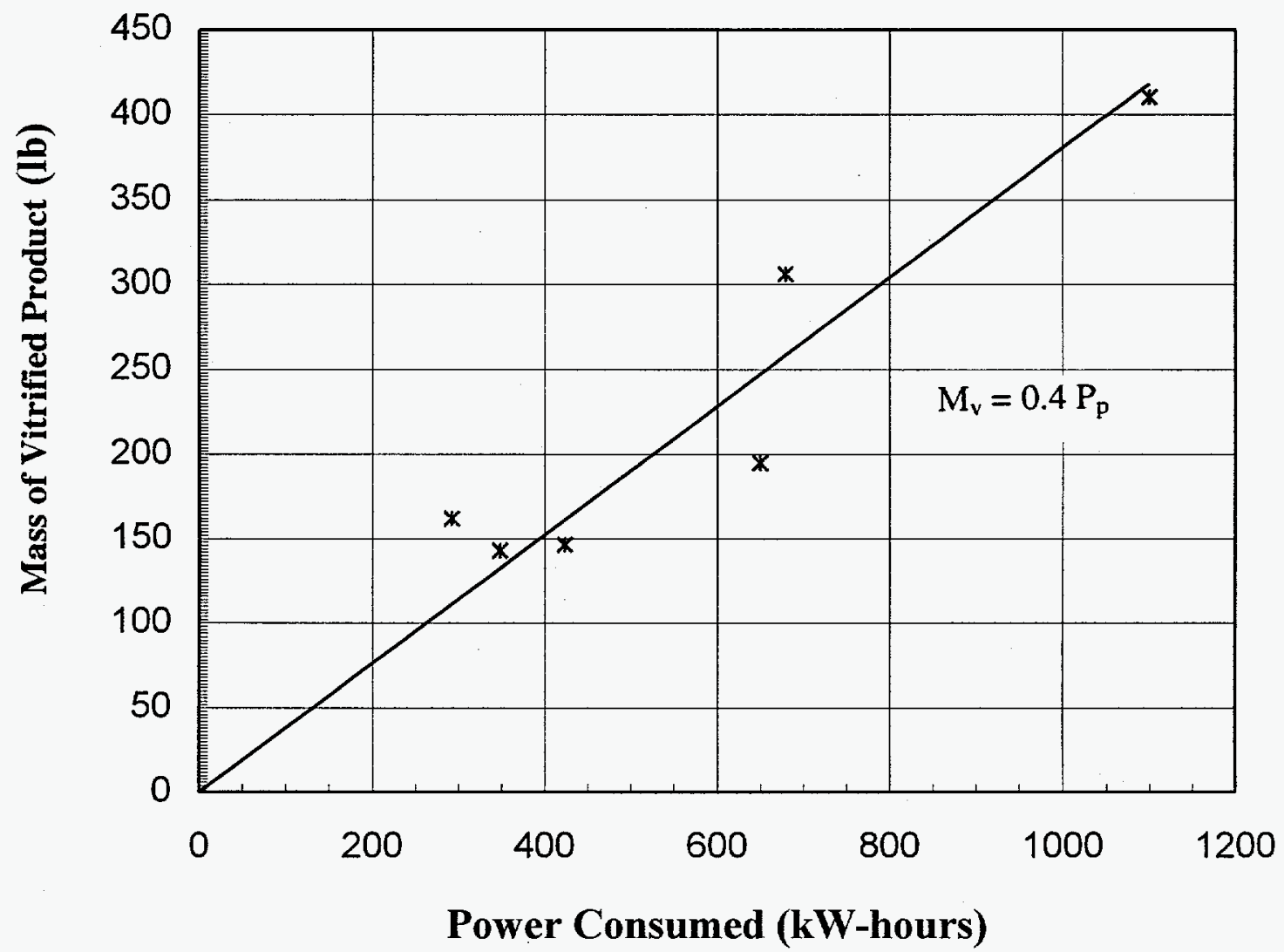

Figure 5.1. Mass of Vitrified Product vs. Power Consumption. 
The ultrasonic wave propagation tests were run on three separate unsaturated cylindrical specimens, each with a diameter of $5.2 \mathrm{~cm}(2 \mathrm{in})$, and with varying lengths of $9.7 \mathrm{~cm}(3.8 \mathrm{in}), 12.7 \mathrm{~cm}(5.0 \mathrm{in})$, and $12.5 \mathrm{~cm}(4.9 \mathrm{in})$. The P-wave velocities of the vitrified soil were measured by dividing the time required for a wave with a frequency of $59 \mathrm{kHz}$ to travel across the specimen by the length of the specimen. P-wave velocities of $4,311 \mathrm{~m} / \mathrm{s}, 3,873 \mathrm{~m} / \mathrm{s}$, and $4,800 \mathrm{~m} / \mathrm{s}$ were found for each of the specimens, respectively. Based on the results of all three specimens, the average $V_{p}$ was found to be $4,328 \mathrm{~m} / \mathrm{s}$, which yields a low strain shear modulus of $\mathrm{G}_{\max }=12.03 \mathrm{Gpa}$.

\subsection{Compressive Strength}

The compressive strength of the vitrified material was determined according to ASTM-D-2938. Tests were run using two different loading apparatuses. The first specimen was tested using a Tinius Olsen loading machine. The specimen was loaded at a rate of $1.1 \mathrm{kN} / \mathrm{sec}(250 \mathrm{lb} / \mathrm{sec})$, and yielded a compressive strength of $27.9 \mathrm{MPa}(4.1 \mathrm{ksi})$. However, the ends of the specimen were not parallel, so it is not believed that an accurate compressive strength was obtained. The second compressive strength test was conducted on an automated loading machine, manufactured by Material Test Systems (MTS). The specimen, which had parallel ends, was loaded at a rate of $440 \mathrm{~N} / \mathrm{sec}(100 \mathrm{lb} / \mathrm{sec})$ until failure. A compressive strength of $59.5 \mathrm{MPa}(8.6 \mathrm{ksi})$ was obtained, which is believed to be the true compressive strength of the vitrified Savannah River Site soil. 
Table 5.2. Comparison of Pre-Test and Post Test Strength and Stiffness Data for SRS Soil

\begin{tabular}{|c|c|c|}
\hline TEST & PRE-TEST & POST TEST \\
\hline Mass Density, $\# / \mathrm{ft}^{3}\left(\mathrm{Mg} / \mathrm{m}^{3}\right)$ & $89.89(1.44)$ & $133.6(2.14)$ \\
\hline $\mathrm{V}_{\mathrm{s}}:$ Shear Wave Velocity, $\mathrm{ft} / \mathrm{sec}(\mathrm{m} / \mathrm{sec})$ & $413.15(125.93)$ & NR* \\
\hline $\mathrm{V}_{\mathrm{p}}:$ Compression Wave Velocity, $\mathrm{ft} / \mathrm{sec}(\mathrm{m} / \mathrm{sec})$ & NR* & $14,199(4,328)$ \\
\hline $\begin{array}{l}\mathrm{E}_{\mathrm{d}}: \text { Elastic Modulus, ksi (MPa) } \\
\text { (Young's Modulus) }\end{array}$ & $13.51(93.2)$ & $4,012(27,669)$ \\
\hline $\mathrm{G}_{\mathrm{d}}:$ Low Strain Shear Modulus, ksi (MPa) & $5.88(40.5)$ & $1,744.4(12,030)$ \\
\hline $\mathrm{q}_{\mathrm{u}}:$ Ultimate Compressive Strength, ksi (MPa) & $0.0072(0.05)$ & $8.63(59.5)$ \\
\hline$* \mathrm{NR}=$ Not Recorded & & \\
\hline
\end{tabular}

This testing system is much more accurate than the first which, along with a better specimen, allowed a more accurate compressive strength to be obtained. Compressive strength testing requires destruction of the sample, so the tests were performed after the ultrasonic tests on the specimens.

Both the low strain shear modulus and the compressive strength of the vitrified product formed from the Savannah River Site soil were among the highest found for each of the vitrified soils. A summary of the pre-test and post-test results of tests for compressive strength and stiffness of the vitrified products is shown in Table 5.2. It can be seen that the compressive strengths and shear moduli of the original soils were vastly improved by the plasma vitrification process. 
The relationship between shear modulus and dry unit weight of the original soils and the vitrified materials is given in Figure 5.2. This figure shows, as with Table 5.2 , that the stiffness was dramatically increased by vitrification. The dry unit weights of the vitrified products were approximately twice as large as those of the original soils. Figure 5.3 shows a comparison of the relationship between the elastic modulus and the ultimate compressive strength for the original soils and the vitrified materials. This figure indicates that the compressive strength of Savannah River Site soil increased by two orders of magnitude as the result of vitrification, while the stiffness increased by three orders of magnitude.

\subsection{Specific Energy Requirement (SER)}

The Specific Energy Requirement (SER) of a material is the electrical power consumption required to vitrify a specific amount of the material. SER is normally measured in kilowatt-hours per pound. Generally the SER of a material can range from $0.3 \mathrm{kWh} / \mathrm{lb}$ for steel scrap melting to $6.8 \mathrm{kWH} / \mathrm{lb}$ for the production of ceramics.

The SER for the six SRS experiments are shown in Table 5.3. The average SER is 2.77 $\mathrm{kWh} / \mathrm{lb}$. The SER for Experiment No. 2 is probably abnormally high because of the power consumption used to melt over 50 pounds of fluxant into a weak crust at the bottom of the vitrified mass. This melted fluxant weight was not used in the SER calculation. Similarly, the SER for Experiment No. 6 may be low since two adjacent melts were combined for the SER calculation. This may indicate that smaller melts are more efficient for soil vitrification than larger melts. It should be possible to reduce the SER required for ISPV processing when the plasma torch in situ melting mechanism, such as the distance between the plasma torch and the level of the molten pool, is better understood and optimized. 


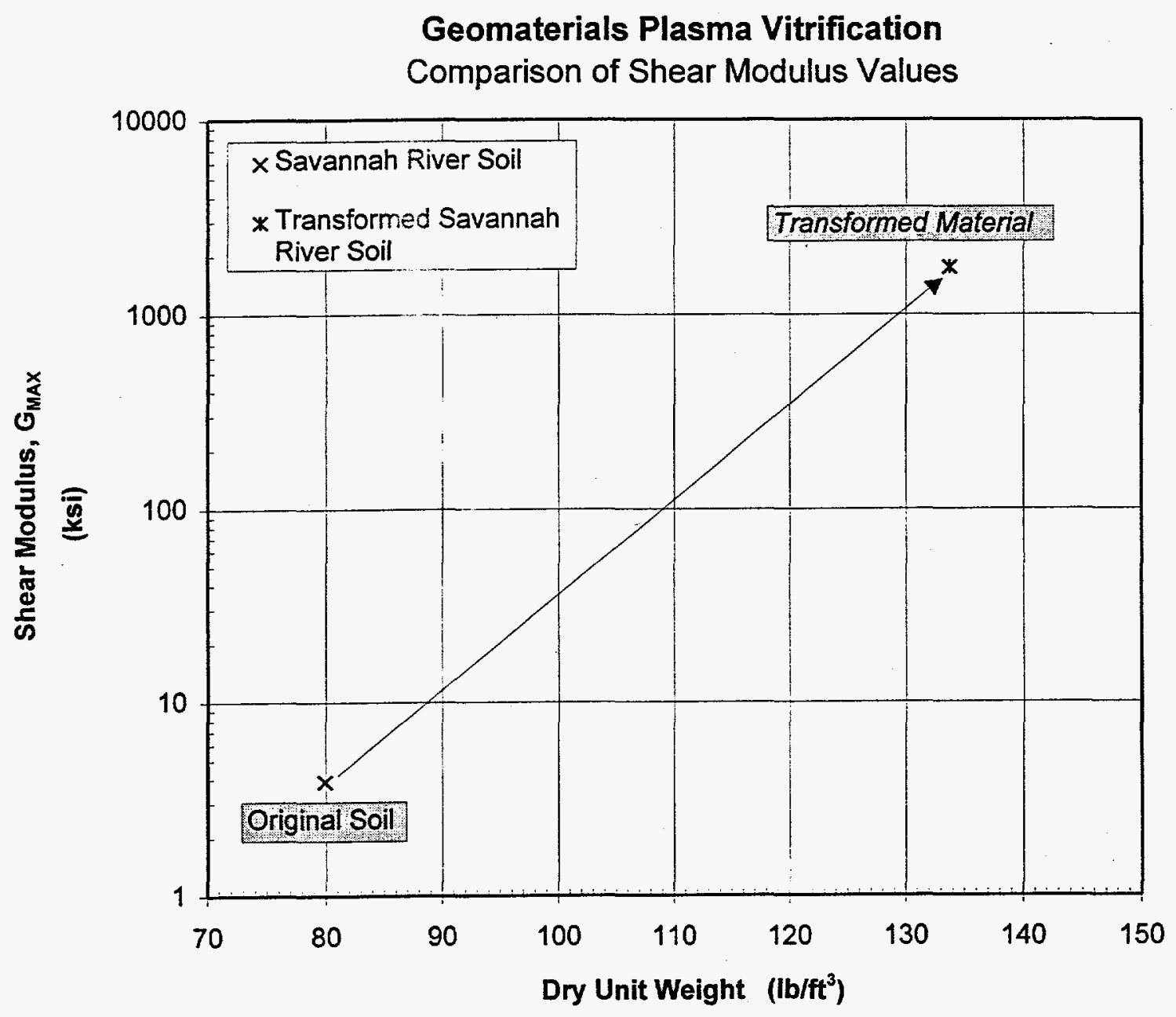

Figure 5.2. Change in Shear Modulus and Dry Unit Weight Between the Original SRS Soils and the Vitrified Products. 


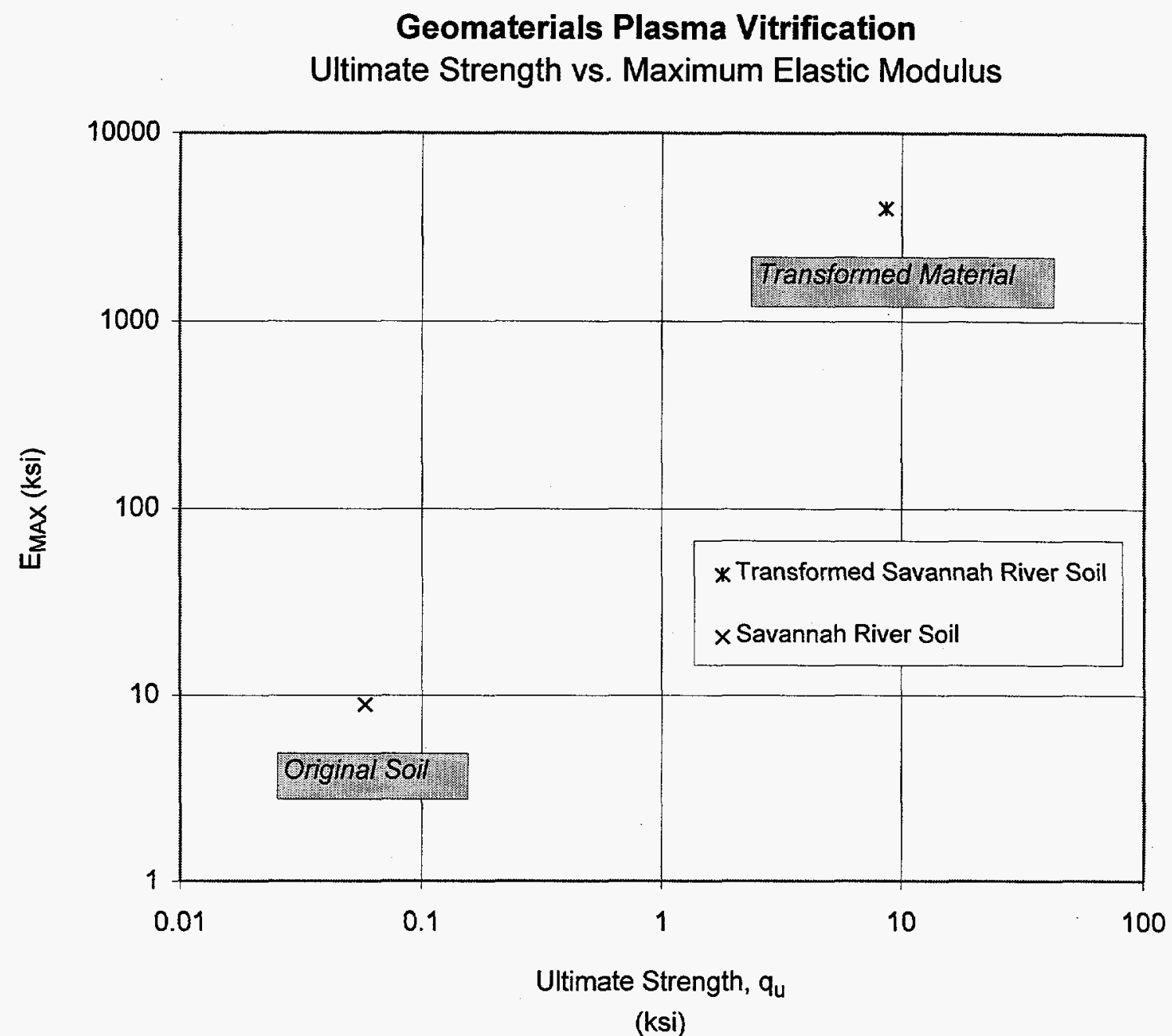

Figure 5.3. Relationship Between Elastic Modulus and the Ultimate Compressive Strength of the Original SRS Soils and the Vitrified Products. 
Table 5.3. Specific Energy Requirement (SER)

\begin{tabular}{|c|c|l|}
\hline Experiment No. & SER $(\mathbf{k W h} / \#)$ & \multicolumn{1}{|c|}{ Remarks } \\
\hline 1. & 2.78 & \\
\hline 2. & 3.31 & Fluxant melt crust not included. \\
\hline 3. & 2.45 & Calculated for melting period only. \\
\hline 4. & 3.20 & \\
\hline 5. & 2.68 & \\
\hline 6. & 2.22 & Combined Dual Contiguous Melts. \\
\hline Average & $\mathbf{2 . 7 7} \mathbf{~} \mathbf{W h} / \#$ & \\
\hline
\end{tabular}

\subsection{Vitrified Column Formation}

The general mechanisms of ISPV column formation can be determined to a great extent by the data in the demonstration series and information from past ISPV studies (Circeo and Mayne, 1993; Beaver and Mayne, 1995; Mayer, 1996). Figure 5.4 illustrates the observed sequence of column formation, using Experiment No. 5 as an example:

1. Figure $5.4 \mathrm{a}$ outlines the initial test geometry prior to the beginning of plasma torch melting operations.

2. Figure $5.4 \mathrm{~b}$ illustrates beginning of column formation during the initial melting period. At this early stage in the melting process the borehole geometry has a significant effect on the shape of the vitrified mass. The volume of the borehole below the plasma torch is the only cavity volume available to contain the molten material created by the plasma. This small volume rapidly fills with molten soil, which would cause the plasma flame and the torch to become rapidly submerged in the melt if left in that position. Thus, before the plasma torch can melt a significant amount of soil at that height, it must be raised to keep it out of the melt and to continue the melting process. This higher level would also result in the torch becoming submerged for the same reasons. However, the torch would be able to remain in this new position for a little longer period of time since the 
cavity volume would be slowly increasing due to the reduction in the volume of the melting soil. This gradual increase in melting time at each incremental height results in a slightly greater cavity and melt diameter each time that the torch is raised to higher positions. As a result, the typical conical shape observed at the bottom of each melt is created (see Figure 4.3).

3. Figure $5.4 \mathrm{c}$ represents the approximate point in column formation where the borehole size no longer influences the size of the vitrified column. The cavity above the pool of molten material has increased in volume such that the plasma torch will not become submerged in the melt prior to a normally scheduled time to be raised up the borehole. At this point the molten pool diameter and the cavity volume will continue to grow until a state of equilibrium is attained between the plasma torch melting mechanisms (power level, thermal radiation, scouring action, etc.) and the diameter of the molten pool.

4. Figure $5.4 \mathrm{~d}$ shows what could be described as a steady state condition for the creation of vitrified columns. The cavity has reached the aforementioned state of equilibrium between the plasma torch operating conditions and the diameter of the molten pool. Because of this steady state condition, the diameter of the vitrified column remains relatively constant. This would result in a vertical column configuration, which is important to the creation of contiguous melts for effective in situ waste remediation processing.

One potential technique to reduce the conical shape at the bottom part of a vitrified column should be investigated during any follow-on field scale trials of the ISPV process. If the length of the borehole is extended several feet below the bottom of the zone to be vitrified, a much larger volume of the borehole would be available to accept the melted soil. This would permit a large cavity to develop immediately adjacent to the plasma torch and the bottom of the region to be vitrified; this technique and should preclude the possibility of the torch becoming submerged in the melt early in the vitrification process. 
The many variables and mechanisms interacting during the creation of ISPV columns emphasize the important requirement to conduct extensive fundamental research and modeling studies to better understand the mechanisms at work in creation of ISPV columns. This understanding is necessary to optimize the ISPV process in terms of both remediation efficiency and cost-effectiveness.

\subsection{Diameter of Melt}

The diameters of melt for this series of tests varied between 15 and 22 inches for the 100 $\mathrm{kW}$ torch and 18 and 22 inches for the $200 \mathrm{~kW}$ torch. Each of the dual columns of Experiment No. 6 had a diameter of 18 inches, with a combined length of 29 inches (see Table 5.1). The diameter of melt is a direct result of the size of the subterranean molten pool created by the operation of the plasma torch, and the size (diameter) of the underground cavity formed around the plasma by the volume reduction of the melted soil. The molten pool diameter and the cavity size increase as a result of the heat from the plasma torch and the scouring action of the hot plasma gases after they leave the torch. Other contributions to the melt diameter are the plasma torch power level, the rate of torch withdrawal up the borehole, and the melting temperatures of the soils (to include moisture contents, additives, etc.) being vitrified.

Examination of the experimental data suggest that the melt diameter may be most closely correlated with the plasma torch power level and the torch withdrawal rate. This can be generally observed from the data of the four experiments not encumbered by complicating influences, e.g., fluxant and saturated soils (see Table 5.4). By inspection of Table 5.4 it is suggested that for a given torch power level the melt diameter increases as the withdrawal rate (in minutes per inch) is increased. It is also interesting to note that the $200 \mathrm{~kW}$ experiments created similar melt diameters to the $100 \mathrm{~kW}$ torch at about half the withdrawal rate (one-half the time in the borehole). However, because of the paucity of these test data, fundamental research programs and modeling studies of in situ plasma vitrification phenomenology should be conducted to confirm these findings and to predict 


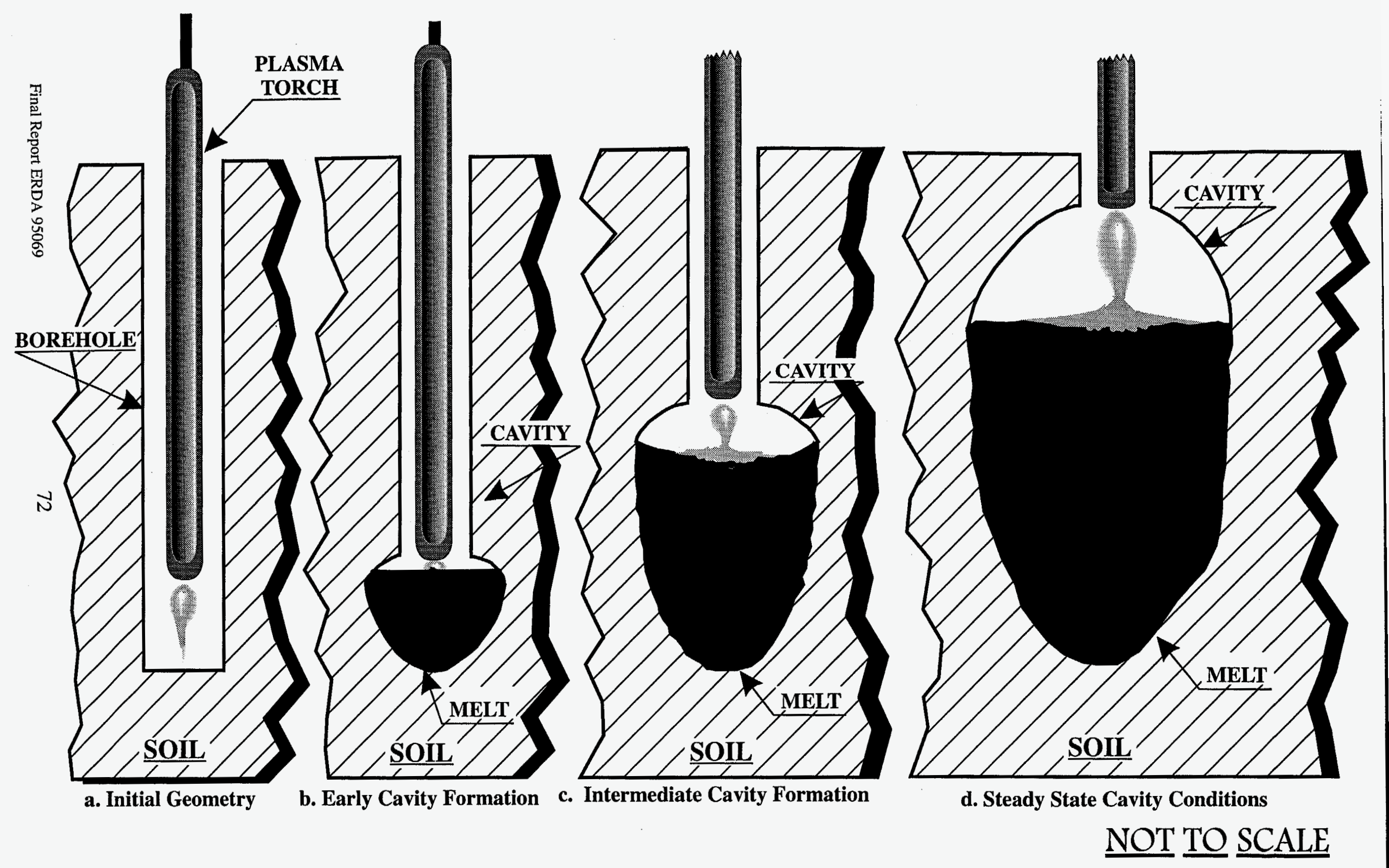

Figure 5.4. Sequence of Vitrified Column Formation (Experiment No. 5 Example). 
Table 5.4 Diameter of Melt of SRS Soil as a Function of Torch Power Level and Torch Withdrawal Rate

\begin{tabular}{|c|c|c|c|c|}
\hline $\begin{array}{c}\text { Experiment } \\
\text { No. }\end{array}$ & $\begin{array}{c}\text { Torch Power } \\
\text { Level (kW) }\end{array}$ & $\begin{array}{c}\text { Moisture } \\
\text { Content (\%) }\end{array}$ & $\begin{array}{c}\text { Maximum } \\
\text { Diameter of } \\
\text { Meter (inches) }\end{array}$ & $\begin{array}{c}\text { Torch Withdrawal } \\
\text { Rate (min/inch) }\end{array}$ \\
\hline 4 & 96 & 8.3 & 15 & 7.5 \\
\hline 1 & 80 & 8.3 & 22 & 12.7 \\
\hline 6 & 200 & 8.3 & 18 & 3.9 \\
\hline 5 & 200 & 8.3 & 22 & 7.5 \\
\hline
\end{tabular}

the diameters of SRS soil melts under a variety of geotechnical and environmental conditions.

\subsection{Torch Withdrawal Rate}

The rate at which the plasma torch is withdrawn up the borehole depends on several variables such as the power levels, the melting characteristics of the soil, the desired diameter of melt, etc. In this series of experiments with SRS soils the torch withdrawal rates varied from 3.9 minutes/inch (Experiment No. 6) to 14.3 minutes/inch (Experiment No. 3). The average withdrawal rate was 9.5 minutes/inch, or 6.3 inches per hour.

Regardless of the many variables which could affect the rate at which the torch is raised up the borehole, this series of experiments has indicated that there are two important rules that should be observed in order to create an efficient and cost-effective ISPV process:

a. The front electrode of the plasma torch should not become submerged in the molten pool of soil.

b. An appropriate distance should be maintained between the front electrode of the plasma torch and the level of the molten pool.

In the former case, the plasma arc would be submerged in the melt, which would significantly reduce its efficiency. In the latter case, a balance should be sought between 
keeping the molten pool at a high temperature, using thermal energy from the plasma to melt and expand the surface of the cavity, and achieving maximum benefit from the scouring action of the plasma gases in cavity (see Figure 5.4). In this series of experiments, the distance between the front electrode of the torch and the level of the molten pool was attempted to be kept at 6 inches for both $100 \mathrm{~kW}$ and $200 \mathrm{~kW}$ torches. This distance appears to be satisfactory for these lower-level plasma torch power levels. However, at megawatt power levels, this distance would be expected to be increased considerably. This is an area where additional fundamental research and modeling studies are warranted.

\subsection{Borehole Size}

The borehole size and integrity were determined to be important factors in the creation of good melt columns (Beaver and Mayne, 1995). The borehole must have adequate room for the torch to be readily inserted and withdrawn. In addition, it must have a sufficient space between the torch and the walls of the borehole to permit the plasma gas passing through the torch and any gaseous products created by the torch to readily escape up the borehole to the surface. If the gap is too large the gas scouring action in the cavity will be reduced, which will reduce process efficiency and melt diameter. This situation is indicated in Experiment No. 2 where the borehole size was 8-inches for most of the test. This resulted effectively in almost a sixfold increase in the borehole area through which gases could escape. This increased plasma gas outlet area could account for the very small diameter of melt (12 inches) and the reduced weight of the vitrified mass created in this experiment.

If the borehole gap is too small, gas pressure in the cavity could build up to levels which could:

a. Extinguish the plasma flame.

b. Scour the borehole and its casing up to the surface where the borehole gap could become excessively large, reducing process efficiency.

c. Cause the gases to create other paths to the surface. This could also reduce process efficiency and result in the collapse of the cavity around the torch. 
A thin casing in the borehole is considered essential when operating in a soil medium in order to maintain the integrity of the borehole during operations. The casing material can be as light as connected lengths of thin stovepipe or as strong as a steel pipe pile; e.g., if a piledriver is used to install the borehole. The principal purpose of the casing would be to maintain the correct gap around the torch to permit the gases to escape, to direct the gases to the gas collection hood at the surface, to prevent the borehole from collapsing around the torch, and to cool the gases as they pass around the "cold finger" of the water-cooled plasma torch body. This latter benefit would result in the condensation of metal volatiles, most of which would eventually be captured in the melt and subsequently immobilized within the final mass of vitrified material.

Previous empirical studies (Circeo and Mayne, 1993; Beaver and Mayne, 1995) have suggested that a gap of approximately 1-inch between the plasma torch and the walls of the borehole was sufficient to maintain a proper balance of the above factors in a soil medium. In this series of SRS soil experiments the gap varied from 0.5 inches (Experiment No. 5), to 0.75 inches (Experiments Nos. 1, 3, 4), to 1.0 inch (Experiment No. 6), and to 2.0 inches for most of Experiment No. 2. In all experiments, the boreholes performed in a satisfactory manner. Until optimization studies are conducted, it is recommended that borehole size follow the guideline that the diameter of the borehole should be from 0.75 to 1.0 inches larger than the diameter of the plasma torch.

The presence of multiple boreholes, spaced to create contiguous vitrified columns, can result in an inefficient melting process. In Experiments No. 5, and No. 6, similar problems relating to the premature escape of gases through adjacent boreholes occurred. As would be expected, at low torch power levels adjacent boreholes would be spaced relatively close together. Thus, one melting operation could breach into the borehole or cavity of an adjacent melt location. This would open a path for the plasma gases to readily escape to the surface through the open borehole of the adjacent melt rather than out the borehole in which the plasma torch was operating (see Figure 4.18). Thus, the vitrification efficiency could be greatly reduced. This problem could also be significant if 
the escaping gases must be captured in a gas collection hood for treatment in an offgas system. Therefore, when conducting operations within a grid of adjacent boreholes, all boreholes subject to being breached should be capped or covered to keep the majority of the plasma gases within the cavity and the borehole of the column being melted. At higher plasma torch power levels (e.g., 1 Megawatt or greater) adjacent borehole breaching should be less of a problem because of the much larger diameter melts, and the subsequently increased borehole spacing.

\subsection{Borehole Spacing}

Experiment No. 6. Created a highly satisfactory contiguous joint between the two adjacent melts. The vitrified cross-section was very homogeneous, with no indication of any boundary between the two melts (Figure 4.21). The overlap of the two melts was 7 inches.

A well-vitrified homogeneous coalescence between adjacent melts is very important to the treatment of hazardous/toxic or radioactive wastes. A high degree of reliability would be necessary to justify ISPV treatment of wastes without a significant follow-on effort to verify that all buried waste materials had been adequately treated. The ability to create contiguous columns as achieved in Experiment No. 6. should readily demonstrate this capability with the ISPV process. Until subsequent research indicates otherwise, a minimum 7 inch overlap between contiguous melts should be specified. In the case where a third contiguous melt is created adjacent to the initial overlap zone (i.e. from a triangular set of boreholes), the 7 inch overlap should be measured across the most distant section that must be overlapped.

\subsection{Effect of High Moisture Content}

Experiment No. 3. was conducted to test the effect of a high ground water table on the vitrification process. The experiment was designed to keep a constant water level 12 inches up from the bottom of a 36 inch cylindrical steel container vessel (see Figure 4.8). The front electrode of the plasma torch was lowered to this level to begin operation. The 
borehole was filled with 6 inches of water at this point. Therefore, the plasma arc itself was initially totally submerged in this section of the water-filled borehole.

The water in the borehole was rapidly evaporated when the plasma arc was initiated and vitrification of the soil medium began. However, after a few minutes of operation it became apparent that when a portion of the 4.5 inches of soil under the bottom of the borehole was melted, water permeability into the borehole increased considerably (Figure 4.8). In addition, when the borehole casing adjacent to the plasma arc (below the level of the water) was melted, water immediately began to flow into the region of the borehole by gravity. Therefore, water readily recharged the borehole and the initial cavity from the sides and the bottom as quickly as the plasma torch was able to evaporate it. This prevented further vitrification from occurring. In order to overcome this problem the water supply was turned off, permitting the vitrification process to proceed. This final test geometry simulated plasma torch operation in a subsurface "vadose zone," the unsaturated zone between the ground surface and the water table. Following rapid evaporation of the residual water in the test vessel, the vitrification process proceeded normally.

Experiment No. 3. resulted in the following observations:

1. The plasma torch will operate well in a borehole when the torch is placed at the water level and the plasma is initially submerged in the water.

2. In a groundwater-saturated soil environment little or no vitrification will take place until:

a. The water is evaporated, or it is otherwise removed from the subsurface region around the borehole; e.g., lower the water table.

b. The water recharging into the borehole and cavity is slower than the evaporation rate from the plasma torch. In this situation the plasma torch will be able to evaporate the flowing water and vitrify the soil at the same time. Thus, the vitrification process will still take place, although in a less efficient manner. 
In soils having low to medium permeability the latter situation of low water recharge would be expected to dominate. Only in cases of very high soil permeability, such as the almost direct water paths described above, would the ISPV vitrification process be significantly affected. Additionally, as the power level of a plasma torch is increased, higher soil permeability and groundwater recharge levels could be adequately controlled because of the increasing capability of the plasma torch to evaporate much greater quantities of water. This latter capability could be important in reducing or eliminating a potentially high cost requirement to lower the ground water table prior to treating contaminants in the soil.

\subsection{Effect of Contaminants}

The soil around each borehole in the large metal container used for Experiments No. 4 . and No. 5. was seeded with several contaminants as indicated in Appendix D. During the conduct of these experiments, no discernible differences from the vitrification of clean soil were noted. The only observed indication of a contaminant was one low popping sound when a can full of water apparently ruptured from the heat. The cross sections of the vitrified columns from the two experiments exhibited no visible signs of the contaminants (see Figures 4.15 and 4.16).

Five samples of the vitrified material were taken at different locations from the cross section of the Experiment No. 5. vitrified mass. These were tested with X-Ray Diffraction, Electron Absorption (EA) Analysis and with a Scanning Electron Microscope (SEM). The micrographs and the data collected in these tests are contained in Appendix G.

\section{X-Ray Diffraction and Electron Absorption (EA) Analysis.}

The X-ray diffraction and EA analysis of the vitrified mass revealed no evidence of the RCRA metal contaminants or the surrogate radionuclides (see Appendix G). In all samples, silicon and oxygen were, by far, the most abundant elements in the vitrified mass ( $94 \%$ or greater by weight). The remaining components consisted mainly of aluminum and sodium, with trace amounts of calcium, magnesium, carbon and iron. Since the SRS soil is principally a sand $\left(\mathrm{SiO}_{2}\right)$, the 
very high percentage of silicon and oxygen detected in the EA analysis would be expected.

\section{Scanning Electron Microscope (SEM) Analysis}

The SEM analysis of the five samples of the vitrified product revealed low porosity glass matrix composition in all micrographs (see Appendix G). These features are indicative of a good wasteform mineral, with high leach resistance, and with geologic lifetimes. One micrograph, taken at the edge of the vitrified column (Figure G.5), illustrates the dramatic transition from a surrogate wastecontaminated briquette to a durable, vitrified waste form. In addition, it reinforces the opinion that ISPV processing can readily and adequately melt SRS soil to create a durable wasteform without a requirement to introduce a fluxant or other additives into the soil.

\subsection{Toxicity Characteristics Leaching Procedure (TCLP) Tests}

Since the EA analysis revealed no significant amounts of contaminants which would be detected by the TCLP leaching tests, it was determined that these tests would not be conducted. Additionally, past experience has adequately demonstrated that vitrified soil will readily meet the TCLP leaching criteria, often by one or more orders of magnitude (Buelt et al., 1987; Camacho et al., 1992). Thus, the absence of these tests is not considered critical to the objectives of this demonstration program.

\subsection{Offgas Analysis}

Due to funding limitations of this demonstration program, it was not possible to conduct a comprehensive offgas collection and analysis program for Experiments No. 2., No. 4. and No. 5. A few gas samples were taken during these tests in a low-cost attempt to determine the composition of the offgases. However, the results were inconclusive and not included in this report. The composition of the offgases resulting from ISPV processing in a contaminated soil medium is an important technical feasibility issue which should be addressed at the earliest opportunity. 


\subsection{SUMMARY}

New environmental technologies are needed to remediate the wide variety of sites which have become contaminated with various radionuclides, heavy metals, toxic materials and organics. A novel method for treating waste sites now under development at the Georgia Institute of Technology is in situ remediation and vitrification by means of a non-transferred plasma arc torch. This process is called "In situ Plasma Vitrification (ISPV)." Contaminated soil (which may include buried wastes) is permanently stabilized by using the intense temperatures created by a plasma $\left(4,000-7,000^{\circ} \mathrm{C}\right)$ to destroy hazardous compounds and to vitrify the soil and its contaminants. By producing a wasteform with long-term chemical durability and stability, vitrification has been deemed the best demonstrated available technology (BDAT) for hazardous and radioactive wastes by the Environmental Protection Agency. It is a permanent treatment technology, as opposed to interim technologies which may require application at intervals.

A buried waste deposit requiring treatment by plasma remediation would be treated by inserting the plasma torch in a borehole and vitrifying the material around the torch, producing a column of vitrified material as the torch is slowly withdrawn. Plasma arc torches operated at power levels exceeding 5MW would be expected to produce vitrified columns greater than 10 feet in diameter. A matrix of overlapping treatment columns would thus form a contiguous vitrified mass of remediated soil. Similarly, plasma vitrification can be used for selective underground treatment; e.g., to create underground horizontal or vertical barriers to prevent migration of contaminants in groundwater, or to selectively vitrify subterranean contaminated zones and to treat "hot spots" in aquifers which feed groundwater contamination plumes.

In September, 1995 the Savannah River Technology Center (SRTC) sponsored a project at the Georgia Institute of Technology to demonstrate the capability of the ISPV process to vitrify typical Savannah River Site (SRS) contaminated soils. Six laboratory bottom-to-top in situ vitrification experiments were conducted at the $100 \mathrm{~kW}$ and $200 \mathrm{~kW}$ plasma torch power levels. The plasma torch depths under the surface of the soil varied between two to five feet. Highly-weathered, highly-refractory, humid soils such as those found at SRS constitute the greatest challenge for in situ remediation and vitrification. Since, chemically, these soils are up to $95 \% \mathrm{SiO}_{2}$, they demand higher melting temperatures than, for example, Western soils which contain natural fluxing agents 
(iron, calcium, and alkalis). Moreover, they do not have the natural electrical conductivity of the latter; such conductivity is crucial to using conventional joule-heated in situ vitrification (ISV) technology. The higher moisture content of Southeastern soils as compared to those found in the Western United States also impose a greater challenge on the heating mechanism for vitrifying such soils.

The four $100 \mathrm{~kW}$ ISPV tests consisted of an SRS baseline soil, the addition of a limestone fluxant, vitrification in a highly saturated soil medium, and an SRS baseline soil seeded with contaminants. The two $200 \mathrm{~kW}$ ISPV tests consisted of an SRS baseline soil seeded with contaminants, and dual contiguous melts to coalesce adjacent columns together. In spite of difficult soil conditions, the results of this demonstration project have indicated that the ISPV process was successful in readily vitrifying SRS soils in a bottom-to-top procedure under a variety of geotechnical and environmental conditions. Overall, the following ISPV concepts were demonstrated:

1. SRS soil which was reconstituted in the laboratory to simulate its undisturbed state was readily vitrified, with a rock-like, homogeneous cross section.

2. The addition of a fluxing agent to the SRS soil had no appreciable effect on the vitrification process and is not considered necessary.

3. A highly saturated SRS soil was thoroughly vitrified with the plasma torch, despite high moisture content under test conditions simulating free contact with a water reservoir.

4. Seeded contaminants (metals, surrogate radioactive briquettes, glass, concrete) were all readily vitrified, stabilized and immobilized within the vitrified soil column.

5. The concept of adjacent columns coalescing to form contiguous columns was fully demonstrated. 


\subsection{CONCLUSIONS}

The principal conclusions of this study are as follows:

1. SRS soil which was reconstituted in the laboratory to simulate its undisturbed state was readily vitrified to a rock-like, homogeneous cross section.

2. A fluxing agent is not required as an additive to fully vitrify SRS soil.

3. A highly saturated SRS soil in a simulated vadose zone was readily vitrified with the plasma torch. In order for vitrification to occur below the ground water level, the plasma torch must be operated at a power level which is high enough to evaporate the groundwater around the borehole at a faster rate than the soil permeability permits groundwater to recharge into the region.

4. Seeded contaminants (metals, contaminated briquettes, glass, concrete) were all readily vitrified, stabilized and immobilized within the vitrified soil column.

5. Adjacent vitrified columns will coalesce together in a highly satisfactory contiguous melt if the proper borehole spacing is used.

6. At the laboratory level, ISPV technology has demonstrated the potential to overcome many significant limitations associated with conventional joule-heated in situ vitrification (ISV) technology.

7. ISPV offers the potential to target many buried wastes and soil contaminants that are not safely or economically treatable using currently available or contemplated commercial in situ or ex situ technologies.

8. Fundamental studies are required to understand the interaction of the many variables involved in the ISPV process. In addition, a significant research effort should be initiated to model the ISPV process in order to predict variables such as the mass of vitrified material, melt diameter, torch withdrawal rate, etc. under a variety of geotechnical and environmental conditions.

9. The ISPV concept should be readily adaptable to existing DOE-developed in situ vitrification (ISV) technology by replacing the ISV graphite electrodes with one or more plasma torches. The opportunity to use this DOE-developed equipment would take advantage of significant development costs and years of development time that would otherwise be required for implementation and commercialization of ISPV technology. 


\subsection{REFERENCES}

Brouns, R. A., J. L. Buelt, and W. F. Bonner. 1983. "In situ Vitrification of Soil." U.S. Patent No. 4,376,598, U.S. Patent Office, Washington, DC.

Fitzpatrick, V., J. Buelt, K. Oma, and C. Timmerman. (1984). "In situ vitrification - A potential remedial action technique for hazardous wastes." Proceedings, The 5th National Conference on Management of Uncontrolled Hazardous Waste Sites, The Institute, Washington, DC, pp 191-194.

Buelt, J. L., C. L. Timmerman, K. H. Oma, V. F. Fitzpatrick, and J. G. Carter. 1987. "In situ Vitrification of Transuranic Wastes: Systems Evaluation and Applications Assessment," PNL-4800, Supplement 1, Pacific Northwest Laboratory, Richland, WA.

Camacho, S. L. 1988. "Industrial-Worthy Plasma Arc Torches: State-of-the-Art," Pure \& Applied Chemistry, V. 60, pp. 619-632.

Hansen, J, V. and Fitzpatrick. 1989. "In situ vitrification: heat and immobilization are combined for soil remediation." Hazmat World, 2(12), pp 30-34.

Spalding, B. P., G. K. Jacobs, and E. C. Davis. 1989. "Demonstrations of Technology for Remediation and Closure of Oak Ridge National Laboratory Sites," ORNL/TM-11286, Oak Ridge National Laboratory, Oak Ridge, TN, 93 pp.

Campbell, B. E., and J. L. Buelt. 1990. "In situ vitrification of soil from the Savannah River Site.” PNL-7421, Pacific Northwest Laboratory, Richland, WA.

Camacho, S. L. 1991. "Harnessing Artificial Lightning." The World \& I, December, 1991, pp. 310-317.

Roberts, J. S., S. L. Woosley, D. L. Lessor, and C. Strachan. 1992. "Preliminary Investigation of the Potential for Transient Vapor Release Events During In situ Vitrification Based on ThermalHydraulic Modeling," PNL-8170. Pacific Northwest Laboratory, Richland, WA.

Thompson, L. E., S. O. Bates, and J. E. Hansen. 1992. "Technology Status Report: In situ Vitrification Applied to Buried Wastes," PNL-8210, Pacific Northwest Laboratory, Richland, WA.

Camacho, S. L., G. Claesen, and M. J. Copsey, et al. 1992. "Plasma Technology for a Better Environment," International Union for Electroheat, U.I.E. Working Group, France, p 144.

Spalding, B. P., G. K. Jacobs, N. W. Dunbar, M. T. Naney, J. S. Tixier, and T. D. Powell. 1992. "Tracer-level Radioactive Pilot-Scale Test of In situ Vitrification for the Stabilization of Contaminated Soil Sites at ORNL," ORNL/TM-12201. Oak Ridge National Laboratory, Oak Ridge, $\mathrm{TN}$. 
Tatsuoka, F. and S. Shibuya. 1992. Deformation characteristics of soils and rocks from field and laboratory tests. Report of the Institute of Industrial Science, University of Tokyo, 37 (1), 136 pp.

Circeo, L. J., Jr. and S. L. Camacho. 1993. "In situ Landfill Pyrolysis, Remediation and Vitrification," U.S. Patent No. 5,181,795, U.S. Patent Office, Washington, DC.

Circeo, L. J., Jr. and P. W. Mayne. 1993. "In situ Thermal Stabilization of Soils Using Plasma Arc Technology," Final Report to National Science Foundation, NSF Grant MSS-9113134, Georgia Institute of Technology, Atlanta, GA, 39 pp.

Jacobs, G. K., and J. S. Tixier. 1993. Trip Report: "Discussion of Plasma Remediation of In situ Materials (PRISM)" Oak Ridge National Laboratory and Pacific Northwest Laboratory, Sep 22.

Circeo, L. J., Jr. and S. L. Camacho. 1994. "In situ Remediation and Vitrification, of Contaminated Soils, Deposits, and Buried Materials," U.S. Patent No. 5,276,253, U. S. Patent Office, Washington, DC.

Boudreau, R. L. 1994. Final report for ITP geotechnical services. Law Engineering Report prepared for Westinghouse Savannah River Company, WSRC Subcontract No. AB08525N, February 21, 1994.

Circeo, L. J., Jr., S. L. Camacho, G. K. Jacobs, and J. S. Tixier. 1994. "Plasma Remediation of In situ Materials - The PRISM Concept," 33rd Hanford Symposium on Health and the Environment: In situ Remediation, Pasco, WA, November 7-11.

The Military Engineer. 1994. "Cleaning Up Federal Waste," December 1994.

Moore, J. 1995. Letter to EM-542, "Technical Task Plan-Plasma Remediation of In situ Materials, “DOE Oak Ridge Operations Office, Oak Ridge, TN, February 13, 1995.

Ponomarev-Stepnoi, N. N. 1995. Letter to the U.S. Secretary of Energy, Russian Research Centre, Kurchatov Institute; Moscow Russia, June, 1995.

Cline, S. R., M. A. Bogle, B. P. Spalding, and M. T. Naney. 1995." In situ Techniques for the Characterization and Monitoring of a Radioactively Contaminated Site for In situ Vitrification." Proceedings, International Symposium on Environmental Technologies: Plasma Systems and Applications (2), Georgia Institute of Technology, Atlanta, pp. 651-661.

Bogatov, S. A., et al. 1995. "PRISM-Plasma Remediation of In situ Materials and its Potential for the Remediation of Chernobyl Consequences," Proceedings of the International Symposium on Environmental Technologies, Georgia Institute of Technology, Atlanta, GA, October 8-11, 1995, pp. 631-638. 
Brooman, E. W., R. J. Patun, and M. A. Qazi. 1995. "Destruction of hazardous waste material using plasma arc technology." Proceedings, International Symposium on Environmental Technologies: Plasma Systems and Applications (1), Georgia Institute of Technology, Atlanta, pp 205-218.

Beaver, James R. and P. W. Mayne. 1995. Final Report, "Plasma Vitrification of Geomaterials," FHWA Contract DTFH61-94-X-00021, Georgia Institute of Technology, November, 1995.

Campbell, B. E. and J. L. Buelt. 1990. "In situ Vitrification of Soil from the Savannah River Site." PNL-7421, Pacific Northwest Laboratory, Richland, Washington.

Lowery, P. S., et al. 1994. "Engineering Scale ISV Meltability Tests on Savannah River Soils," U.S. DOE Contract DE-ACO6-76RLO-1830, Pacific Northwest Laboratory, May 1994.

Schumacher, R. F., et al. 1995. "High Temperature Vitrification of Low-Level Radioactive and Hazardous Wastes," Proceedings of the International Symposium on Environmental Technologies, Georgia Institute of Technology, Atlanta, GA, October 8-11, 1995, pp. 461-470.

Mayer, K.A. 1996. "Plasma Vitrification for Geoenvironmental Concerns," M.S. Thesis, College of Civil and Environmental Engineering, Georgia Tech, December. 


\section{APPENDIX A \\ Supplemental Test Data: ISPV Experiment No. 1. $100 \mathrm{~kW}$ in Clean SRS Soil}

\section{A. Test Procedure}

1. A cylindrical 24 -inch diameter by 36 -inch high steel container vessel was used for this experiment.

2. The vessel was loaded with Savannah River Site uncontaminated soil.

3. A 4-inch diameter torch insertion hole (borehole) with a 4-inch diameter thin metal pipe casing was centered and aligned as the soil was loaded into the vessel.

4. The open borehole extended to a depth 6 inches from the bottom of the vessel.

5. The physical properties of the soil were measured as loaded in the vessel. Measurements included soil moisture content, soil density, and the weight of the soil. A sample of the soil was collected for comparison with the thermally-treated soil.

6. The $100 \mathrm{~kW}$ torch was inserted to a distance 6 inches from the bottom of the borehole (12 inches from the bottom of the steel container).

7. The $100 \mathrm{~kW}$ torch was ignited and operated in accordance with the procedures for the plasma heating system provided by Plasma Energy Corporation.

8. The torch was withdrawn upward, at a minimum rate to keep the torch out of the molten pool.

9. Thermocouples were used to collect thermal data as a tool to track the progress of the melt zone within the vessel, and to assist in understanding the vitrification process in the soil.

10. The test duration was largely determined by the withdrawal rate of the torch.

11. Data relating to the operation of the plasma heating system was collected during this test.

12. Following a cooldown period of at least 24 hours, the vessel was unloaded and samples collected for testing, analysis and evaluation. 


\section{B. Table A.1. Test Sequence}

\begin{tabular}{|c|l|}
\hline $\begin{array}{c}\text { Duration of } \\
\text { Test } \\
\text { (minutes) }\end{array}$ & \multicolumn{1}{|c|}{ Event } \\
\hline 0 & Torch Ignited 6" from bottom of borehole (12" from bottom of vessel) \\
\hline 2 & Torch Power @ 56 kW \\
\hline 3 & Torch Power @ 64 kW \\
\hline 9 & Torch Power @ 80 kW \\
\hline 21 & Torch Raised 2" (8" from bottom of borehole) \\
\hline 51 & Torch Raised 2" (10" from bottom of borehole) \\
\hline 54 & Torch Raised 2" (12" from bottom of borehole) \\
\hline 73 & Torch Raised 2"' (14" from bottom of borehole) \\
\hline 106 & Torch Raised 2" (16" from bottom of borehole) \\
\hline 133 & Torch Raised 2" (18" from bottom of borehole) \\
\hline 153 & Torch Raised 2"' (20" from bottom of borehole) \\
\hline 183 & Torch Raised 2" (22" from bottom of borehole) \\
\hline 215 & Torch Raised 2"' (24" from bottom of borehole) \\
\hline 245 & Torch Raised 2"' (26" from bottom of borehole) \\
\hline 271 & Torch Raised 4" (30" from bottom of borehole) \\
\hline 290 & $\begin{array}{l}\text { Soil collapsed around borehole. Torch lowered 4" (26" from bottom } \\
\text { of borehole). }\end{array}$ \\
\hline 305 & Torch Off \\
\hline & \\
\hline
\end{tabular}




\section{Thermocouple Temperature Data}

Thermocouples were used in Experiment No. 1 to detect the outward propagation of the melt by providing temperature readings. The thermocouples were C-type thermocouples composed of tungsten and rhenium. Tungsten has the highest melting temperature of any material on earth at $2400^{\circ} \mathrm{C}$, and the thermocouples were rated up to $2320^{\circ} \mathrm{C}$, with a $1 \%$ error range. The instruments were encased in ceramic insulators and attached to stiff wires, which allowed them to be inserted into the container. The location of each thermocouple in the test chamber can be seen in Figure A.1.

Because soil is such a good insulating material, the temperatures at the thermocouples did not fluctuate significantly until the melt had almost engulfed the instrument. Because of the high temperatures of the melt, once the thermocouples had been overtaken by the melt, the instruments were damaged. The initiation time and the time required for destruction of each thermocouple can be seen in Table A.2. This trend can be seen in Figure A.2, which details the results obtained from thermocouples used in Experiment No. 1.

The time required for destruction of each of the thermocouples can be used to estimate the propagation rate of the melt, if a uniform expansion is assumed. In this experiment, thermocouples 2 and 3 were located at a height of $60 \mathrm{~cm}$ ( 24 inches), separated by a distance of $2.5 \mathrm{~cm}$ ( 1 in). Thermocouple 2 was damaged 90 minutes ( 1.5 hours) into the test, and thermocouple 3 was damaged 16 minutes later, 106 minutes (1.77 hours) into the test. This shows an outward propagation rate of $0.16 \mathrm{~cm} / \mathrm{min}(0.06 \mathrm{in} / \mathrm{min})$, which is comparable to the rate of $0.2 \mathrm{~cm} / \mathrm{min}$ which was found in previous tests using the $100 \mathrm{~kW}$ torch (Beaver and Mayne, 1995). 


\section{C.1. Table A.2. Thermocouple Temperature Data}

\begin{tabular}{|c|c|c|c|c|}
\hline $\begin{array}{c}\text { Time } \\
\text { (Minutes) }\end{array}$ & \multicolumn{5}{|c|}{ Thermocouple Temperatures $\left({ }^{\circ} \mathbf{C}\right)$} \\
\hline & $\underline{\mathbf{T C}}_{1}$ & $\underline{\mathbf{T C}}_{2}$ & $\underline{\mathbf{T C}}_{3}$ & $\underline{\mathbf{T C}}_{4}$ \\
\hline 0 & $21^{\circ} \mathrm{C}$ & & & \\
\hline 40 & -- & & Initiated & \\
\hline 47 & 350 & & -- & \\
\hline 51 & 1,470 & & -- & \\
\hline 52 & 2,100 & & -- & \\
\hline 53 & Damaged & & -- & \\
\hline 55 & & Initiated & -- & \\
\hline 90 & & Damaged & -- & \\
\hline 98 & & & -- & Initiated \\
\hline 105 & & & $1,300^{\circ} \mathrm{C}$ & -- \\
\hline 106 & & & Damaged & -- \\
\hline 152 & & & & $918^{\circ} \mathrm{C}$ \\
\hline
\end{tabular}




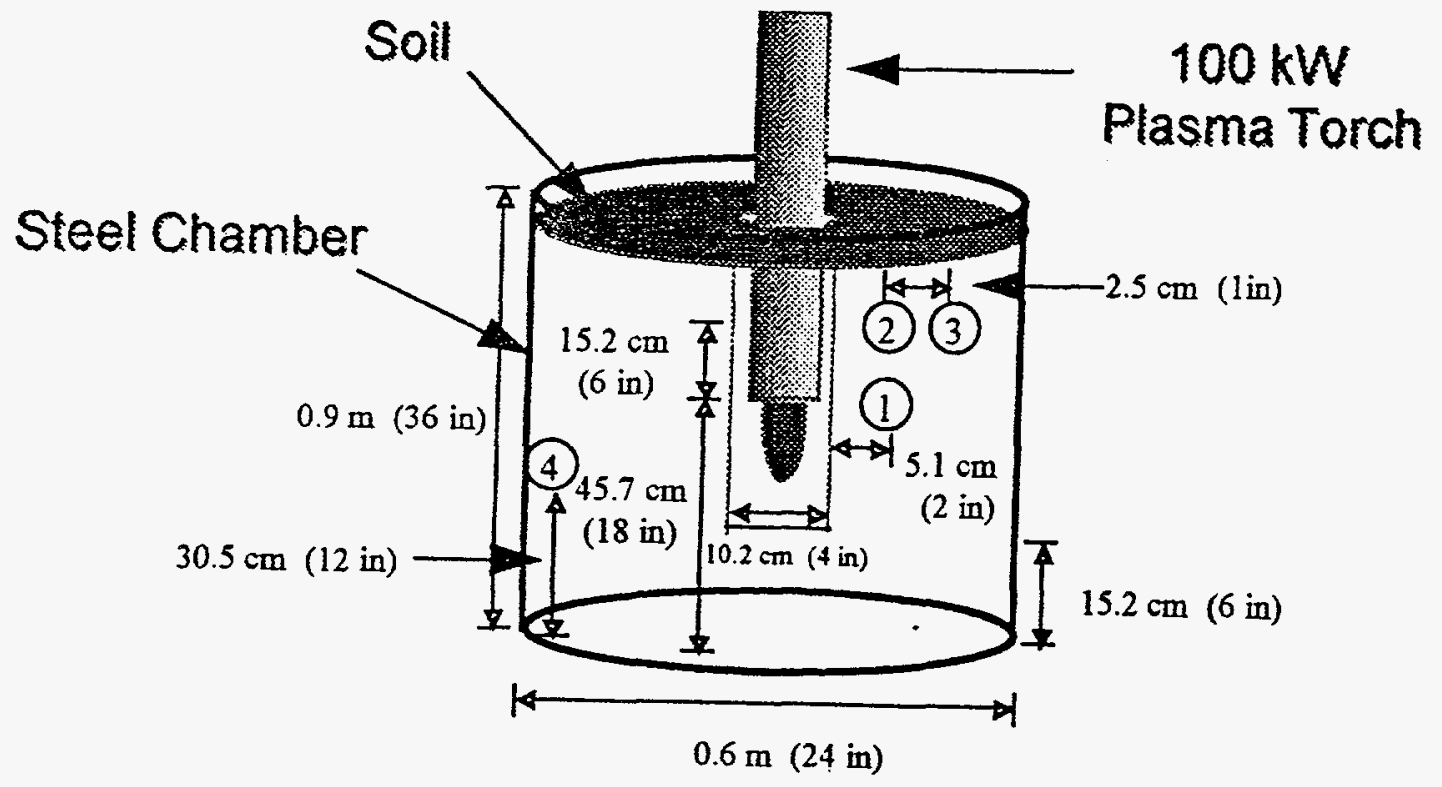

Figure A.1. Location of Thermocouples during Experiment No. 1. 


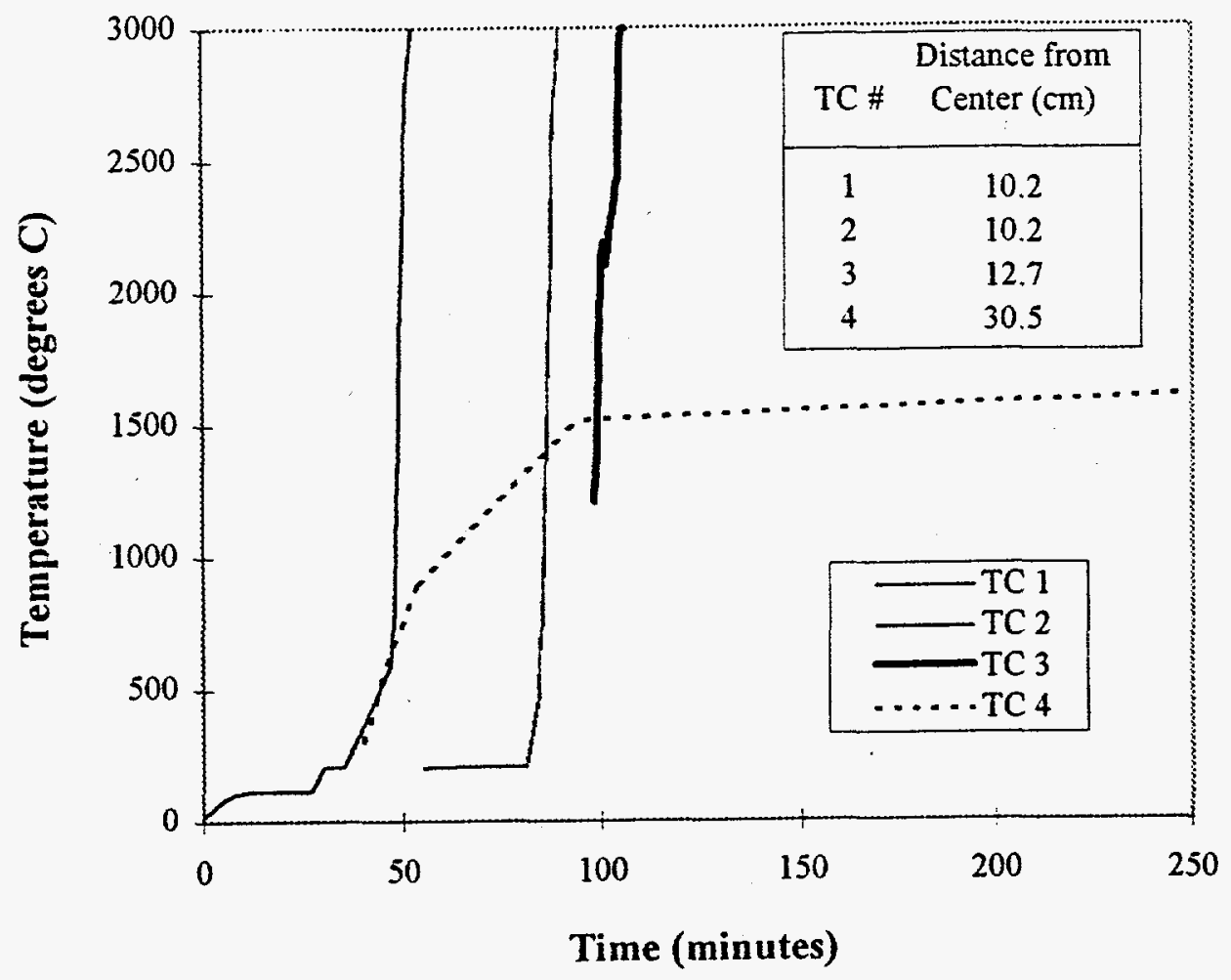

Figure A.2. Thermocouple Temperatures during Experiment No. 1. 


\section{APPENDIX B}

\section{Supplemental Test Data: ISPV Experiment No. 2. $100 \mathrm{~kW}$ in Clean SRS Soil and Fluxant}

\section{A. Test Procedure}

1. A cylindrical 24-inch diameter by 36-inch high steel container vessel was used for this experiment. A 12-inch high offgas collection hood with an exhaust port was added to the top of the container.

2. The vessel was loaded with Savannah River Site uncontaminated soil plus a fluxant.

3. A 4-inch diameter borehole with a thin metal pipe casing was centered for the torch. An 8-inch diameter thin metal pipe casing was placed around the borehole casing. A marble chip $\left(\mathrm{CaCO}_{3}\right)$ fluxant was placed in the 2 -inch space between the two casings.

4. The open borehole extended to a depth 6 inches from the bottom of the container vessel.

5. The physical properties of the soil were measured as loaded in the vessel. Measurements included soil moisture content, soil density, and the weight of the soil. A sample of the soil was collected for comparison with the thermally-treated soil.

6. The $100 \mathrm{~kW}$ torch was inserted to a distance 6 inches from the bottom of the borehole (12 inches from the bottom of the steel container).

7. The $100 \mathrm{~kW}$ torch was ignited and operated in accordance with the procedures for the plasma heating system provided by Plasma Energy Corporation.

8. The torch was withdrawn upward, at a minimum rate to keep the torch out of the molten pool.

9. No thermocouples were used in this experiment.

10. Since this test vessel did not have an open configuration, both visual and sound observation of the plasma process could not be used as an indication of the location and size of the molten pool. Therefore the data from Experiment No. 1 was used as a guide for the withdrawal of the torch.

11. The test duration was largely determined from the withdrawal rate of the torch.

12. Data relating to the operation of the plasma heating system was collected.

13. Following a cooldown period of at least 24 hours, the vessel was unloaded and samples collected for testing, analysis and evaluation. 
B. Table B.1. Test Sequence

\begin{tabular}{|c|l|}
\hline $\begin{array}{c}\text { Duration of } \\
\text { Test } \\
\text { (minutes) }\end{array}$ & \multicolumn{1}{|c|}{ Event } \\
\hline 0 & Torch Ignited 6" from bottom of borehole (12" from bottom of vessel) \\
\hline 17 & Torch Power @ 68 kW \\
\hline 22 & Torch Raised 2" (8" from bottom of borehole) \\
\hline 43 & Torch Raised 3" (11" from bottom of borehole) \\
\hline 60 & Torch Raised 3" (14" from bottom of borehole) \\
\hline 80 & Torch Raised 3" (17" from bottom of borehole) \\
\hline 118 & Torch Raised 3" (20" from bottom of borehole) \\
\hline 150 & Torch Raised 4" (24" from bottom of borehole) \\
\hline 180 & Torch Raised 2" (26" from bottom of borehole) \\
\hline 210 & Torch Raised 2" (28" from bottom of borehole) \\
\hline 214 & $\begin{array}{l}\text { Torch Raised 2" (30" from bottom of borehole) (36" from bottom of } \\
\text { vessel) }\end{array}$ \\
\hline 260 & Torch Off \\
\hline
\end{tabular}




\section{APPENDIX C}

\section{Supplemental Test Data: ISPV Experiment No. 3. $100 \mathrm{~kW}$ in Clean SRS Soil and High Moisture Content}

\section{A. Test Procedure}

1. A cylindrical 24-inch diameter by 36 -inch high steel container vessel was used for this experiment. The container was modified to permit water to flow into the bottom of the container.

2. The vessel was loaded with Savannah River Site uncontaminated soil. A 1.5-inch pea gravel layer was placed in the bottom of the container to permit water to readily recharge the soil. Five pea gravel vertical vent columns were placed equidistant around the inside rim of the container to permit steam to vent to the surface. This would eliminate any steam pressure buildup in the soil. An adjacent water vessel was used as a reservoir to maintain the water level at 12 inches above the bottom of the container during the test.

3. A 4-inch diameter torch insertion hole (borehole) with a 4-inch diameter thin metal pipe casing was centered and aligned as the soil was loaded into the vessel.

4. The open borehole extended to a depth 6 inches from the bottom of the vessel.

5. The physical properties of the soil were measured as loaded in the vessel. Measurements included soil moisture content, soil density, and the weight of the soil. A sample of the soil was collected for comparison with the thermally-treated soil.

6. The $100 \mathrm{~kW}$ torch was inserted to a distance 6 inches from the bottom of the borehole (12 inches from the bottom of the steel container).

7. The $100 \mathrm{~kW}$ torch was ignited and operated in accordance with the procedures for the plasma heating system provided by Plasma Energy Corporation.

8. The torch was withdrawn upward, at a minimum rate to keep the torch out of the molten pool.

9. Thermocouples were used in this experiment solely to ensure that excess steam was not being formed in the cylinder. These data are presented in Table C.2.

10. The test duration was largely determined from the withdrawal rate of the torch. The data from Experiments No. 1 and No. 2 were used to determine torch withdrawal rate.

11. Data relating to the operation of the plasma heating system was collected.

12. Following a cooldown period of at least 24 hours, the vessel was unloaded and samples collected for testing, analysis and evaluation. 


\section{B. Table C.1. Test Sequence}

\begin{tabular}{|c|l|}
\hline $\begin{array}{c}\text { Duration of } \\
\text { Test } \\
\text { (minutes) }\end{array}$ & \multicolumn{1}{|c|}{ Event } \\
\hline 0 & $\begin{array}{l}\text { Torch Ignited. Water Table and Torch at 6" above bottom of borehole } \\
\text { (12" from bottom of vessel). }\end{array}$ \\
\hline 10 & Torch Power = 56 kW \\
\hline 27 & Torch Power = 60 kW \\
\hline 30 & $\begin{array}{l}\text { Torch Raised 2" (8" from bottom of borehole). Water Table: 2" added } \\
\text { to bring back to the initial 6" level. }\end{array}$ \\
\hline 55 & Water Table: 1" added to bring back to initial level. \\
\hline 65 & Water Temp @ 12 ${ }^{\circ} \mathrm{C}$ \\
\hline 83 & Torch Raised 2" (10" from bottom of borehole) \\
\hline 109 & Water Table: 1" added to bring back to initial level. \\
\hline 121 & Torch Raised 2" (12" from bottom of borehole). Water pipe closed. \\
\hline 143 & Torch Raised 2" (14" from bottom of borehole) \\
\hline 173 & Torch Raised 2"' (16" from bottom of borehole) \\
\hline 204 & Torch Raised 2" (18" from bottom of borehole) \\
\hline 234 & Torch Raised 2" (20" from bottom of borehole) \\
\hline 264 & Torch Raised 2"' (22" from bottom of borehole) \\
\hline 294 & Torch Raised 2" (24" from bottom of borehole) \\
\hline 324 & Torch Raised 2" (26" from bottom of borehole) \\
\hline 335 & Soil collapsed around borehole. \\
\hline 350 & Torch Off \\
\hline
\end{tabular}


C. Table C.2. Thermocouple Temperature Data

\begin{tabular}{|c|c|c|c|c|}
\hline $\begin{array}{c}\text { Time } \\
\text { (Minutes) }\end{array}$ & \multicolumn{4}{|c|}{ Thermocouple Temperatures ( $\left.{ }^{\mathbf{C}} \mathbf{C}\right)$} \\
\hline & $\underline{\mathbf{T C}}_{1}$ & $\underline{\mathbf{T C}}_{1 \mathrm{a}}$ & $\underline{\mathbf{T C}}_{\mathbf{2}}$ & $\underline{\mathbf{T C}}_{\mathbf{3}}$ \\
\hline 0 & $16.4^{\circ} \mathrm{C}$ & & & \\
\hline 1 & 59 & & & \\
\hline 8 & 56 & & & \\
\hline 21 & 56 & & & \\
\hline 42 & Damaged & $28^{\circ} \mathrm{C}$ & $69^{\circ} \mathrm{C}$ & \\
\hline 48 & & 31 & 74 & \\
\hline 54 & & 33.6 & 78 & \\
\hline 56 & & 34.6 & 79 & \\
\hline 66 & & 35.6 & 80 & \\
\hline 85 & & -- & -- & $93^{\circ} \mathrm{C}$ \\
\hline 95 & & 39.8 & 81 & -- \\
\hline 102 & & 42 & 83 & -- \\
\hline 230 & & & 1,093 & 107 \\
\hline 254 & & & 2,200 & \\
\hline & & & Damaged & \\
\hline
\end{tabular}




\section{APPENDIX D}

\section{Contaminant Layout Plan for Experiments No. 4 and No. 5}

Experiments No. 4 and No. 5 were conducted in a specially constructed rectangular steel container, with Experiment No. 4 using the $100 \mathrm{~kW}$ torch and Experiment No. 5 using the 200 $\mathrm{kW}$ torch. The container size was 56 inches long, 44 inches wide and 69 inches high; it contained SRS soil to a depth of 65 inches. The borehole for the $100 \mathrm{~kW}$ torch was 4 -inches in diameter and the borehole for the $200 \mathrm{~kW}$ torch was 5-inches in diameter. Both boreholes extended into the soil to a depth of 59 inches, or 6 inches from the bottom of the container. The centers of the boreholes were spaced 18 inches apart. Stovepipe casings were used to maintain the integrity of the boreholes. A diagram showing the dimensions of the container can be seen in Figure 4.11. A photograph of the container can be seen in Figure 4.12.

In an attempt to simulate melting of contaminated Savannah River Site soil, various buried "contaminants" were dispersed throughout the soil, including broken glass in plastic bags, pieces of concrete, metal cans (both empty and filled with water), and specially-made briquettes that were a mixture of several real and surrogate contaminated materials known to exist at the Savannah River Site. The glass pieces were each about 0.4 inches thick, and were broken into various sizes. A block of concrete was broken into smaller pieces, each weighing approximately one pound, which were buried at various locations throughout the container. The cylindrical metal cans were 3 -inches in diameter and 5-inches long. The briquettes were the size of standard charcoal briquettes, approximately 2 inches square and 1 inch thick. The composition of the briquettes is given in Table D.1.

Figure D. 1 is a profile view of the ISPV test geometry for Experiments No. 4 and No. 5. The general layout of the seeded contaminants are shown. Figures D.2 and D.3 show plan view elevations where the contaminants were located. These two figures indicate the placement of specific contaminants at each level throughout the container. Figures D.4 and D.5 are photographs of the contaminant arrays taken during the placement of the soil and contaminants. 
Table D.1. Composition of the Contaminated Briquettes

\begin{tabular}{|c|c|}
\hline Component & Percent by Weight \\
\hline Water & 20.0 \\
\hline Starch & 7.5 \\
\hline Activated Carbon & 4.5 \\
\hline Pecan Shell Flour & 10.0 \\
\hline PVC Granules & 10.0 \\
\hline Iron Powder & 10.0 \\
\hline Glass Beads (SLS) & 10.0 \\
\hline Portland Cement & 4.0 \\
\hline Alumina & 7.25 \\
\hline Aluminum Powder & 1.5 \\
\hline Silica Sand & 4.0 \\
\hline Pearlite (Harborlite) & 10.0 \\
\hline Subtotal & $98.75 \%$ \\
\hline \multicolumn{2}{|l|}{ RCRA Metals } \\
\hline Cadmium Chloride & 0.23 \\
\hline Lead Chloride & 0.23 \\
\hline Chromic Chloride & 0.23 \\
\hline Nickel Chloride & 0.23 \\
\hline Subtotal & $0.92 \%$ \\
\hline \multicolumn{2}{|l|}{ Radionuclide Surrogates } \\
\hline Cesium Chloride & 0.23 \\
\hline Cerium Chloride & 0.12 \\
\hline Subtotal & $0.35 \%$ \\
\hline TOTAL & $100.02 \%$ \\
\hline
\end{tabular}




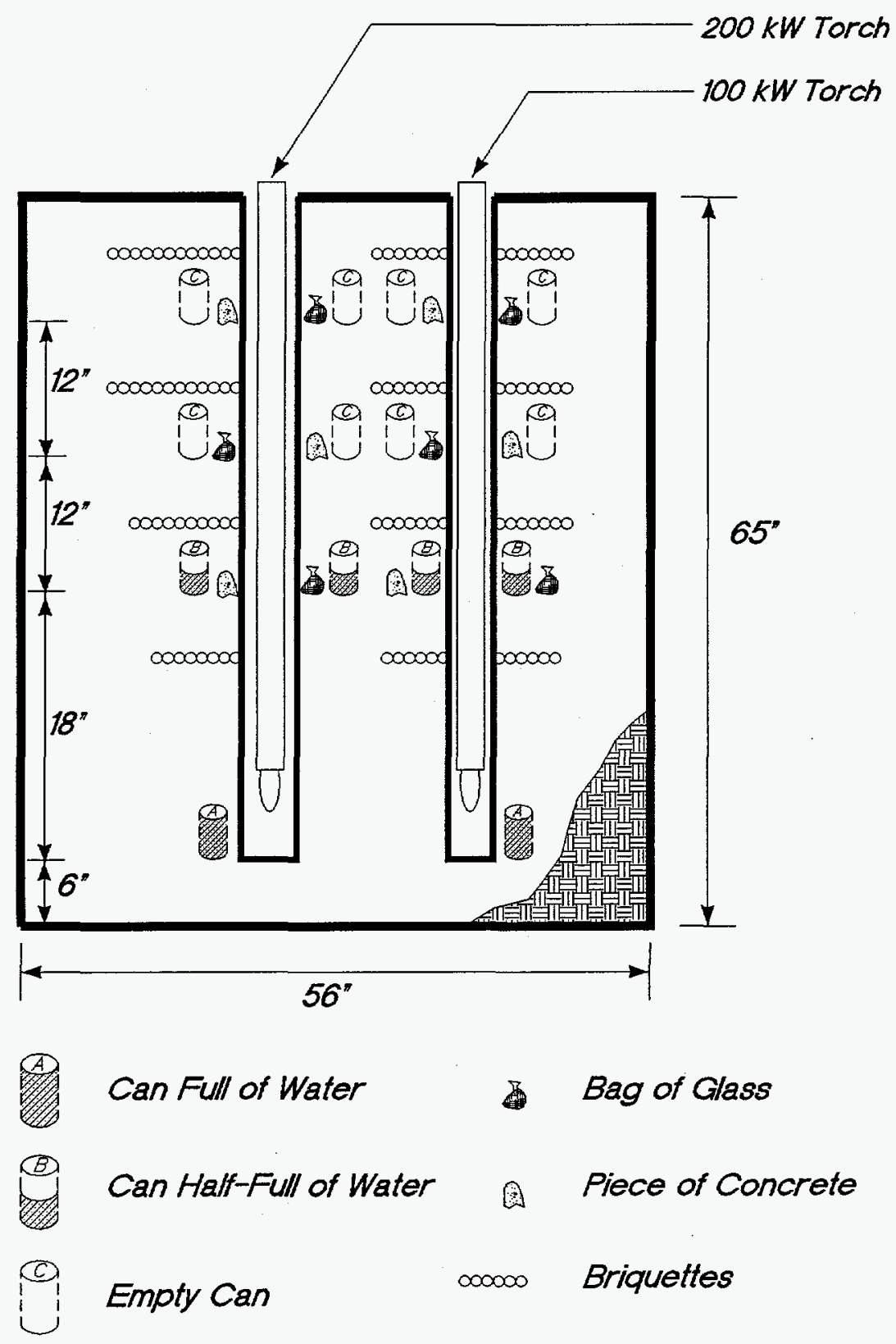

Figure D.1. Profile View of Buried

Contaminants in Experiments No. 4 and No. 5. 


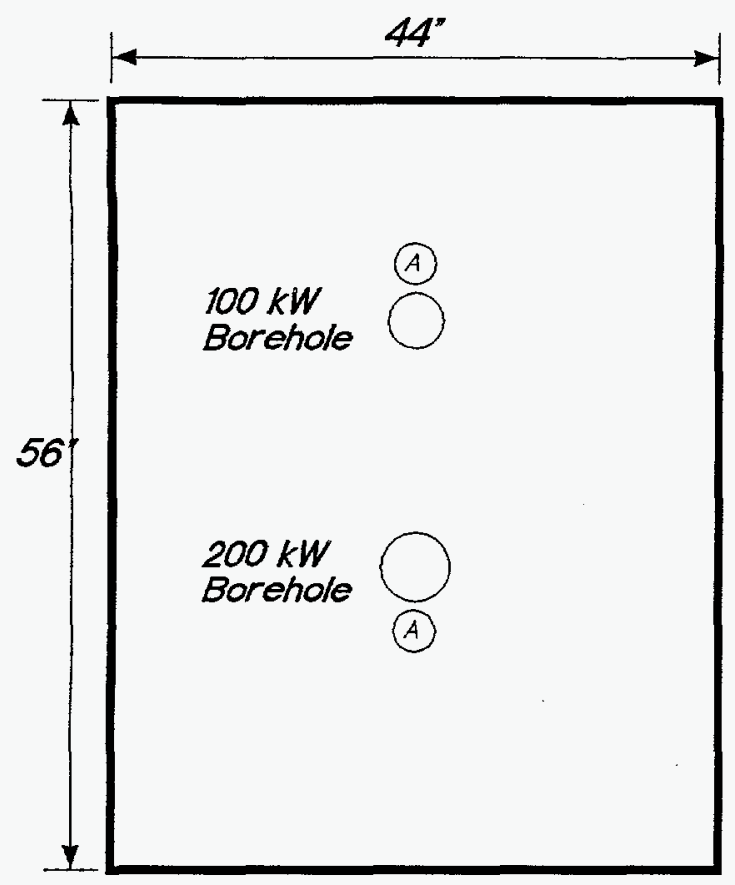

Plan View - 6" From Bottom

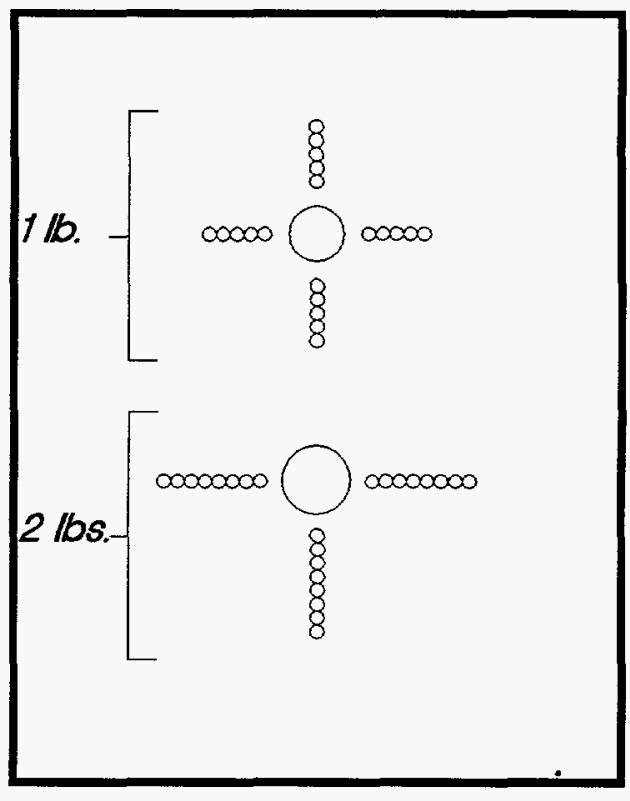

Plan View - 18" From Bottom

(A) Can Full of Water

(B) Can Half-Full of Water

(C) Empty Can

Bag of Glass

(1) Piece of Concrete

000000 Briquettes

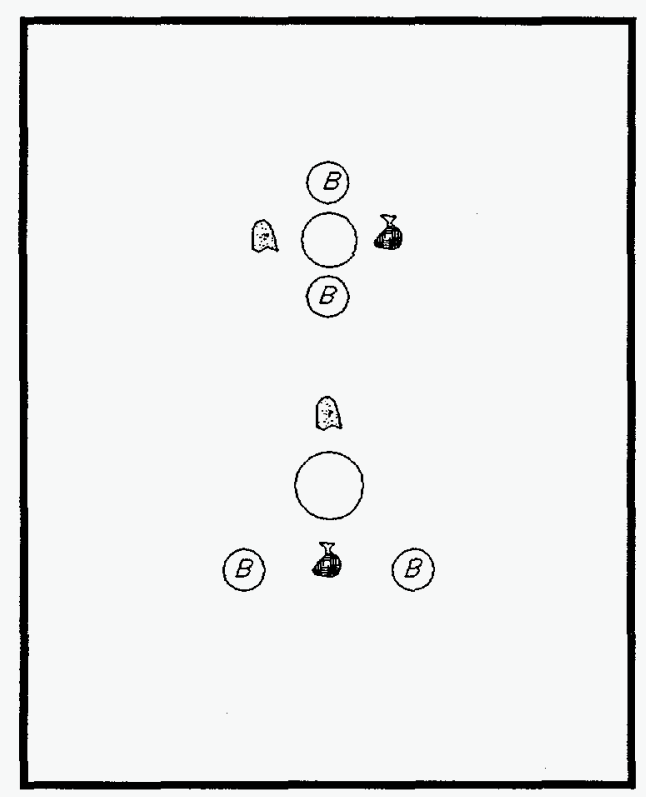

Plan View - 30" From Bottom

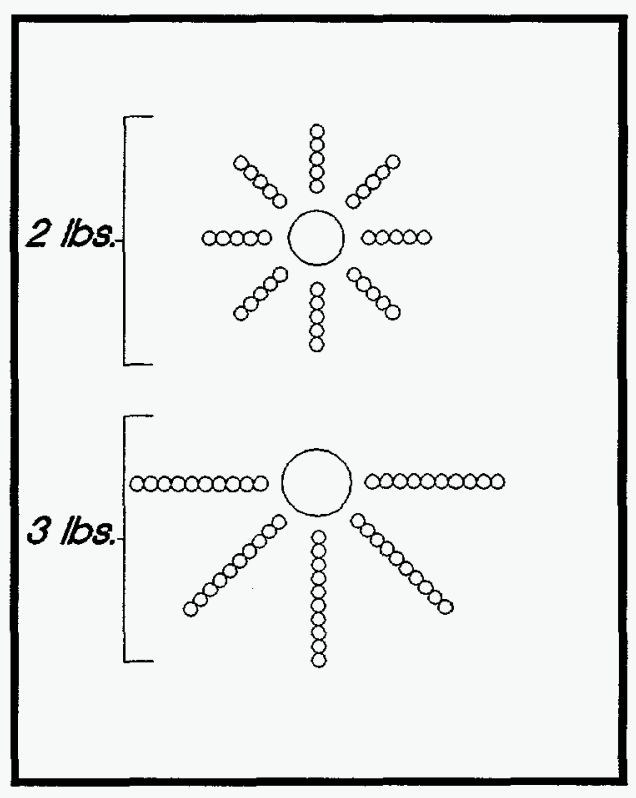

Plan View - 36" From Bottom

Figure D.2. Plan Views of Buried Contaminants in the Lower Container Portion of Experiments No. 4 and No. 5. 


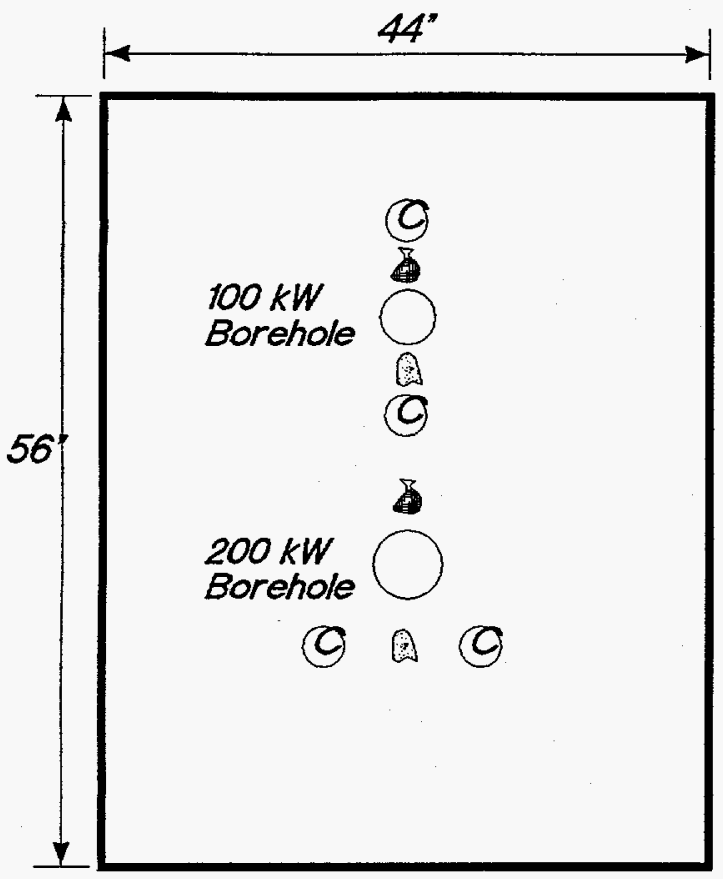

Plan View - 42" From Bottom

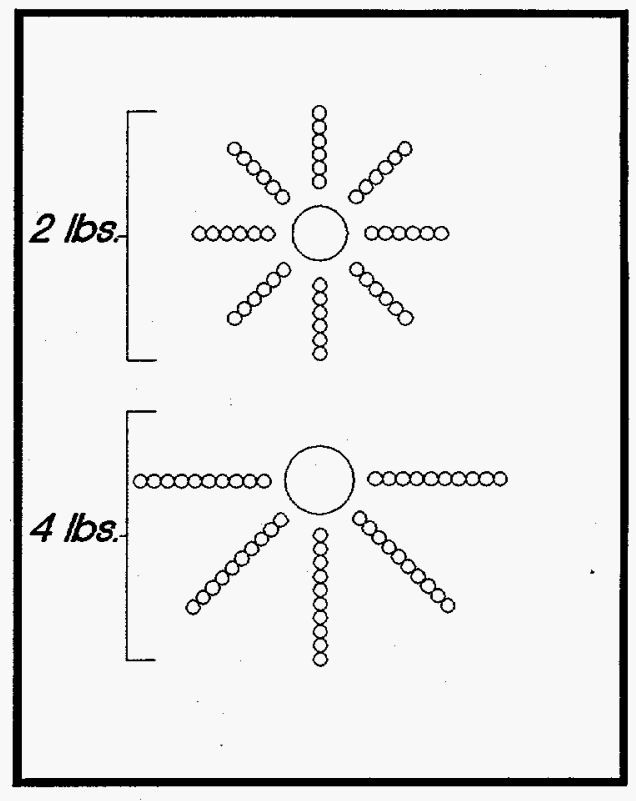

Plan View - 48" From Bottom

(A) Can Full of Water

(B) Can Half-Full of Water

(C) Empty Can

5 Bag of Glass

(1) Piece of Concrete

-00000 Briquettes

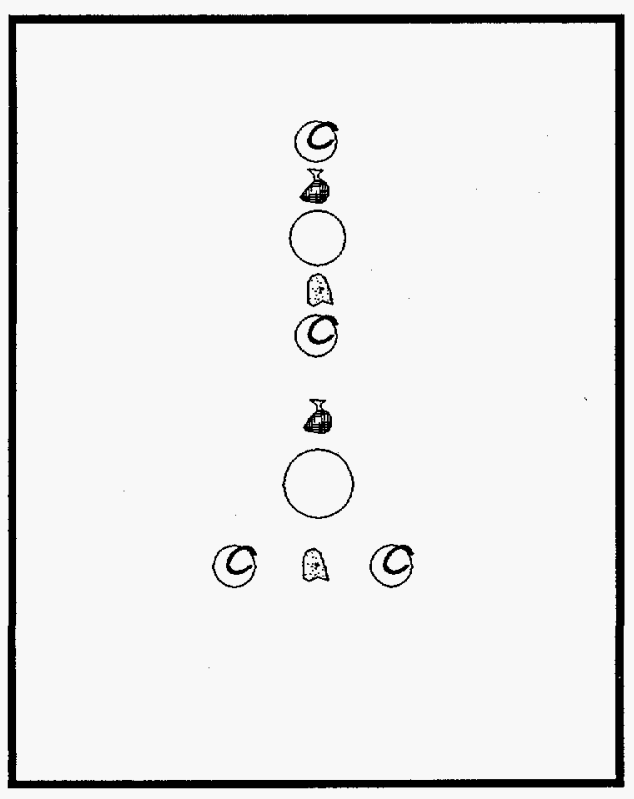

Plan View - $54^{\prime \prime}$ From Bottom

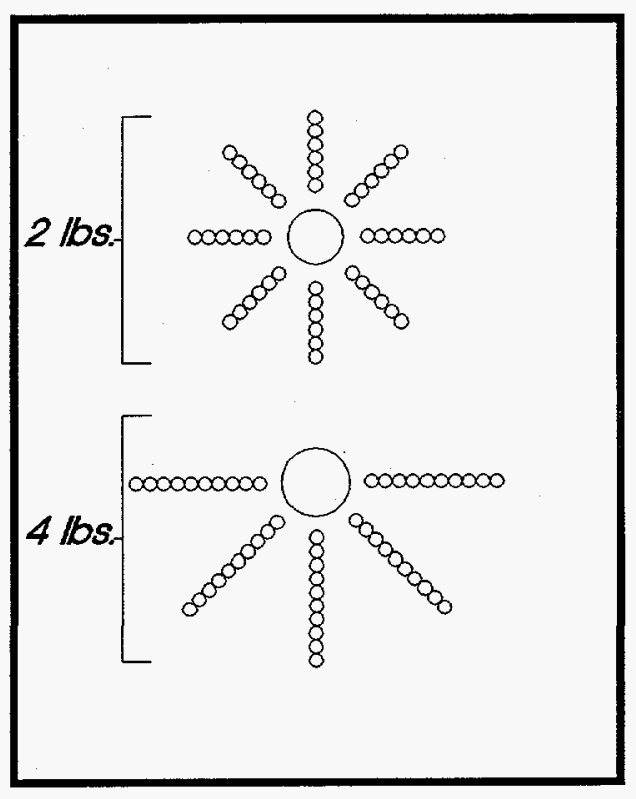

Plan View - $60^{\prime \prime}$ From Bottom

Figure D.3. Plan Views of Buried Contaminants in the Upper Container Portion of Experiments No. 4 and No. 5. 


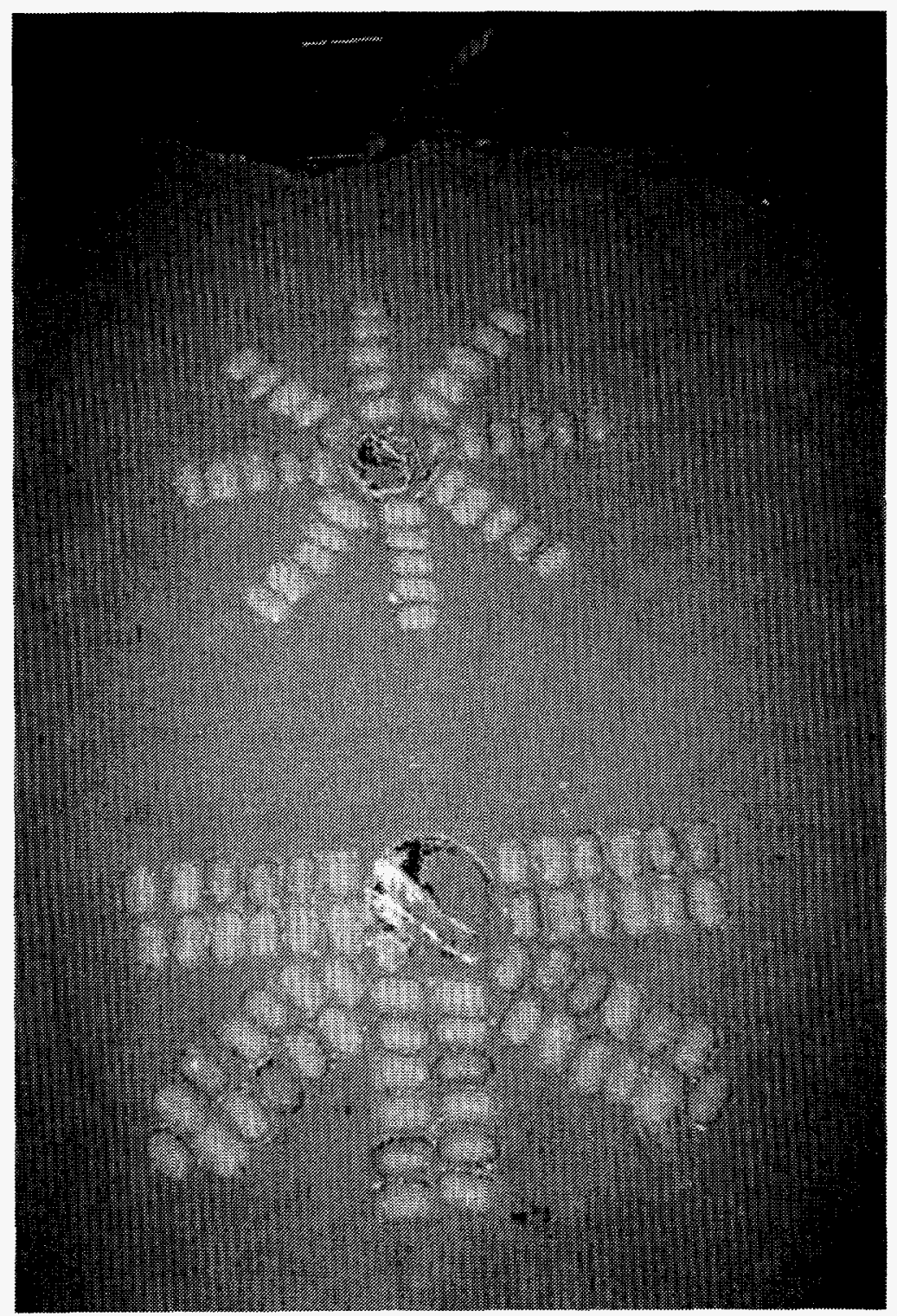

Figure D.4. Photograph of Briquette Array in Experiments No. 4 and No. 5. 


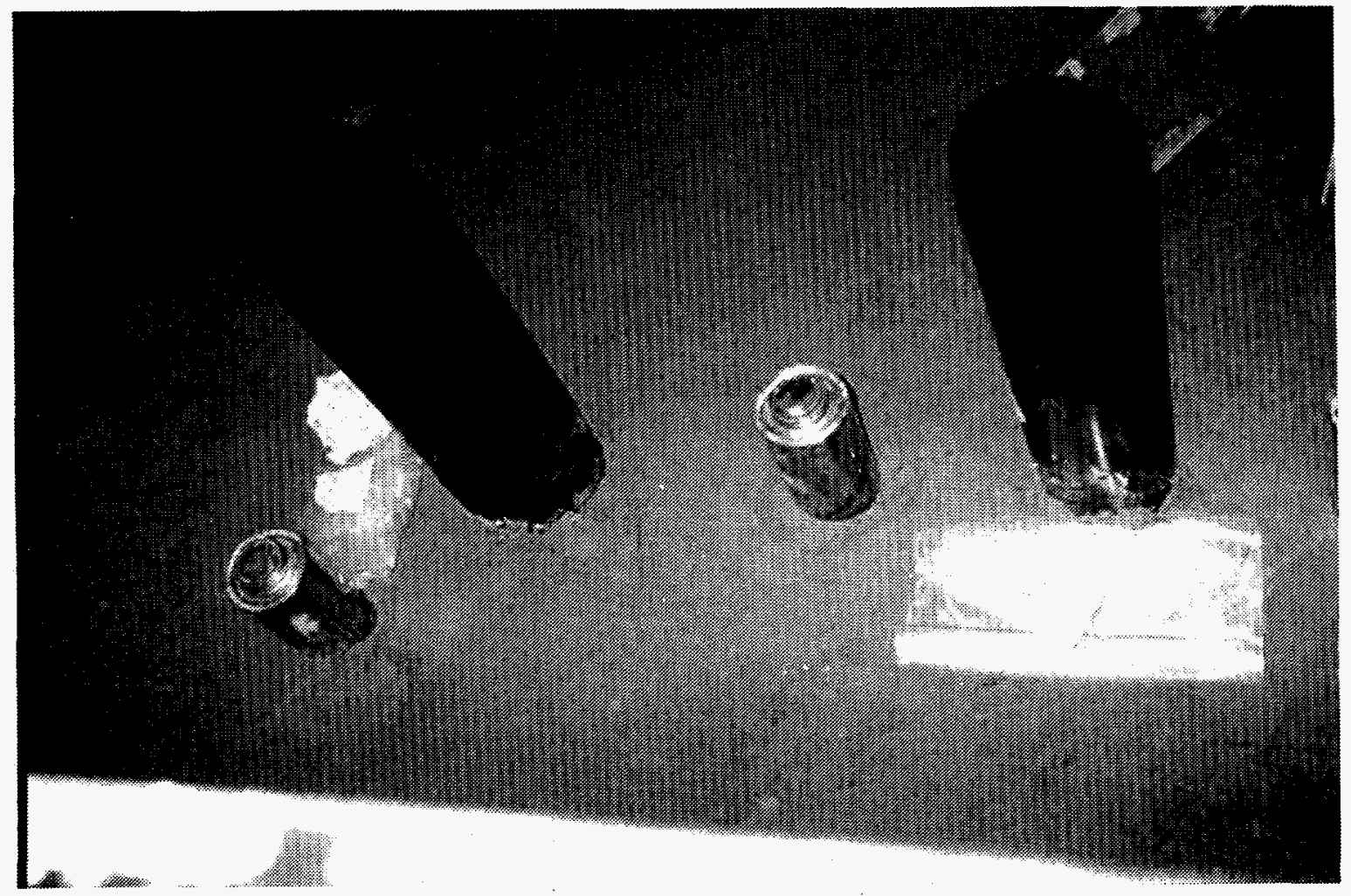

Figure D.5. Photograph of Glass, Cement, and Metal Can Array in Experiments No. 4 and No. 5. 


\section{APPENDIX E}

\section{Supplemental Test Data: ISPV Experiment No. 4. $100 \mathrm{~kW}$ in Contaminated SRS Soil}

\section{A. Test Procedure}

1. A specially prepared rectangular steel container vessel (69" high, 56" wide, 44 " deep) was constructed to permit adjacent $100 \mathrm{~kW}$ and $200 \mathrm{~kW}$ in situ experiments to take place (Experiments No. 4 and No.5).

2. The vessel was loaded with Savannah River Site uncontaminated soil. Simulated Savannah River Site waste was seeded in the soil. The simulated waste consisted of specially fabricated briquettes plus various amounts of glass, concrete and cans. The briquettes included tracer elements (cerium and cesium) and other waste components that are common to low-level radioactive wastes. The soil was loaded into the rectangular vessel to a height of $65^{\prime \prime}$.

3. The vessel design included a flat cover plate over the top of the container. A 4-inch offgas exhaust port under a negative pressure fed the offgas to a collection unit and then to the scrubber system. A baffle was installed in the exhaust port to limit particulate matter being drawn into the offgas line and the scrubber system.

4. A 4-inch diameter torch insertion hole (borehole) with a 4-inch diameter thin metal pipe casing was centered and aligned for the $100 \mathrm{~kW}$ experiment as the soil was loaded into the vessel.

5. The open borehole extended to a depth 6 inches from the bottom of the vessel.

6. The physical properties of the soil were measured as loaded in the vessel. Measurements included soil moisture content, soil density, and the weight of the soil. A sample of the soil was collected for comparison with the thermally-treated soil.

7. The $100 \mathrm{~kW}$ torch was inserted to a distance 6 inches from the bottom of the borehole (12 inches from the bottom of the steel container).

8. The $100 \mathrm{~kW}$ torch was ignited and operated in accordance with the procedures for the plasma heating system provided by Plasma Energy Corporation.

9. The torch was withdrawn upward, at a minimum rate to keep the torch out of the molten pool. Since this test vessel did not have an open configuration, the data from previous experiments were used as a guide for the torch withdrawal rate. 
10. Thermocouples were used to collect thermal data as a tool to track the progress of the melt zone within the vessel, and to assist in understanding the vitrification process in the soil.

11. The test duration was largely determined from the withdrawal rate of the torch.

12. Data relating to the operation of the plasma heating system was collected.

13. Following a cooldown period of 24 hours, Experiment No. 5 was conducted adjacent to this experiment. The experiment No. 5 borehole was centered 18 inches from the Experiment No. 4 borehole center.

14. Following a cooldown period of at least 48 hours after Experiment No. 5 was completed, the entire vessel was unloaded and samples from both experiments were collected for testing, analysis and evaluation. 


\section{B. Table E.1. Test Sequence}

\begin{tabular}{|c|l|}
\hline $\begin{array}{c}\text { Duration of } \\
\text { Test } \\
\text { (minutes) }\end{array}$ & \multicolumn{1}{c|}{ Event } \\
\hline 0 & Torch Ignited 6" from bottom of borehole (12" from bottom of vessel). \\
\hline 8 & $\begin{array}{l}\text { A burn-through occurred in the bottom of the vessel. Torch off for 10 } \\
\text { minutes. Procedures to insulate the bottom of the vessel were } \\
\text { performed. }\end{array}$ \\
\hline 30 & $\begin{array}{l}\text { Torch raised 10", to 16" from bottom of borehole (22" from bottom of } \\
\text { vessel). Torch formed a solid vitrified plug which closed off the hole in } \\
\text { the bottom of the vessel. Torch Power @ 96 kW. }\end{array}$ \\
\hline 50 & Torch Raised 2" (18" from bottom of borehole \\
\hline 70 & Torch Raised 2" (20" from bottom of borehole) \\
\hline 90 & Torch Raised 2" (22" from bottom of borehole) \\
\hline 110 & Torch Raised 2" (24" from bottom of borehole) \\
\hline 130 & Torch Raised 2" (26" from bottom of borehole) \\
\hline 150 & Torch Raised 2" (28" from bottom of borehole) \\
\hline 170 & Torch Raised 2" (30" from bottom of borehole) \\
\hline 190 & Torch Raised 2" (32" from bottom of borehole) \\
\hline 210 & Torch Raised 2" (34" from bottom of borehole) \\
\hline 230 & Torch Raised 3" (37" from bottom of borehole) \\
\hline 250 & Torch Raised 3" (40" from bottom of borehole) \\
\hline 270 & Torch Raised 3" (43" from bottom of borehole) \\
\hline 290 & Torch Raised 3" (46" from bottom of borehole) \\
\hline 310 & Torch Raised 3" (49" from bottom of borehole) \\
\hline 330 & Torch Raised 3" (52" from bottom of borehole) \\
\hline 350 & Torch Raised 3" (55" from bottom of borehole) \\
\hline 390 & Torch Raised 3" (58" from bottom of borehole) \\
\hline & Torch Off \\
\hline & \\
\hline & \\
\hline & \\
\hline &
\end{tabular}


C. Thermocouple Temperature Data

i

C.1. Table E.2. Experiment No. 4. Thermocouple Locations

\begin{tabular}{|c|c|c|}
\hline $\begin{array}{c}\text { Thermocouple } \\
\text { Number }\end{array}$ & $\begin{array}{c}\text { Height Above } \\
\text { Container Bottom }\end{array}$ & $\begin{array}{c}\text { Distance from } \\
\text { Borehole Centerline }\end{array}$ \\
\hline 1 & 12 inches & 4 inches \\
\hline 2 & 12 & 6 \\
\hline 3 & 24 & 9 \\
\hline 4 & 24 & 6 \\
\hline 5 & 24 & 4 \\
\hline 6 & 24 & 9 \\
\hline 7 & 48 & 16 \\
\hline 8 & 48 & 8 \\
\hline 9 & 48 & \\
\hline 15 & 48 & 4 \\
\hline
\end{tabular}

*Estimated Distance 
C.2. Table E.3. Thermocouple Temperature Data

\begin{tabular}{|c|c|c|c|c|c|c|c|c|c|c|}
\hline Time & \multicolumn{10}{|c|}{ Thermocouple Temperatures $\left({ }^{\circ} \mathrm{C}\right)$} \\
\hline & $\mathbf{T C}_{1}$ & $\mathbf{T C} \mathbf{C}_{2}$ & $\mathbf{T C}_{3}$ & $\mathbf{T C}_{4}$ & $\mathbf{T C}_{5}$ & $\mathbf{T C}_{6}$ & $\mathbf{T C}_{7}$ & $\mathbf{T C}_{8}$ & TC, & $\mathbf{T C}_{15}$ \\
\hline 90 & 879 & 94 & 30 & 63 & 110 & 24 & 542 & 28 & -- & 86 \\
\hline 102 & 819 & 99 & 32 & 70 & 133 & 25 & 551 & 52 & 30 & 91 \\
\hline 116 & 760 & 92 & 34 & 83 & 193 & 26 & 560 & 53 & 31 & 91 \\
\hline 131 & 613 & 90 & 40 & 151 & 359 & 31 & 597 & 61 & 38 & 93 \\
\hline 149 & 500 & 97 & 65 & 219 & 487 & 35 & 622 & 66 & 42 & 95 \\
\hline 155 & 490 & 104 & 74 & 244 & 532 & 37 & 643 & 66 & 43 & 92 \\
\hline 169 & 413 & 114 & 102 & 355 & 587 & 40 & 649 & 66 & 45 & 96 \\
\hline 183 & 354 & 119 & 187 & 509 & 742 & 45 & 660 & 67 & 47 & 93 \\
\hline 195 & 324 & 121 & 291 & 615 & 802 & 49 & 650 & 69 & 48 & 95 \\
\hline 198 & 312 & 121 & 335 & 668 & 871 & 50 & 652 & 68 & 48 & 96 \\
\hline 226 & 228 & 117 & 860 & 752 & 1250 & 60 & 713 & 70 & 50 & 96 \\
\hline 232 & 214 & 116 & 968 & 747 & 1549 & 64 & 725 & 71 & 51 & 96 \\
\hline 233 & 208 & 125 & 926 & 739 & -- & 67 & 733 & 71 & 51 & 96 \\
\hline 252 & 250 & 127 & 620 & 575 & 561 & 81 & 748 & 73 & 53 & 96 \\
\hline 275 & 328 & 184 & 489 & 465 & 428 & 92 & 810 & 77 & 58 & 113 \\
\hline 285 & 373 & 231 & 432 & 424 & 407 & 96 & 837 & 74 & 56 & 130 \\
\hline 295 & 486 & 342 & 663 & 578 & Damaged & 86 & 1350 & 76 & 56 & 154 \\
\hline 305 & 1392 & 1579 & 953 & 1064 & -- & 86 & 1200 & 76 & 55 & 180 \\
\hline 312 & 843 & Damaged & 987 & 1061 & -- & 83 & Damaged & 72 & 55 & 251 \\
\hline 320 & 770 & -- & 1051 & 1052 & -- & 80 & -- & 69 & 53 & 466 \\
\hline 330 & 690 & -- & 1082 & 1030 & -- & 80 & - & 69 & 52 & 1344 \\
\hline 338 & 651 & -- & 1089 & 1023 & -- & 82 & -- & 72 & 53 & 1782 \\
\hline 348 & 586 & -- & 1082 & 1013 & -- & 82 & - & 75 & 59 & Damaged \\
\hline 358 & 559 & - & 1049 & 998 & - & 83 & -- & 290 & 64 & -- \\
\hline 365 & 501 & - & 1048 & 989 & -- & 85 & -- & 1389 & 73 & -- \\
\hline 371 & 493 & -- & 1039 & 986 & -- & 85 & -- & 1531 & 76 & -- \\
\hline 377 & 486 & -- & 1033 & 1008 & -- & 86 & - & Damaged & 84 & - \\
\hline 387 & 476 & -- & 1013 & 999 & - & 86 & -- & -- & 180 & -- \\
\hline
\end{tabular}




\section{APPENDIX F}

\section{Supplemental Test Data: ISPV Experiment No. 5. $200 \mathrm{~kW}$ in Contaminated SRS Soil}

\section{A. Test Procedure}

1. A specially prepared rectangular steel container vessel (69" high, 56" wide, 44 " deep) was constructed to permit adjacent $100 \mathrm{~kW}$ and $200 \mathrm{~kW}$ in situ experiments to take place (Experiments No. 4 and No.5).

2. The vessel was loaded with Savannah River Site uncontaminated soil. Simulated Savannah River Site waste was seeded in the soil. The simulated waste consisted of specially fabricated briquettes plus various amounts of glass, concrete and cans. The briquettes included tracer elements (cerium and cesium) and other waste components that are common to low-level radioactive wastes. The soil was loaded into the vessel to a height of $65 "$.

3. The vessel design included a cover plate over the top of the container. A 4-inch offgas exhaust port under a negative pressure fed the offgas to a collection unit and then to the scrubber system. A baffle was installed in the exhaust port to limit particulate matter being drawn into the offgas line and the scrubber system.

4. A 5-inch diameter torch insertion hole (borehole) with a 5-inch diameter thin metal pipe casing was centered and aligned for the $200 \mathrm{~kW}$ experiment as the soil was loaded into the vessel.

5. The open borehole extended to a depth 12 inches from the bottom of the vessel. This 12-inch depth of soil in the bottom of the container was placed to prevent the plasma flame from melting through the bottom of the container as occurred in Experiment No. 4.

6. The physical properties of the soil were measured as loaded in the vessel. Measurements included soil moisture content, soil density, and the weight of the soil. A sample of the soil was collected for comparison with the thermally-treated soil.

7. The $200 \mathrm{~kW}$ torch was inserted to a distance 6 inches from the bottom of the borehole (18 inches from the bottom of the steel container).

8. The $200 \mathrm{~kW}$ torch was ignited and operated in accordance with the procedures for the plasma heating system provided by Plasma Energy Corporation.

9. The torch was withdrawn upward, at a minimum rate to keep the torch out of the molten pool. Since this test vessel did not have an open configuration, the data from previous experiments were used as a guide for the torch withdrawal rate. 
10. Thermocouples were used to collect thermal data as a tool to track the progress of the melt zone within the vessel, and to assist in understanding the vitrification process in the soil.

11. The test duration was largely determined from the withdrawal rate of the torch.

12. Data relating to the operation of the plasma heating system was collected.

13. Experiment No. 5 was conducted adjacent to Experiment No. 4 following a cooldown period of 24 hours. The Experiment No. 5 borehole was centered 18 inches from the Experiment No. 4 borehole center.

14. Following a cooldown period of 48 hours after Experiment No. 5 was completed, the vessel was unloaded and samples from both experiments were collected for testing, analysis and evaluation. 


\section{B. Table F.1. Test Sequence}

\begin{tabular}{|c|c|}
\hline $\begin{array}{c}\text { Duration of } \\
\text { Test } \\
\text { (minutes) }\end{array}$ & Event \\
\hline 0 & $\begin{array}{l}\text { Torch Ignited 6" from bottom of borehole (18" from bottom of vessel). } \\
\text { Torch Power @ } 130 \mathrm{~kW}\end{array}$ \\
\hline 1 & Torch Power @ $155 \mathrm{~kW}$ \\
\hline 4 & Torch Power@165 kW \\
\hline 6 & Torch Power@175 kW \\
\hline 10 & Torch Power@195kW \\
\hline 15 & Torch Power@ $200 \mathrm{~kW}$ \\
\hline 50 & Torch Raised 4" (10" from bottom of borehole) \\
\hline 70 & Torch Raised 4" (14" from bottom of borehole) \\
\hline 90 & Torch Raised 4" (18" from bottom of borehole) \\
\hline 110 & Torch Raised 4" (22" from bottom of borehole) \\
\hline 130 & Torch Raised 4" (26" from bottom of borehole) \\
\hline 150 & Torch Raised 4" (30" from bottom of borehole) \\
\hline 152 & $\begin{array}{l}\text { Torch Water Leak at O-Ring. Torch turned off for } 40 \text { minutes to replace } \\
\text { O-ring. Torch restarted. }\end{array}$ \\
\hline 200 & Torch Raised 3" (33" from bottom of borehole) \\
\hline 220 & Torch Raised 3" (36" from bottom of borehole) \\
\hline 240 & Torch Raised 3" (39" from bottom of borehole) \\
\hline 270 & Torch Raised 3" (42" from bottom of borehole) \\
\hline 290 & Torch Raised 3" (45" from bottom of borehole) \\
\hline 310 & Torch Raised 2" (47" from bottom of borehole) \\
\hline 330 & Torch Off \\
\hline
\end{tabular}


C. Thermocouple Temperature Data

C.1. Table F.2. Thermocouple Locations

\begin{tabular}{|c|c|c|}
\hline $\begin{array}{c}\text { Thermocouple } \\
\text { Number }\end{array}$ & $\begin{array}{c}\text { Height Above } \\
\text { Container Bottom }\end{array}$ & $\begin{array}{c}\text { Distance from } \\
\text { Borehole Center }\end{array}$ \\
\hline 1 & 18 inches & 5 inches \\
\hline 2 & 48 & 6 \\
\hline 3 & 36 & 6 \\
\hline 4 & 48 & 6 \\
\hline 6 & 24 & 6 \\
\hline 7 & 12 & 12 \\
\hline 9 & 48 & \\
\hline
\end{tabular}




\section{C.2. Table F.3. Thermocouple Temperature Data}

\begin{tabular}{|c|c|c|c|c|c|c|c|}
\hline Time & \multicolumn{7}{|c|}{ Thermocouple Temperatures $\left({ }^{\circ} \mathrm{C}\right)$} \\
\hline & $\mathbf{T C} \mathbf{C}_{1}$ & $\mathbf{T} \mathbf{C}_{2}$ & $\mathbf{T C}_{\mathbf{3}}$ & $\mathbf{T C}_{4}$ & $\mathbf{T C}_{6}$ & $\mathbf{T C}_{7}$ & TC, \\
\hline 13 & - & $48^{*}$ & -- & -- & -- & -- & $118^{*}$ \\
\hline 20 & -- & 53 & -- & - & -- & -- & 117 \\
\hline 25 & -- & 56 & -- & -- & -- & -- & 117 \\
\hline 28 & -- & 60 & -- & -- & -- & - & 119 \\
\hline 36 & -- & 67 & -- & -- & -- & -- & 118 \\
\hline 40 & -- & 80 & -- & -- & -- & -- & 118 \\
\hline 50 & -- & 92 & -- & - & -- & -- & 119 \\
\hline 57 & -- & 90 & -- & -- & -- & -- & 118 \\
\hline 65 & -- & 90 & -- & -- & -- & -- & 117 \\
\hline 70 & -- & 96 & -- & -- & -- & -- & 118 \\
\hline 80 & 610 & 95 & -- & -- & -- & -- & 118 \\
\hline 87 & 690 & 97 & -- & -- & -- & -- & 117 \\
\hline 91 & 711 & 96 & -- & -- & -- & -- & 119 \\
\hline 99 & 980 & 96 & -- & -- & -- & -- & 117 \\
\hline 104 & 1030 & 93 & -- & -- & -- & -- & 117 \\
\hline 115 & 1045 & 97 & 203 & 97 & 99 & 112 & 117 \\
\hline 120 & 1085 & 95 & -- & 99 & 99 & 111 & 118 \\
\hline 130 & 1200 & 99 & -- & 98 & 100 & 114 & 118 \\
\hline 135 & 1250 & 101 & -- & 96 & 100 & 117 & 118 \\
\hline 140 & 1250 & 99 & a- & 96 & 100 & 112 & 119 \\
\hline 145 & 1160 & 101 & -- & 97 & 100 & 116 & 118 \\
\hline 150 & 1200 & 99 & 1055 & 97 & 100 & 120 & 117 \\
\hline 152 & 868 & 81 & 1070 & 95 & 125 & 201 & 117 \\
\hline 200 & 842 & 88 & 1056 & 99 & 137 & 214 & 118 \\
\hline 205 & 831 & 468 & 1049 & 106 & 150 & 215 & 118 \\
\hline 210 & 818 & 1204 & 1038 & 131 & 152 & 217 & 113 \\
\hline 215 & 815 & 1466 & 1031 & 266 & 155 & 218 & 114 \\
\hline
\end{tabular}


Table F.3. (continued)

\begin{tabular}{|c|c|c|c|c|c|c|c|}
\hline Time & \multicolumn{7}{|c|}{ Thermocouple Temperatures $\left({ }^{\circ} \mathrm{C}\right)$} \\
\hline & $\mathbf{T C} \mathbf{C}_{1}$ & $\mathbf{T C}_{2}$ & $\mathbf{T C}_{3}$ & $\mathbf{T C}_{4}$ & $\mathbf{T C}_{6}$ & $\mathbf{T C}_{7}$ & TC9 \\
\hline 220 & 810 & Damaged & 1022 & 576 & 156 & 219 & 115 \\
\hline 226 & 804 & - & 1031 & 1490 & 160 & 220 & 117 \\
\hline 230 & 798 & - & 1004 & 1133 & 162 & 222 & 118 \\
\hline 236 & 794 & - & 997 & 1120 & 163 & 223 & 122 \\
\hline 240 & 790 & -- & 991 & 1292 & 166 & 225 & 136 \\
\hline 245 & 783 & -- & 985 & 1350 & 168 & 226 & 163 \\
\hline 255 & 776 & - & 975 & 1309 & 172 & 229 & 517 \\
\hline 270 & 765 & -- & 950 & Damaged & 177 & 250 & 711 \\
\hline 275 & 758 & - & 942 & -- & 179 & 251 & 1290 \\
\hline 290 & 746 & - & 925 & -- & 184 & 250 & 1317 \\
\hline 300 & 737 & -- & 915 & -- & 188 & 240 & 1353 \\
\hline 310 & 728 & - & 901 & -- & 245 & 240 & 1358 \\
\hline 330 & 720 & -- & 890 & - & 194 & 240 & Damaged \\
\hline
\end{tabular}

*Temperatures are elevated due to residual heating from Experiment No. 4 the previous day. 


\section{APPENDIX G}

\section{EXPERIMENT No. 5: X-RAY DIFFRACTION TESTS AND SCANNING ELECTRON MICROSCOPE MICROGRAPHS}

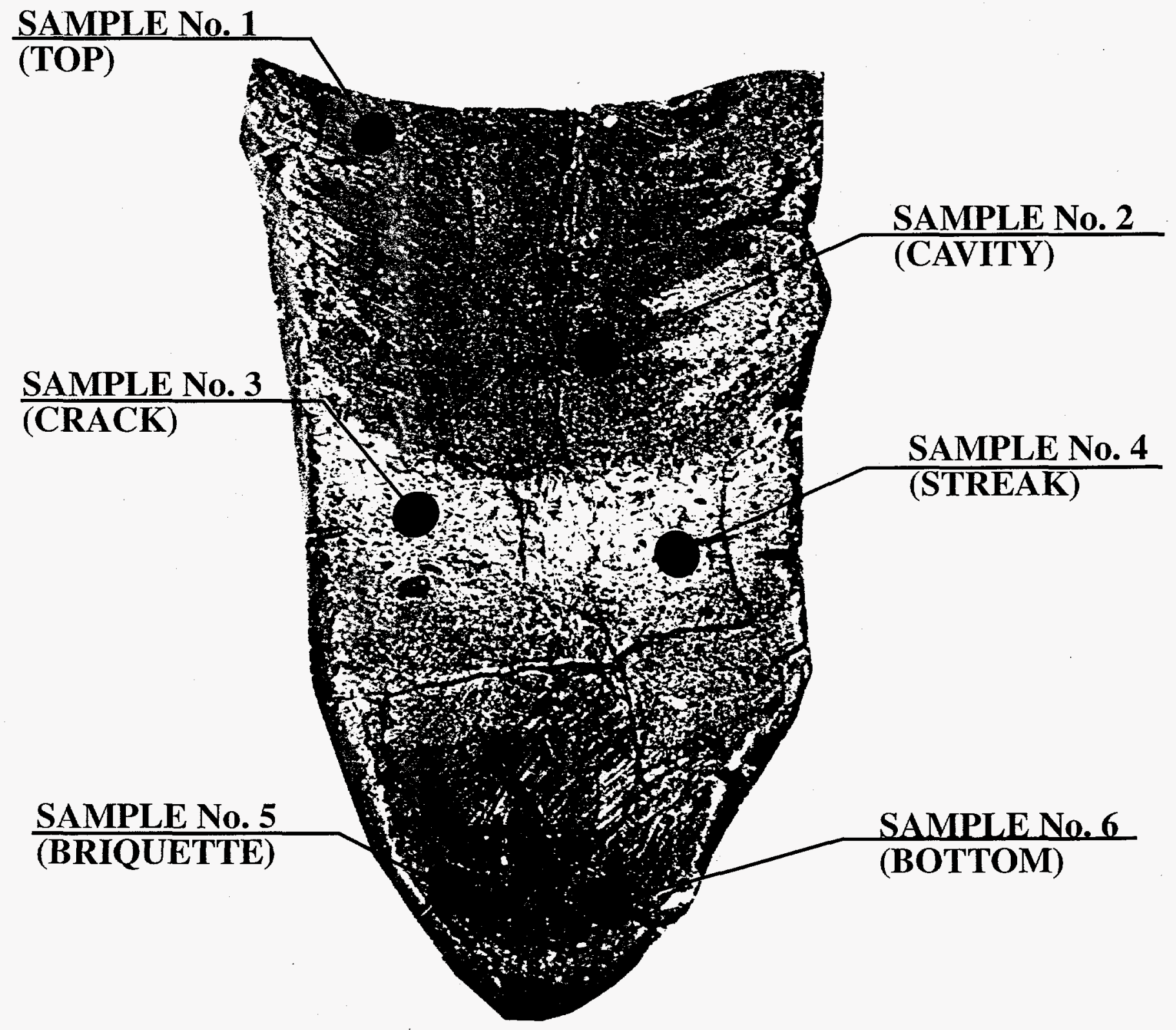




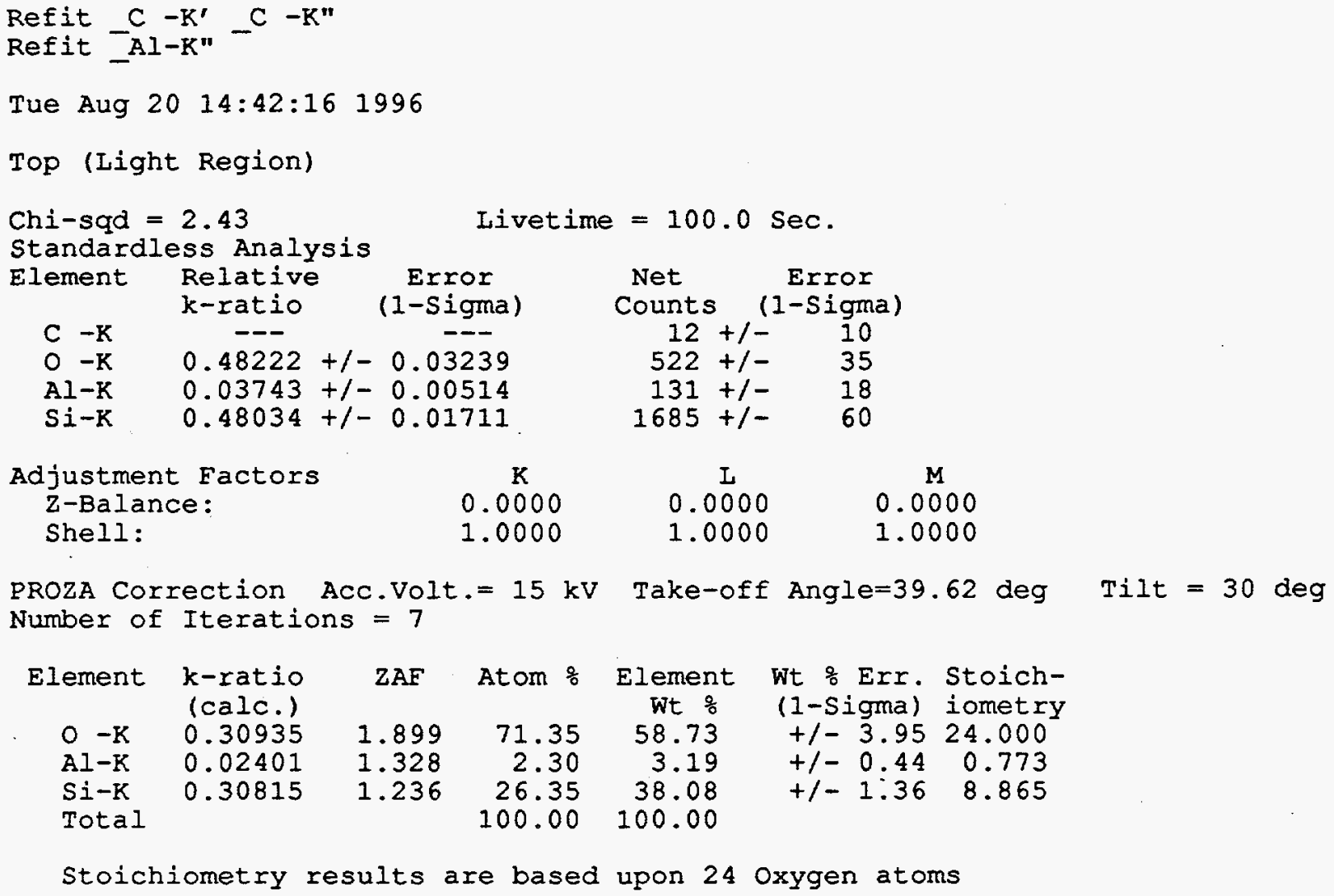

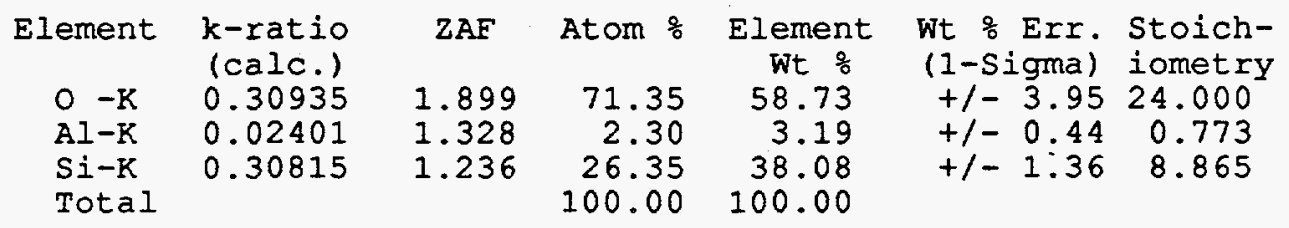

Stoichiometry results are based upon 24 oxygen atoms

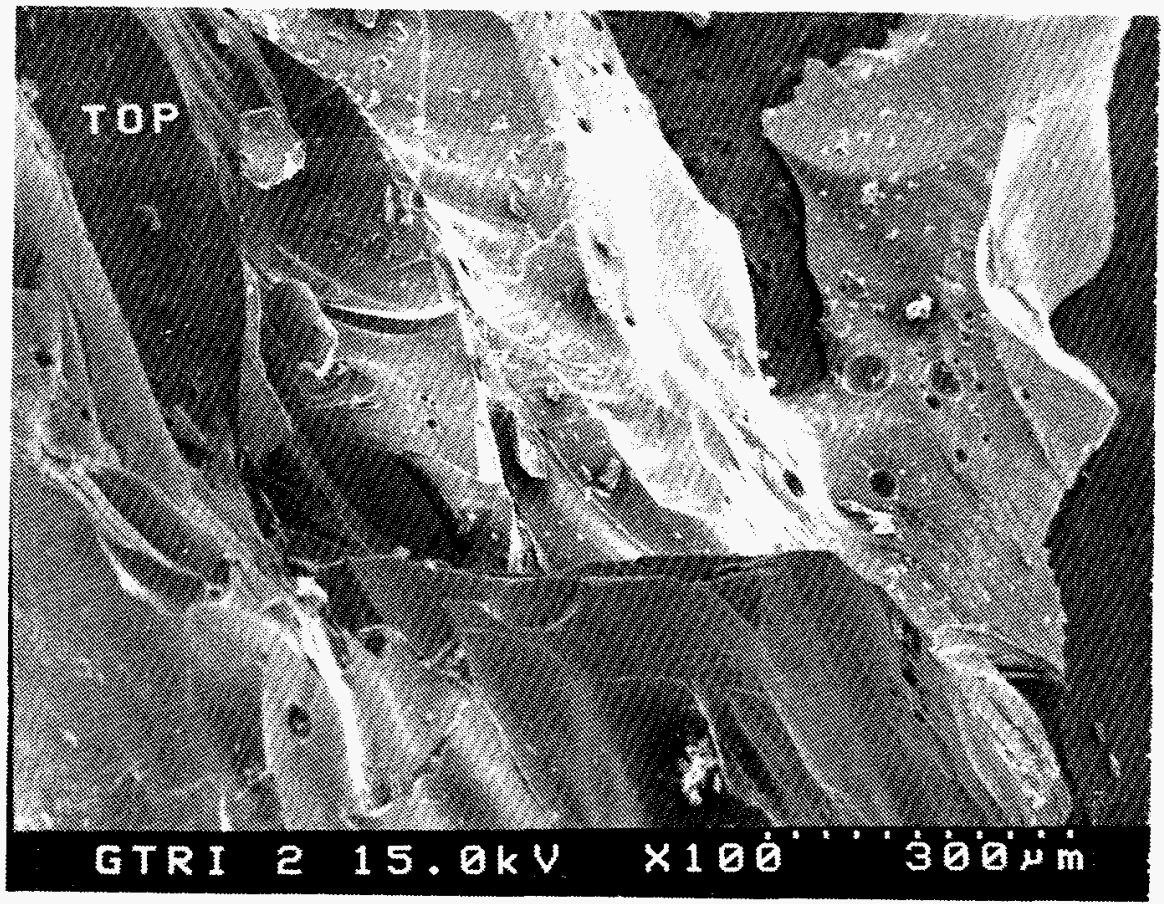

Figure G.1. Micrograph of Sample No. 1 (Top Location) 


\begin{tabular}{l}
$\bullet$ \\
\hline
\end{tabular}




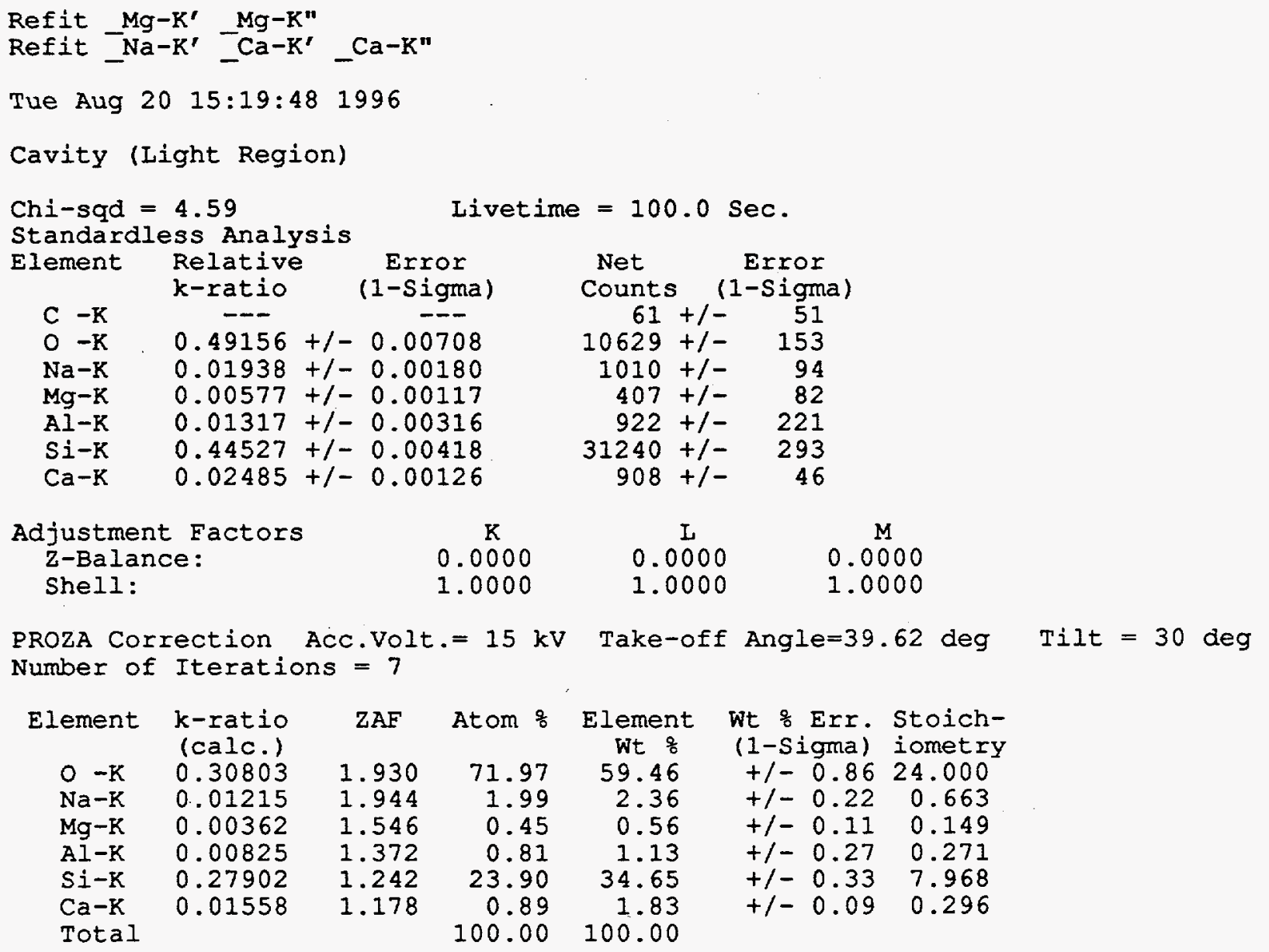

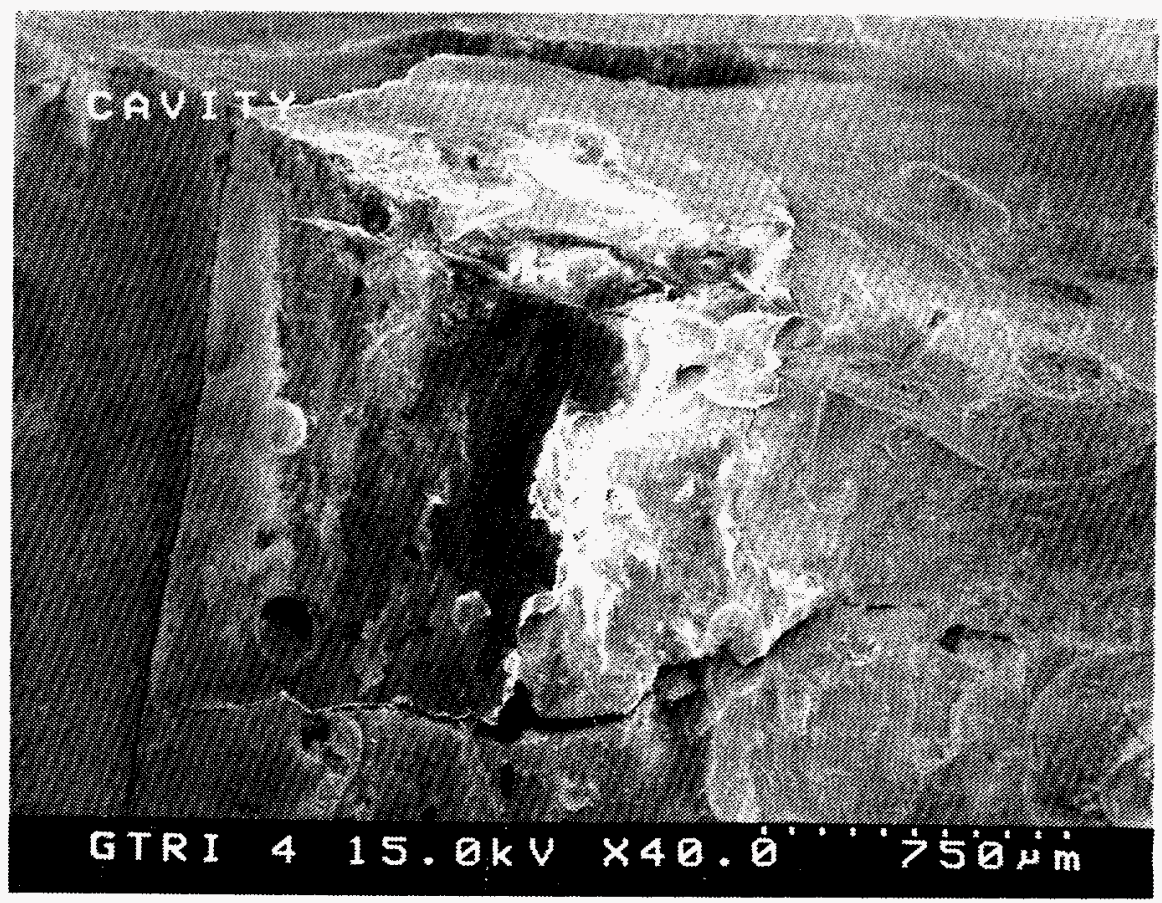

Figure G.2. Micrograph of Sample No. 2 (Cavity Location) 


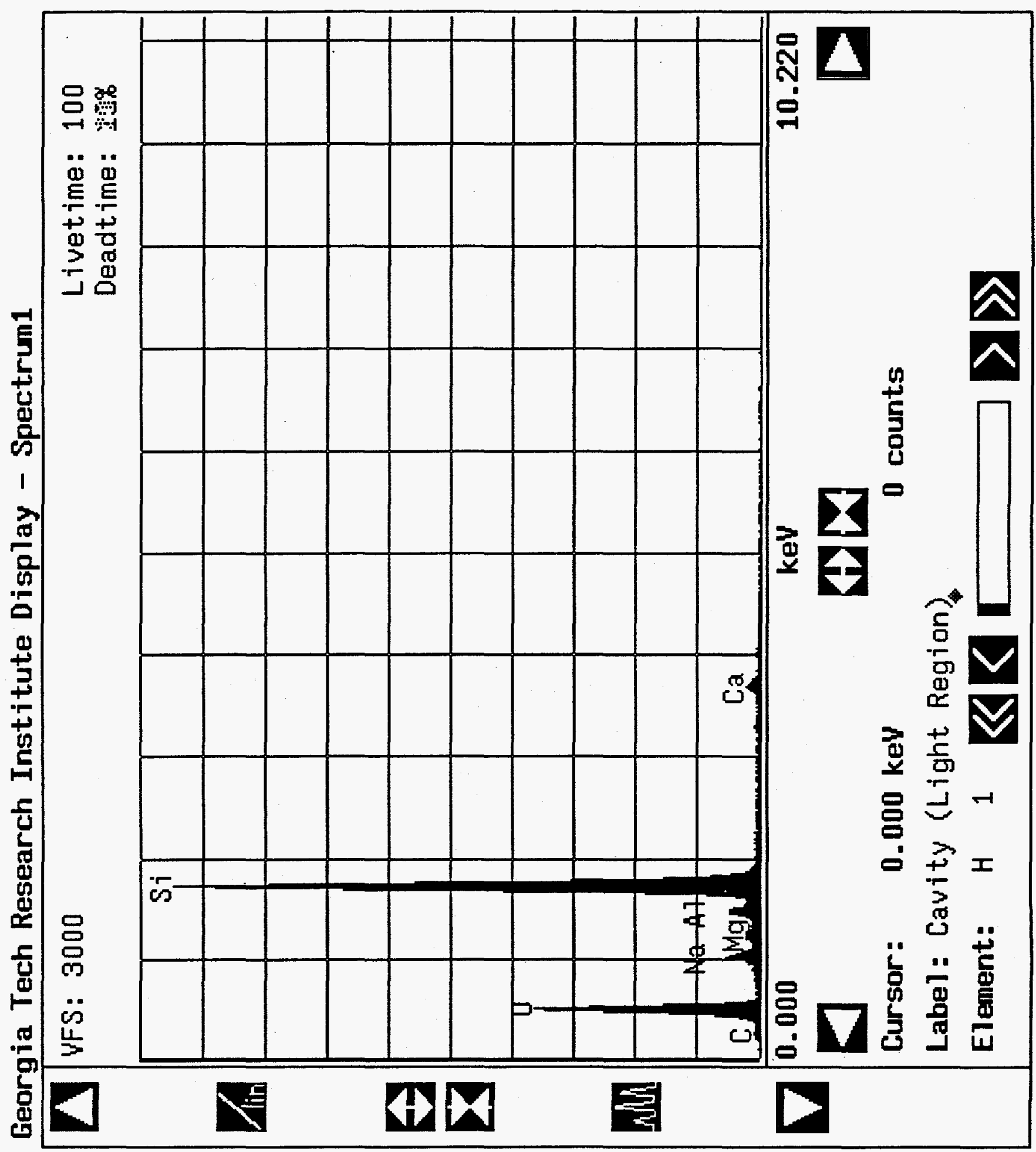


Tue Aug $20 \quad 14: 00: 261996$

\section{Crack}

\begin{tabular}{|c|c|c|c|c|c|c|}
\hline $\begin{array}{l}\text { Chi-sqd } \\
\text { Standaro }\end{array}$ & $\begin{array}{l}5.45 \\
\text { ess Analy }\end{array}$ & Livet & $e=100$ & $.0 \mathrm{~s}$ & Sec. & \\
\hline Element & $\begin{array}{l}\text { Relative } \\
\text { k-ratio }\end{array}$ & $\begin{array}{c}\text { Error } \\
\text { (1-Sigma) }\end{array}$ & $\begin{array}{l}\text { Net } \\
\text { Counts }\end{array}$ & & $\begin{array}{l}\text { Error } \\
\text { 1-Sigma }\end{array}$ & \\
\hline$C-K$ & -- & - & 593 & $+1-$ & 67 & \\
\hline $0-k$ & 0.42060 & $+/-0.00535$ & 15264 & $+1-$ & 194 & \\
\hline$A 1-K$ & 0.03507 & $+1-0.00208$ & 4122 & $+1-$ & 245 & \\
\hline$S i-K$ & 0.51869 & $+1-0.00349$ & 61079 & $+1-$ & 411 & \\
\hline $\mathrm{Fe}-\mathrm{K}$ & 0.02564 & $+1-0.00409$ & 653 & $+1-$ & 104 & \\
\hline djust & acto & & & I & & $\mathbf{M}$ \\
\hline $\begin{array}{l}\text { z-Bala } \\
\text { shell }\end{array}$ & & $\begin{array}{l}0.0000 \\
1.0000\end{array}$ & 0.0 & 000 & & 0.0000 \\
\hline
\end{tabular}

PROZA Correction Acc.Volt. $=15 \mathrm{kV}$ Take-off Angle=39.62 deg Tilt $=30 \mathrm{deg}$ Number of Iterations $=6$

\begin{tabular}{|c|c|c|c|c|c|c|}
\hline Element & $\begin{array}{l}\text { k-ratio } \\
\text { (calc.) }\end{array}$ & $\mathrm{ZAF}$ & Atom : & $\begin{array}{c}\text { Element } \\
\text { Wt } \because\end{array}$ & $\begin{array}{l}\text { Wt } \text { \& Err } \\
\text { (1-Sigma) }\end{array}$ & $\begin{array}{l}\text { Stoich- } \\
\text { iometry }\end{array}$ \\
\hline-1 & 0.27177 & 1.979 & 67. & 53.78 & $+/-0.68$ & $24.000^{-}$ \\
\hline & 0.02266 & 1.320 & 2.23 & 2.99 & $+/-0.18$ & 0.792 \\
\hline $\mathrm{Si-K}$ & 0.33516 & 1.228 & 29.45 & 41.14 & $+1-0.28$ & 10.459 \\
\hline $\mathrm{Ee}-\mathrm{K}$ & 0.01657 & 1.262 & 0.75 & 2.09 & $+1-0.33$ & 0.267 \\
\hline Total & & & 00.8 & 100.00 & & \\
\hline
\end{tabular}

Stoichiometry results are based upon 24 oxygen atoms

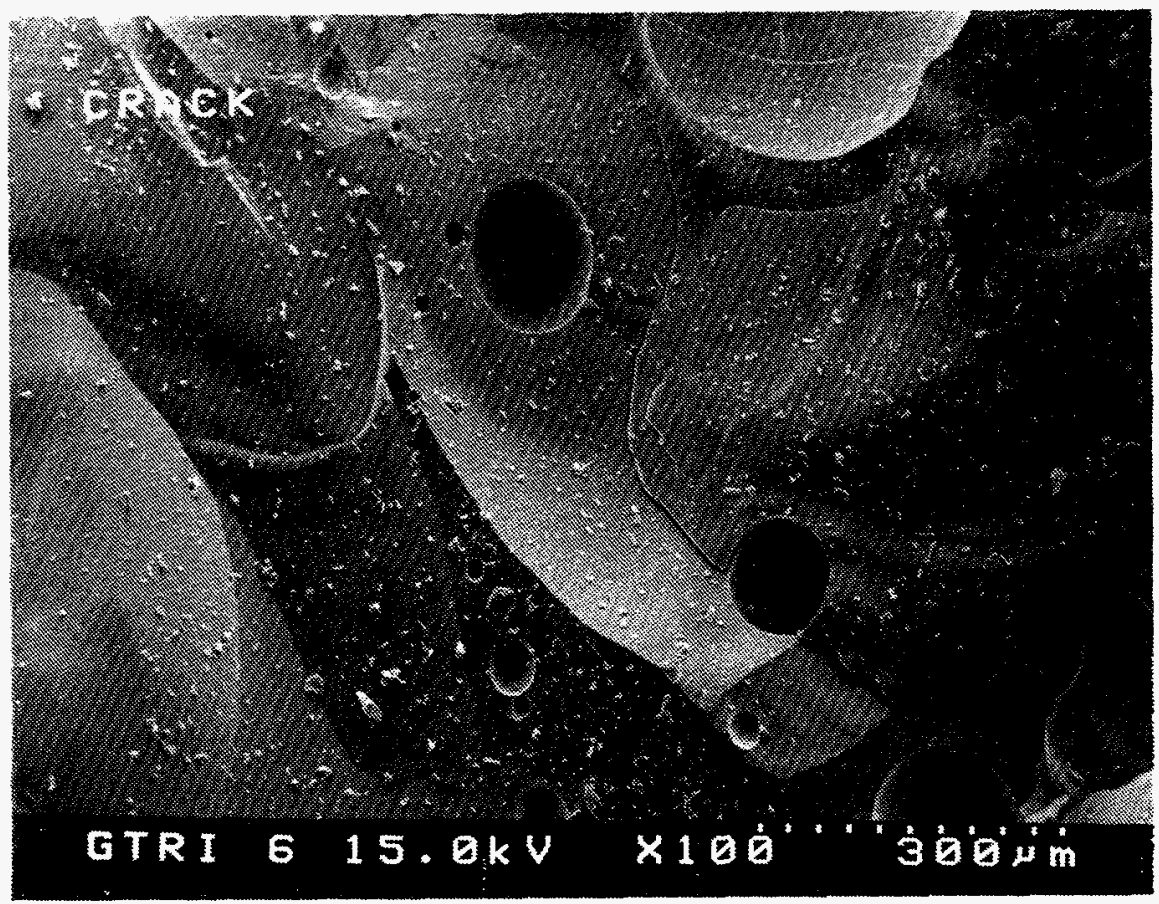

Figure G.3. Micrograph of Sample No. 3 (Crack Location) 


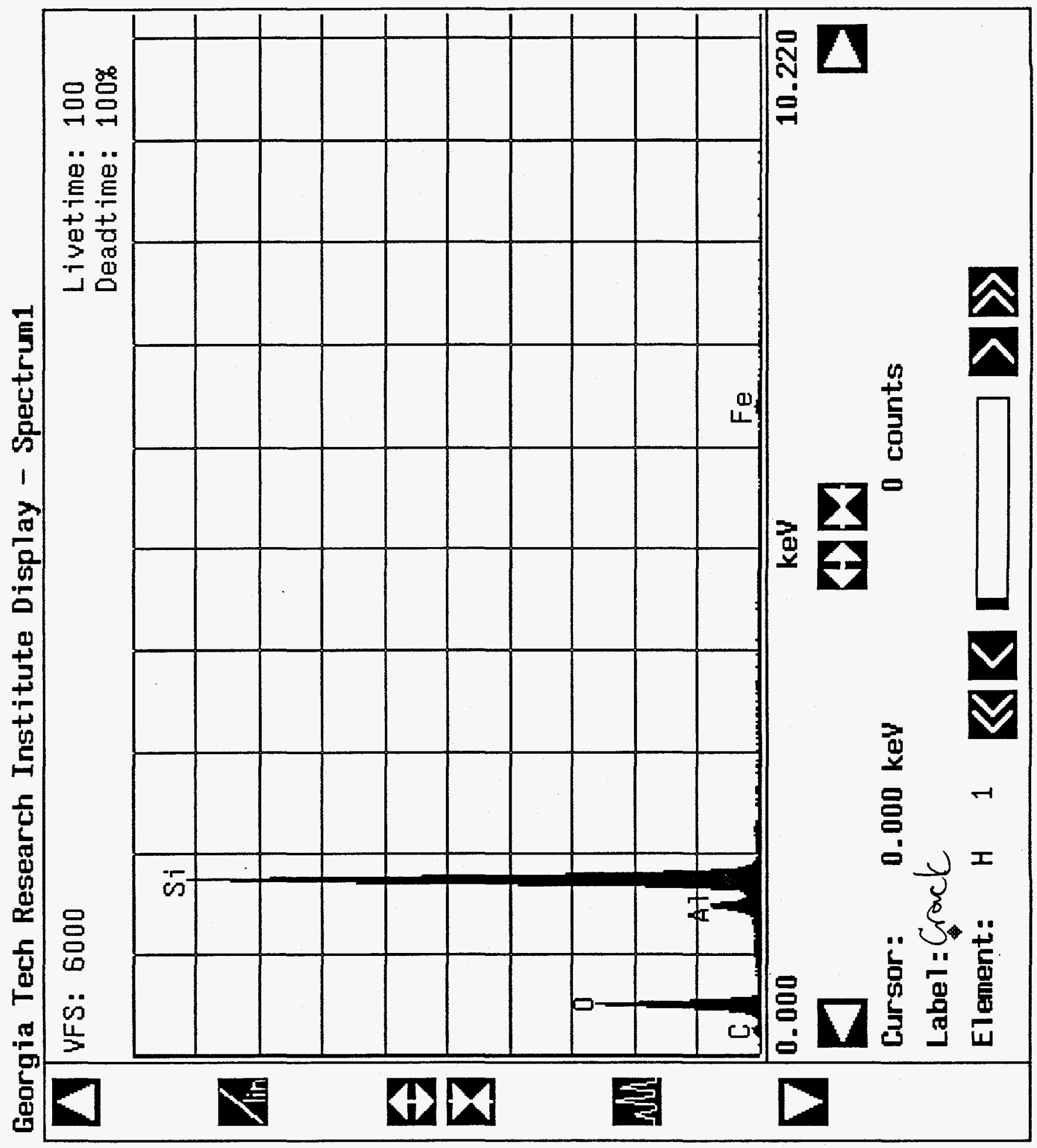


Tue Aug 20 15:04:03 1996

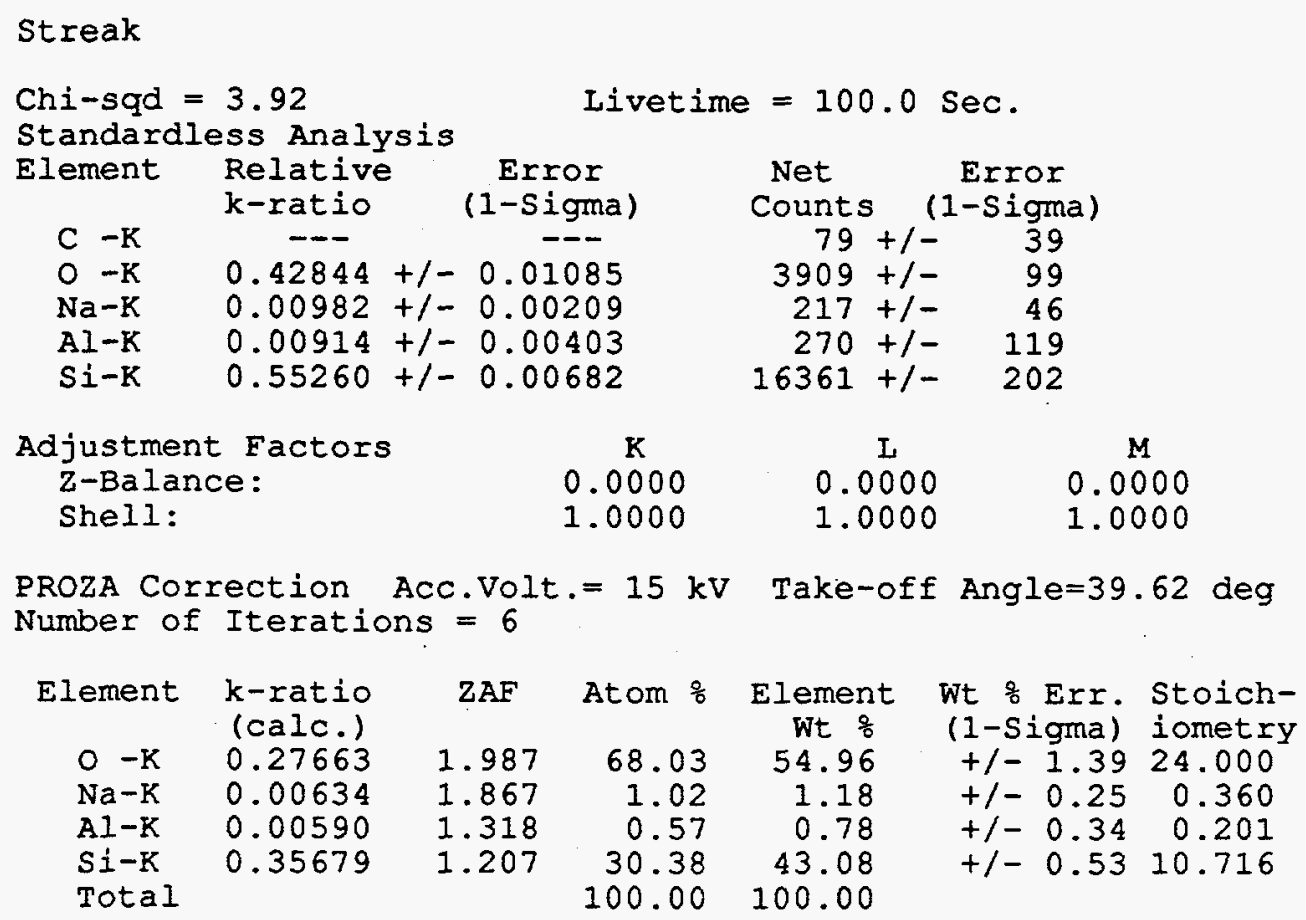

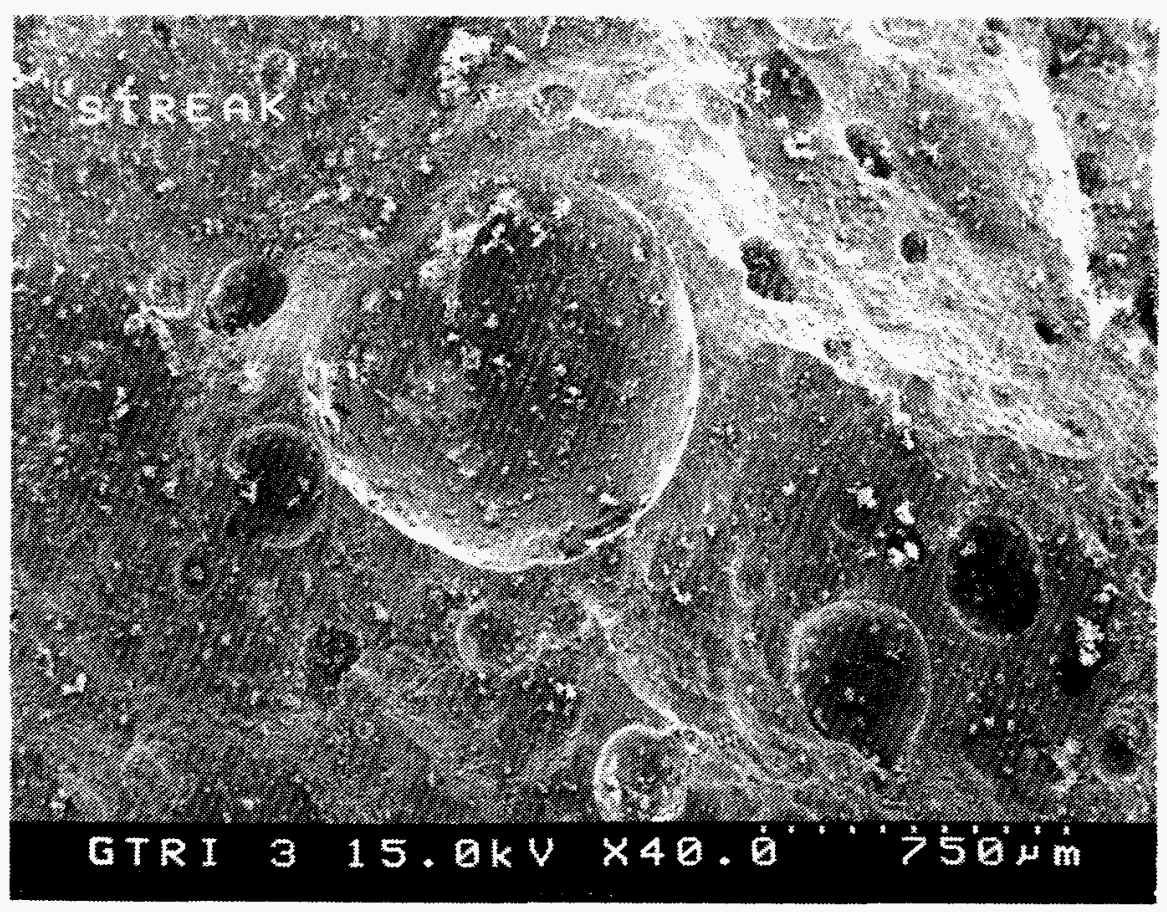

Figure G.4. Micrograph of Sample No. 4 (Streak Location) 
Georgia Tech Research Institute Display - Spectrum1

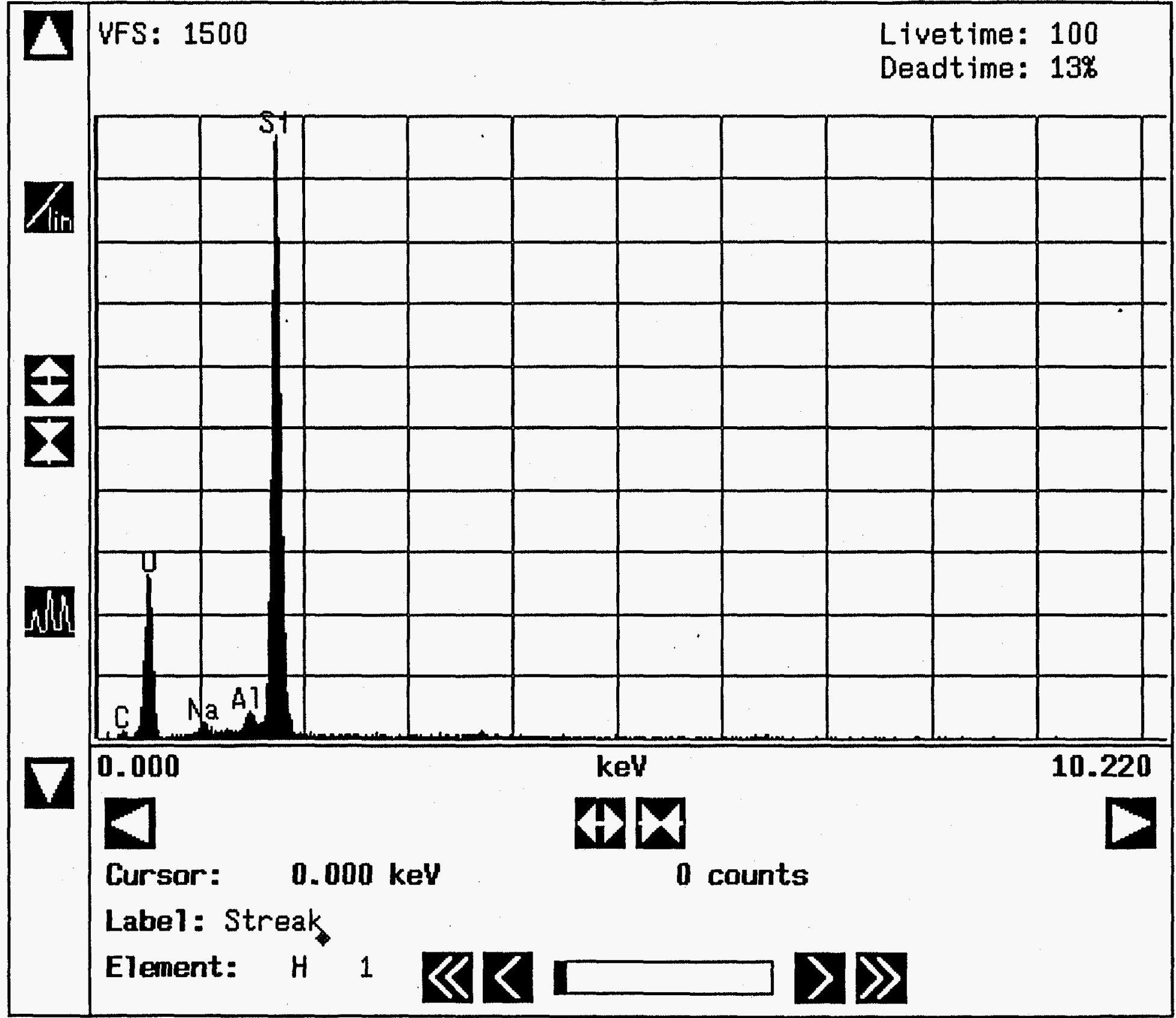




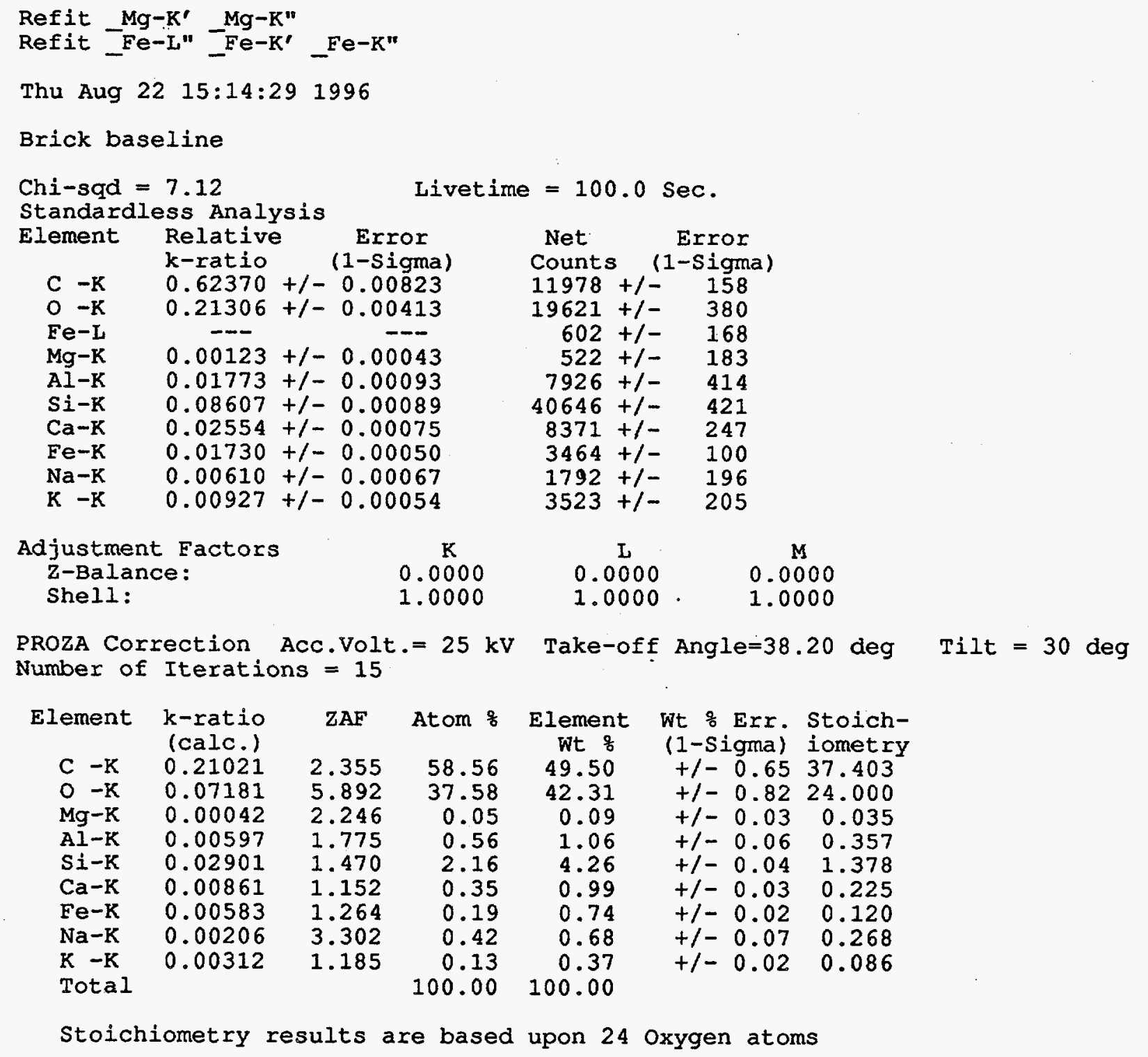




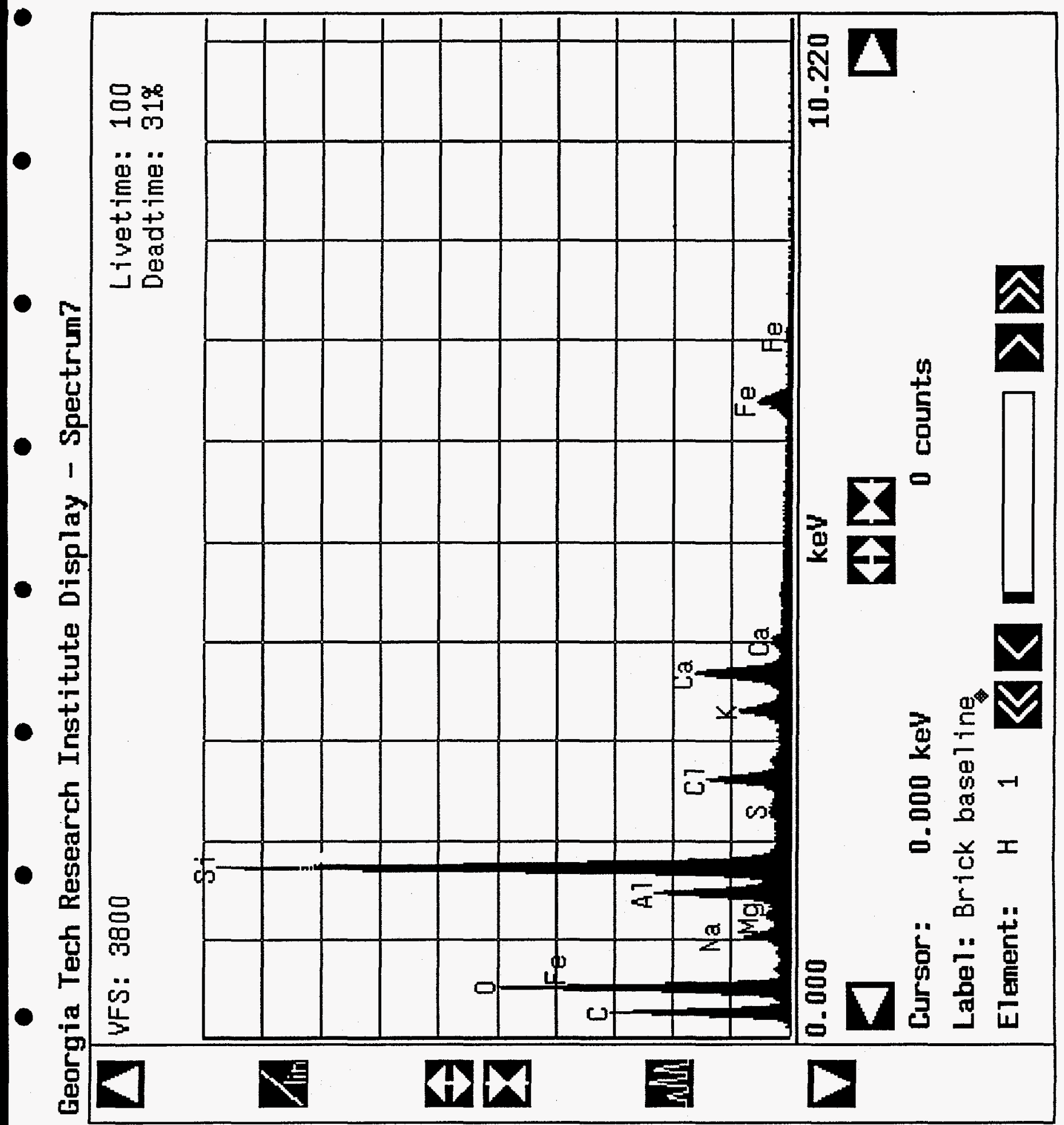


Refit $\mathrm{Mg}-\mathrm{K}^{\prime} \mathrm{Mg}^{\prime} \mathrm{K}^{\prime \prime}$

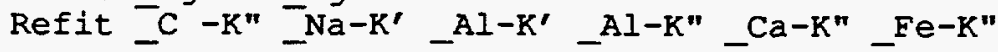

Tue Aug $20 \quad 16: 02: 321996$

Brick (Region \#1)

Chi-sqd $=1.54$

Standardless Analysis

C $-K$

k-ratio

Error
$(1-$ Sigma $)$

Livetime $=100.0 \mathrm{sec}$.

$\mathrm{O}-\mathrm{K}$

$0.40098+1-0.01870$

Counts (1-Sigma)

$\mathrm{Na}-\mathrm{K} \quad 0.01156+/-0.00318$

$\mathrm{Mg}-\mathrm{K} \quad 0.00464+/-0.00150$

AI-K $\quad 0.03023+/-0.00230$

Si-K $\quad 0.37991+1-0.00746$

Ca-K $0.01118+/-0.00235$

Fe-K $\quad 0.16150+/-0.01032$

Adjustment Factors

Z-Balance:

Shell:

$\mathrm{K}$
0.0000
1.0000

PROZA Correction Acc.Volt. $=15 \mathrm{kV}$ Number of Iterations $=6$

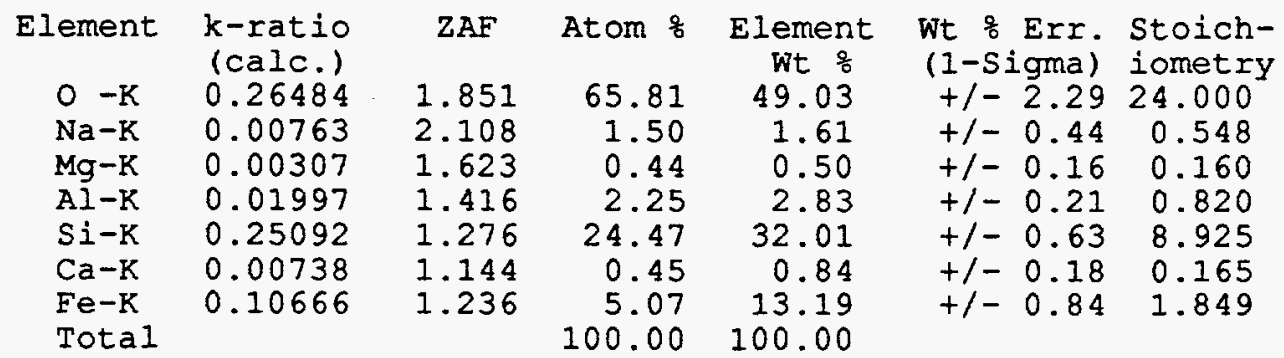

Take-off Angle=41.15 deg Tilt $=30 \mathrm{deg}$

$\begin{array}{rr}309+1- & 24 \\ 1737+1- & 81 \\ 120+1- & 33 \\ 65+1- & 21 \\ 422+1- & 32 \\ 5297+1- & 104 \\ 81+1- & 17 \\ 485+1- & 31\end{array}$

$\begin{array}{cc}\mathrm{L} & \mathrm{M} \\ 0.0000 & 0.0000 \\ 1.0000 & 1.0000\end{array}$

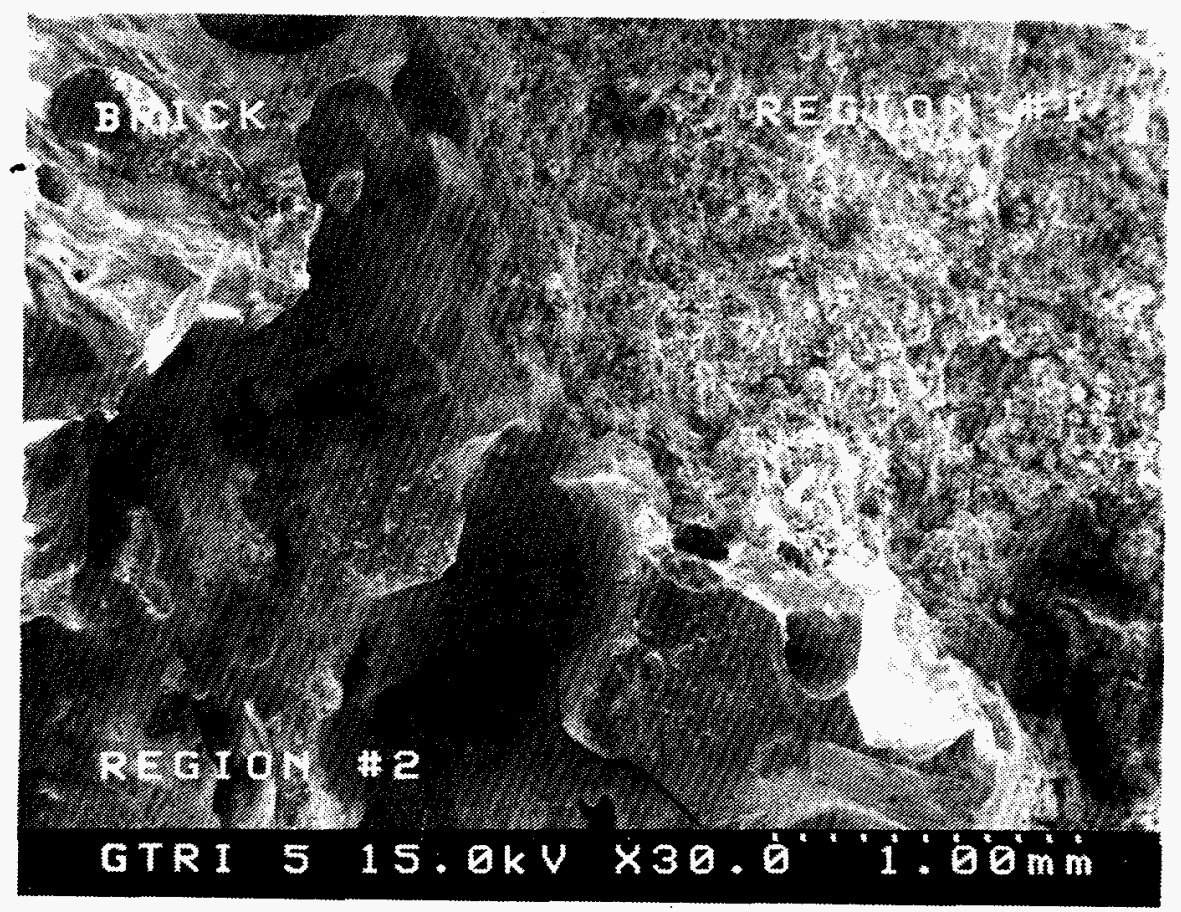

Figure G.5. Micrograph of Sample No. 5 (Briquette [Brick] Location) 


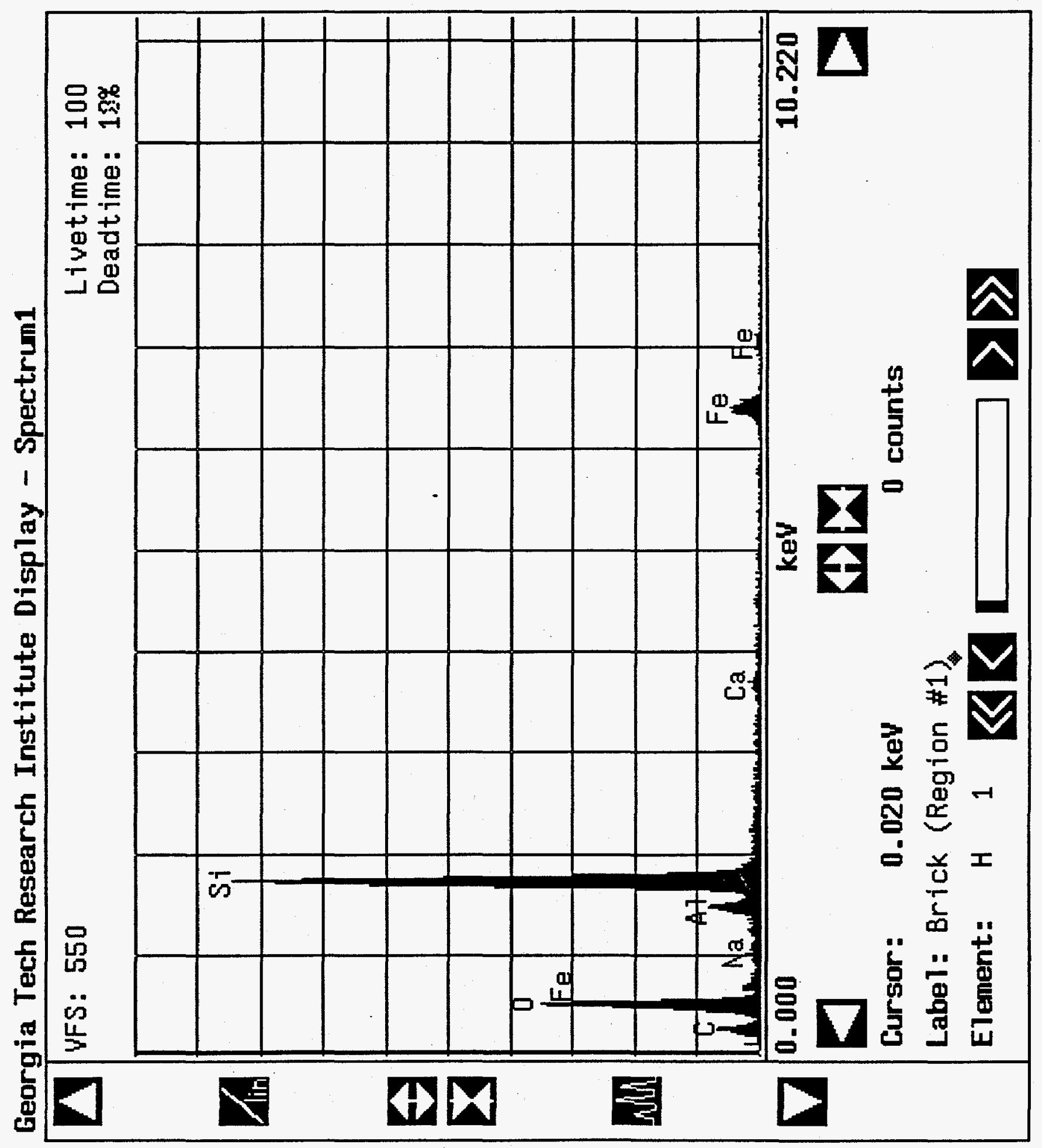

Final Report ERDA 95069

G-13 

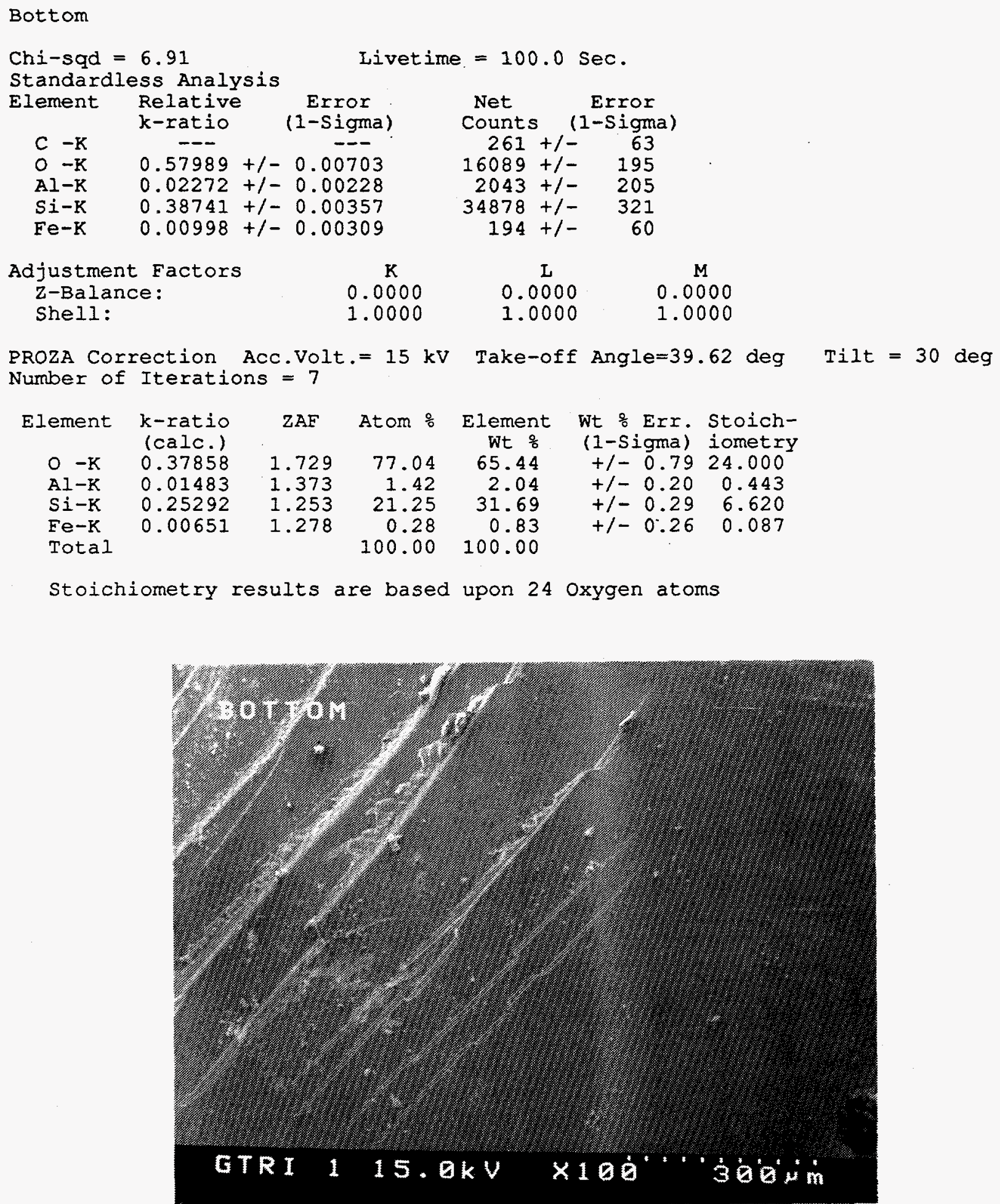

Figure G.6. Micrograph of Sample No. 6 (Bottom Location) 


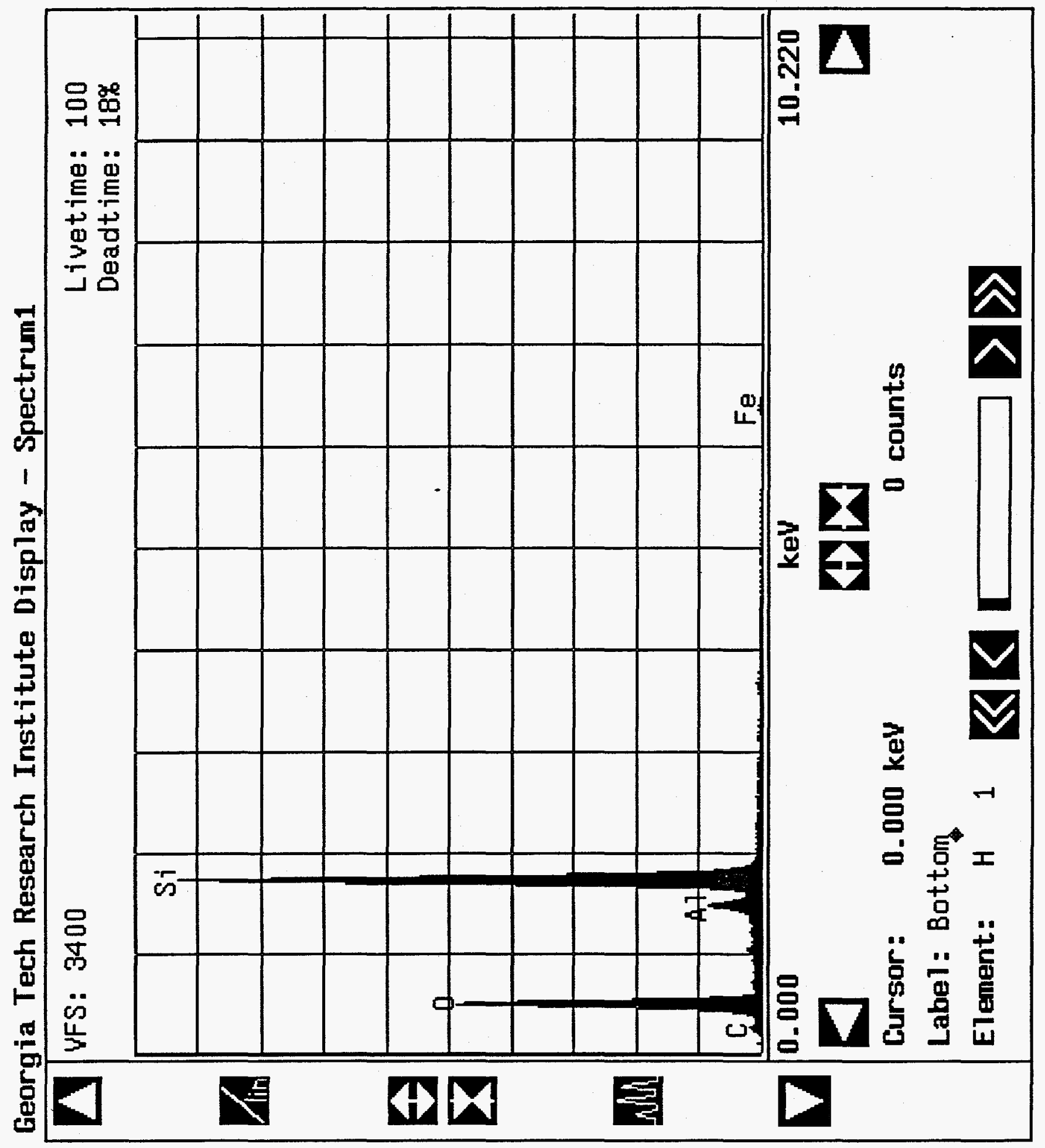




\section{APPENDIX H}

\section{Supplemental Test Data: ISPV Experiment No. 6. $200 \mathrm{~kW}$ Dual Contiguous Melts in Clean SRS Soil}

\section{A. Test Procedure}

1. A cylindrical 48 -inch diameter by 48 -inch high steel container vessel was used for this experiment.

2. The vessel was loaded with Savannah River Site uncontaminated soil.

3. Two 6-inch diameter torch insertion boreholes with 6-inch diameter thin metal pipe casings were aligned with 12 -inch center-to-center spacing equidistant along a diameter of the cylinder.

4. The open boreholes extended to a depth 6 inches from the bottom of the vessel.

5. The physical properties of the soil were measured as loaded in the vessel. Measurements included soil moisture content, soil density, and the weight of the soil. A sample of the soil was collected for comparison with the thermally-treated soil.

6. The $200 \mathrm{~kW}$ torch was inserted to a distance 6 inches from the bottom of each borehole at the start of each of the two melts (12 inches from the bottom of the steel container).

7. The $200 \mathrm{~kW}$ torch was ignited and operated in accordance with the procedures for the plasma heating system provided by Plasma Energy Corporation.

8. The torch was withdrawn upward, at a minimum rate to keep the torch out of the molten pool. Experience gained in Experiment No. 5 was used as a guide for the withdrawal rate.

9. No thermocouples were used in this experiment.

10. The test duration was largely determined from the withdrawal rate of the torch in each borehole.

11. Data relating to the operation of the plasma heating system was collected during this test.

12. Following completion of the test in the first borehole, the plasma torch was immediate relocated to the second borehole and operated to form the second column, which was spaced to be contiguous with the first column.

13. Following a cooldown period of at least 24 hours, the vessel was unloaded and samples collected for testing, analysis and evaluation. 


\section{B. Table H.1. Test Sequence: Borehole No. 1}

\begin{tabular}{|c|l|}
\hline $\begin{array}{c}\text { Duration of Test } \\
\text { (minutes) }\end{array}$ & \multicolumn{1}{c|}{ Event } \\
\hline 0 & Torch Ignited 6" from bottom of borehole (12" from bottom of vessel) \\
\hline 5 & Torch Power @ 200 kW \\
\hline 14 & Torch Raised 4" (10" from bottom of borehole) \\
\hline 30 & Torch Raised 4" (14" from bottom of borehole) \\
\hline 45 & Torch Raised 4" (18" from bottom of borehole) \\
\hline 60 & Torch Raised 4" (22" from bottom of borehole) \\
\hline 66 & Torch Raised 4" (26" from bottom of borehole) \\
\hline 70 & Torch Raised 4" (30" from bottom of borehole) \\
\hline 72 & Torch Off \\
\hline
\end{tabular}

C. Table H.2. Test Sequence: Borehole No. 2

\begin{tabular}{|c|l|}
\hline $\begin{array}{c}\text { Duration of Test } \\
\text { (minutes) }\end{array}$ & \multicolumn{1}{c|}{ Event } \\
\hline 0 & Torch Ignited 6" from bottom of borehole (12" from bottom of vessel) \\
\hline 5 & Torch Power @ 200 kW \\
\hline 15 & Torch Raised 2" (8" from bottom of borehole) \\
\hline 31 & Torch Raised 2" (10" from bottom of borehole) \\
\hline 45 & Torch Raised 2" (12" from bottom of borehole) \\
\hline 60 & Torch Raised 2" (14" from bottom of borehole) \\
\hline 70 & Torch Raised 2" (16" from bottom of borehole) \\
\hline 80 & Torch Raised 2" (18" from bottom of borehole) \\
\hline 87.5 & Torch Raised 4" (22" from bottom of borehole) \\
\hline 100 & Torch Raised 4" (26" from bottom of borehole) \\
\hline 110 & Torch Raised 4" (30" from bottom of borehole) \\
\hline 120 & Torch Raised 4" (34" from bottom of borehole) \\
\hline 130 & Torch Off \\
\hline
\end{tabular}

